\title{
Revision of the Xenacanthida (Chondrichthyes: Elasmobranchii) from the Carboniferous of the British Isles
}

\author{
Oliver Hampe
}

\begin{abstract}
Xenacanthids were a very successful group of elasmobranchs that ranged from the Lower Carboniferous to the Upper Triassic. The history of discovery of the xenacanthids, which is closely connected with the history of coal prospecting in England, began with the finding of the type specimen of Xenacanthus laevissimus in the Westphalian B of the West Midlands. In this first review of British Carboniferous xenacanthids, the number of taxa, mainly erected during Victorian times, is reduced to 14 species distributed among six genera. Determinable remains are recorded from at least 96 localities in the British Isles. Unique characteristics of the Dinantian Diplodoselache suggest that the lineage to which this taxon belongs marks a dead end in xenacanthid evolution. This investigation also shows that the Pendleian Dicentrodus, formerly described as Cladodus, belongs to the xenacanthids. The occurrence of Orthacanthus cf. kounoviensis in the Pennines, also known from the German Saar-Nahe basin, the Saale depression and from Bohemia, indicates a faunal exchange between these intramontainous basins during the Carboniferous. The genus Triodus is identified from British deposits for the first time. A cladistic analysis of the xenacanthids suggests that they evolved from phoebodontid elasmobranchs. This analysis also confirms separation of the Middle Devonian Antarctilamna from a relationship with xenacanthid sharks.
\end{abstract}

KEY WORDS: Coal Measures, Great Britain, histology, Ireland, Palaeozoic, phylogeny, spines, stratigraphy, teeth

The Xenacanthida is one of the most spectacular shark-orders in the fossil record. They have a practically simultaneous global appearance in early Palaeozoic deposits of marine as well as freshwater environments. Articulated skeletons up to $3.5 \mathrm{~m}$ long of Lebachacanthus senckenbergianus from the Lower Permian of the SW-German Saar-Nahe basin are the largest xenacanthids known. The distinct characteristics of these fusiform chondrichthyans are a single elongated dorsal fin and paired fins of the archipterygium type. All known genera carry a dorsal spine of varying proportions and positions on the anterior half of the body (see Hampe 1997b, fig. 4). The teeth are very important for systematic determination and show a tricuspid crown with two longer lateral cusps flanking a smaller, often weaker median cusp. The base of the teeth is extended lingually with a coronal button on the upper surface and a rather differently shaped basal tubercle on the basal surface.

Xenacanthids were first reported in England when Agassiz (1837, p. 66) described a spine as 'Pleuracanthus' laevissimus from the Manchester Coalfield, although he believed it belonged to a ray. Later, the name Pleuracanthus was determined to be preoccupied by a South American coeleopterid (see discussion below). In the year 1840, Binney described the teeth of xenacanthid elasmobranchs for the first time ( $\supset$ Orthacanthus gibbosus, see 4). Later, Agassiz (1843, tab. 45, figs 7-9) illustrated spines belonging to the same species under the name O. cylindricus Binney (1840), and Garner (1844, pl. 6, fig. 11) figured a so-far-undeterminable tooth.

Owen (1867) and Barkas $(1873,1874)$ later introduced early histological aspects of xenacanthid teeth which they described under a variety of names (Diplodus, Dittodus, Ochlodus, Aganodus, Pternodus).

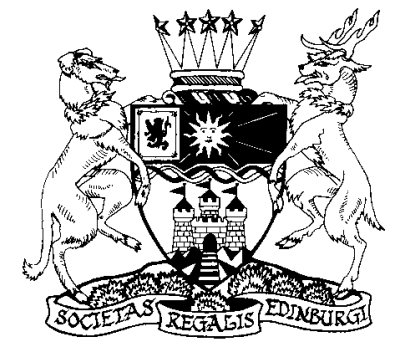

The most prolific xenacanthid research in Britain was accomplished by Traquair (1881, 1882, 1888b) and Davis (1880a-c, 1881, 1892). The detailed descriptions of several newly erected species were completed in the faunal lists from several depositional areas (e.g. Traquair 1903). A few publications were presented by other authors (Stock 1880; Ward 1890). Woodward (1889a) also made a significant contribution in his Catalogue of the fossil fishes in the British Museum of Natural History. Woodward \& Sherborn (1890) gave a synopsis of the British fossil vertebrate fauna and summed up the data published by Agassiz.

The twentieth century yielded only a few contributions to xenacanthid literature: Cox (1926) described Carboniferous and Permian deposits, including biostratigraphical remarks and the erection of new gastropods from Northern Worcestershire, and mentioning Diplodus teeth in a foot note.

Dick (1981) and in a more popular version, Dick et al. (1986), described Diplodoselache woodi from the Viséan of Scotland, the mostly complete xenacanthid from the British Isles, and the oldest known genus belonging to the group. Paton (1994) described tooth remains of this species in a short paper.

Major episodes in xenacanthid research outside Britain include the initial descriptions and investigations of Jordan (1849), Kner (1867), Fritsch (1889, 1890), Koken (1889), and Jaekel $(1895,1906)$ on isolated material as well as partly articulated fossils from the famous Upper Carboniferous and Lower Permian 'Gaskohle' of Bohemia and specimens from the German Saar-Nahe basin.

Recently, a renaissance has taken place in xenacanthid research. After sporadic contributions between the beginning of the twentieth century and the 1960s, intensive work began on the faunas of the Autunian basins in France, mainly 
by Daniel Heyler and Cecile Poplin (Heyler 1969; Heyler \& Debriette 1986; Heyler \& Poplin 1982, 1989, 1990; Poplin \& Heyler 1989; Soler-Gijón \& Hampe 1998), from the Upper Carboniferous and Lower Permian of SW Germany by the author and Ulrich Heidtke (Hampe 1988a, b, 1989, 1991, 1993, 1994, 1995, 1997a, b; Heidtke 1982, 1998, 1999a; Schneider et al. 2000), from the Central and E German basins and the Czech Republic mainly by Jörg Schneider (Schneider 1985, 1988, 1996; Schneider \& Zajíc 1994; Schneider et al. 2000), and for the Puertollano basin in Spain published by Rodrigo SolerGijón (Soler-Gijón 1997a, b, 1999, 2000; Schneider et al. 2000). For North America, Gary Johnson produced several papers starting with his Ph.D. programme in Texas and Oklahoma (Johnson 1980, 1984, 1995, 1996, 1999).

A consequence of this contribution is a lumping of the large number of genera and species erected during the last decades of the nineteenth century and based largely on fragmentary and unprepared material. Whilst teeth and spines were often described separately, leading to the problem of form genera in the past, this current revision, working from a large number of newly prepared fossils, has reduced the numbers to six genera with 14 species. Determinate remains are known from at least 96 localities. A stratigraphic chart showing the distribution of the valid taxa completes this contribution (Fig. 1; Tab. 1).

\section{Material and methods}

This publication is based upon studies of original material during five visits to Great Britain and Ireland between 1994 and 1998. Xenacanthid material was examined at the following institutions: Bristol Museums \& Art Gallery; Sedgwick Museum, Cambridge; Cliffe Castle Museum, Keighley; Leicestershire Museums Arts \& Gallery; The Natural History Museum, London; The Manchester Museum; The Hancock Museum, Newcastle upon Tyne; British Geological Survey in Nottingham; Sheffield City Museum; Stoke-on-Trent City Museum \& Art Gallery; Sunderland Museum \& Art Gallery; Yorkshire Museum; Royal Museum of Scotland in Edinburgh; Kelvingrove Art Gallery and Museum, Glasgow; Hunterian Museum, Glasgow; National Museum of Ireland, Dublin. In addition, British xenacanthid remains from two collections in Germany were investigated at the Museum für Naturkunde, Berlin, and the Naturhistorisches Museum, Mainz.

A large number of specimens was borrowed to permit further preparation of the material. The preservation and/or status of preparation was, in many cases, unsatisfactory. Most specimens were described in the form in which they were collected from the outcrops and pits in the nineteenth century. Many teeth and spines were prepared mechanically in Mainz, Berlin and London. Subsequent documentation was undertaken through camera lucida drawings and additional photographs.

Studies of tooth histology were carried out using fluorescence microscopy technology on a Leitz DMR research microscope and a Leica ORTHOPLAN ${ }^{\mathrm{TM}}$ microscope with reflected light fluorescence illuminators attached with filterblocks and a camera system. Both a halogen lamp and a high-pressure mercury lamp provided the light source. Three filterblocks were installed and used: filterblock A (UV-light, 340-380 nm wavelength), filterblock D (UV violet, $355-425 \mathrm{~nm}$ ), and filterblock H3 (blue, 420-490 nm).

Methodology involved reflected light observations for excitation of fluorescence radiation. Fluorescing substances will emit light of specific colour, while the non-fluorescing material remains dark. If an object or specimen is irradiated by shortwave excitation light, filters select exactly those wavelengths which cause fluorescence from the light which comes from the source. All other wavelengths not contributing to the fluorescence in question are cut out by barrier filters. Instead of using the usual water immersion technique, some of the photographs were shot under dry conditions. This produced images without the bubbles which often occur when the immersing fluid is absorbed by the pore space of the sample (matrix as well as spaces in the dentine). The exposure time is therefore reduced. In most cases this method produces a picture of the internal structure of the investigated teeth which is rich in contrast (see also Hampe 1991, 1995, 1997a; Hampe \& Heidtke 1997; Hampe \& Long 1999). The teeth, mostly embedded in their original matrix, were sectioned in different directions and polished with grinding powder. The teeth were ground down in a series of steps, investigated and photographed at each stage, thus simulating tomography. Sir Richard Owen's original slides, prepared for his 1867 paper, were also examined.

The cladistic analysis was performed using PAUP 3.1.1. for Apple ${ }^{\circledR}$ Macintosh $^{\mathbf{T M}}$ in connection with MacClade 3.01.

Stratigraphic correlations were made possible by reference to those charts in the Special Reports of the Geological Society, and the publications of the British Geological Survey (Memoirs) supported by primary literature concerning the localities.

\section{Abbreviations}

\subsection{Collections}

BMNH - The Natural History Museum, London

GTM - Geiseltalmuseum, Halle/Saale

HM - The Hancock Museum, Newcastle upon Tyne

HMUG - Hunterian Museum, University of Glasgow

MB - Museum für Naturkunde, Berlin

MCZ - Museum of Comparative Zoology, Harvard University, Cambridge/Mass.

MM - The Manchester Museum

MNHN - Muséum Nationale d'Histoire Naturelle, Paris

NHM - Naturhistorisches Museum Mainz

NMI - National Museum of Ireland, Dublin

RSM, - Royal Museum of Scotland/National Museums of

NMS Scotland, Edinburgh

STOT - Stoke-on-Trent City Museum \& Art Gallery

SM - Sunderland Museum \& Art Gallery

YM - Yorkshire Museum, York

\begin{tabular}{|c|c|}
\hline \multicolumn{2}{|c|}{ 2.2. Anatomy } \\
\hline ba & - base \\
\hline bt & - basal tubercle \\
\hline $\mathrm{cb}$ & - coronal button \\
\hline $\mathrm{cr}$ & - crown \\
\hline $\ln$ & - depression \\
\hline fpda & - foramina for the paired dorsal aorta \\
\hline 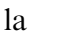 & - lateral angle \\
\hline $\mathrm{c}$ & - lateral cusp \\
\hline e & - lateral edge \\
\hline nc & - median cusp \\
\hline if & - median foramen \\
\hline & - nasal capsule \\
\hline$n f$ & - nutrient foramen \\
\hline $\mathrm{tp}$ & - otic process \\
\hline op & - postorbital process \\
\hline $\mathrm{p}$ & - preorbital process \\
\hline & - serration \\
\hline & - shaft \\
\hline & - vertical cristae \\
\hline
\end{tabular}




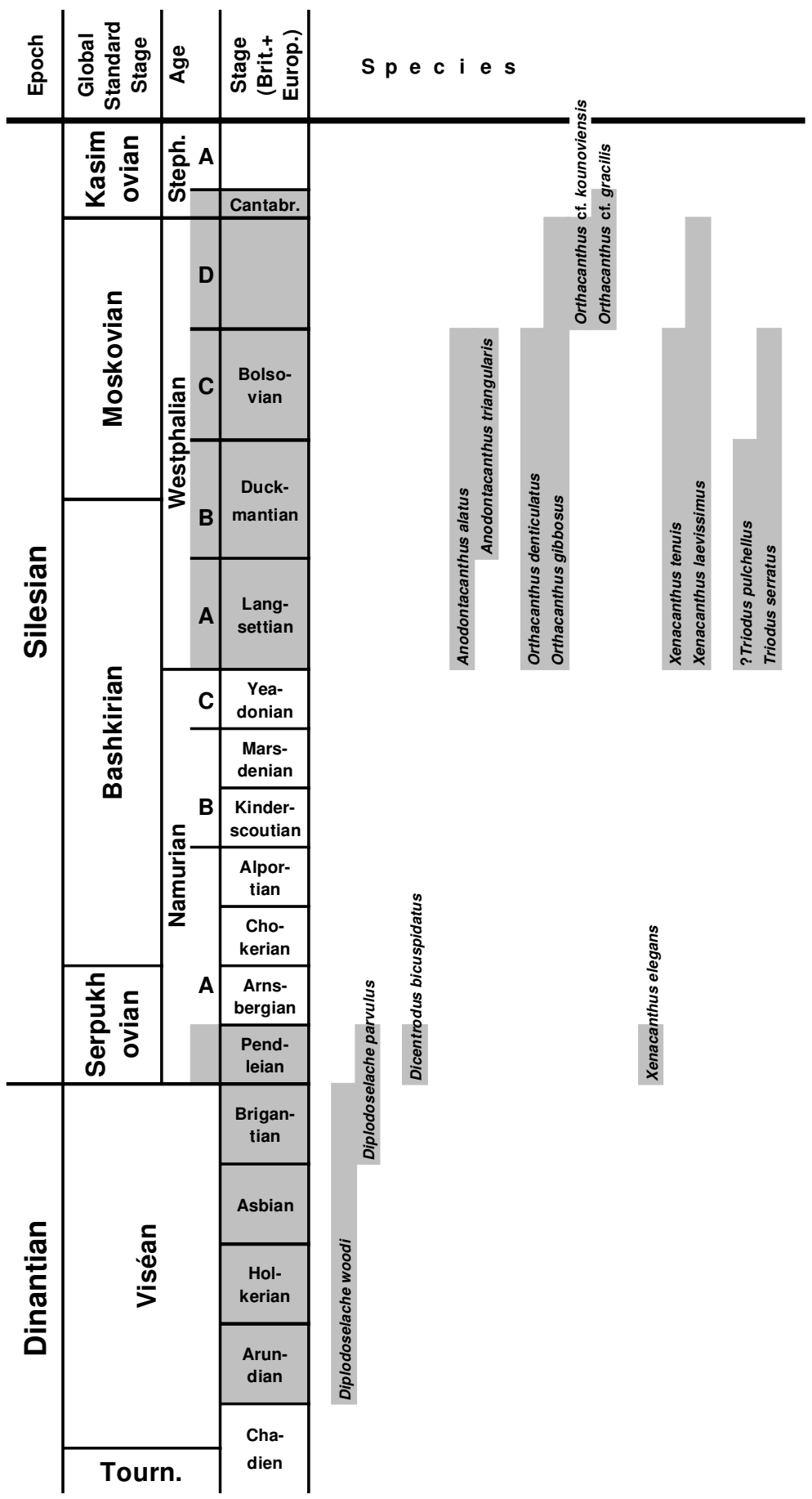

Figure 1 Stratigraphic distribution of xenacanthid species in Carboniferous deposits of Great Britain and Ireland (global standard correlation, after German Stratigraphic Commission, 2002).

\subsection{Histology}

$\begin{array}{ll}\text { den } & - \text { denteon } \\ \text { det } & - \text { dentine tubule } \\ \text { nuc } & - \text { nutrient canal } \\ \text { otd } & - \text { orthodentine } \\ \text { owl } & - \text { Owen's lines } \\ \text { pad } & - \text { pallial dentine } \\ \text { trd } & - \text { trabecular dentine }\end{array}$

\subsection{Stratigraphy}

W/S - Westphalian/Stephanian boundary

WD - Westphalian D

WC - Westphalian C

$$
\begin{array}{ll}
\text { WB } & - \text { Westphalian B } \\
\text { WA } & - \text { Westphalian A } \\
\text { PE } & - \text { Pendleian (Lower Namurian A) } \\
\text { BR } & - \text { Brigantian } \\
\text { AS } & - \text { Asbian } \\
\text { HO } & - \text { Holkerian } \\
\text { AR } & - \text { Arundian }
\end{array}
$$

\subsection{Technicalities}

B - blue light excitation, range 420-490 nm

UV - ultraviolet excitation, range 340-380 nm

$\mathrm{V}$ - violet light excitation, range $355-425 \mathrm{~nm}$

h $\quad-$ source of light: halogen lamp 


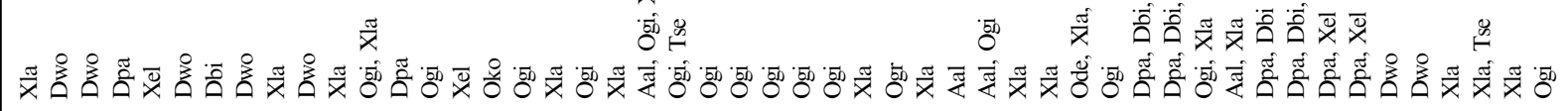

흘

के ठ

흥 흥 혀

o

兴

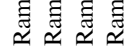

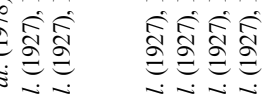

उ)

ป ธ

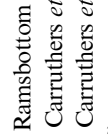

ป

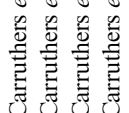

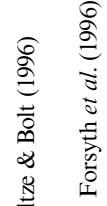

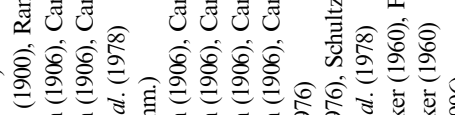

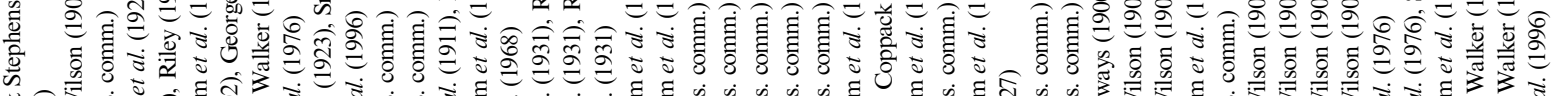
के

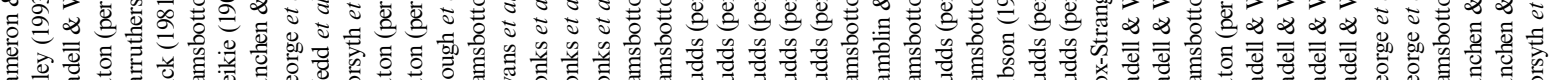

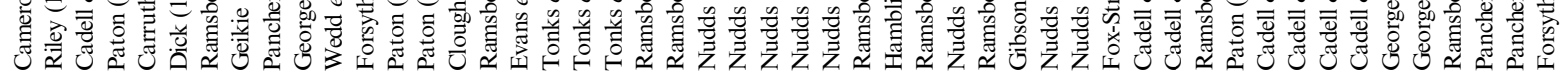

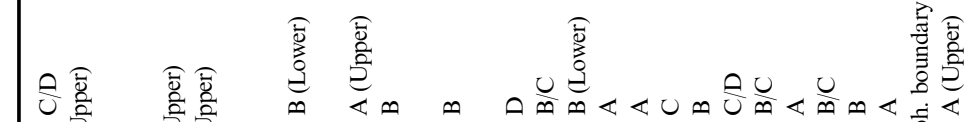

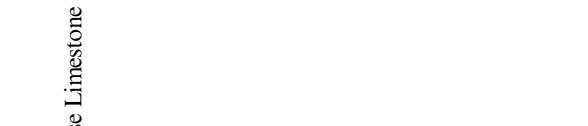

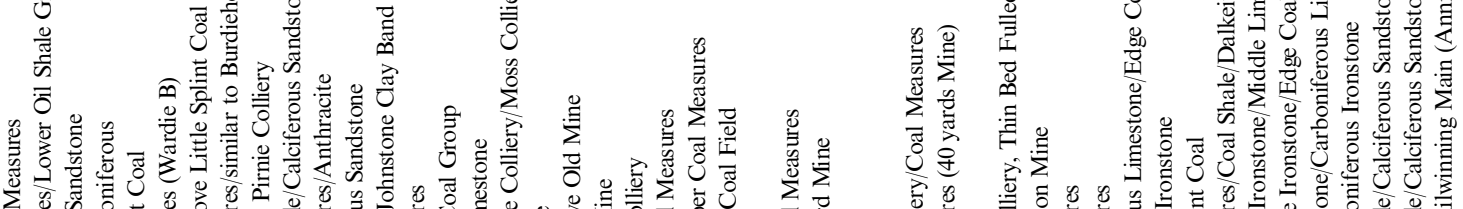

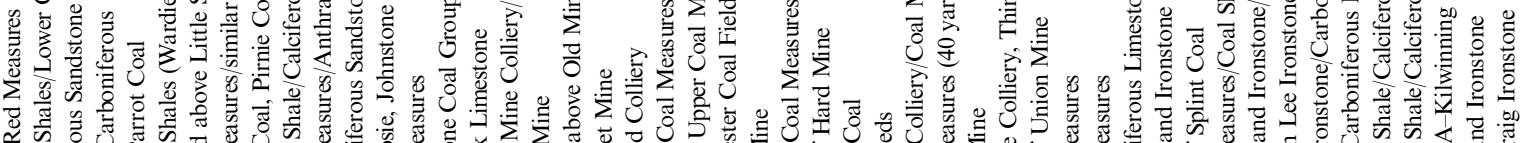

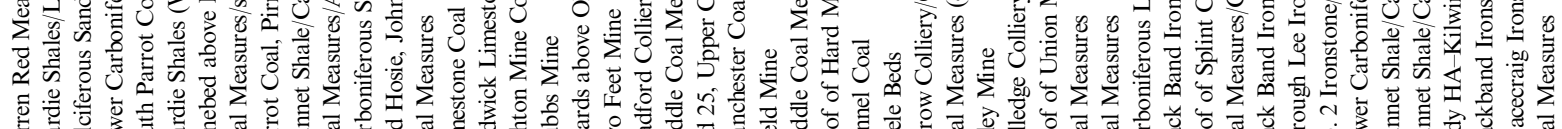

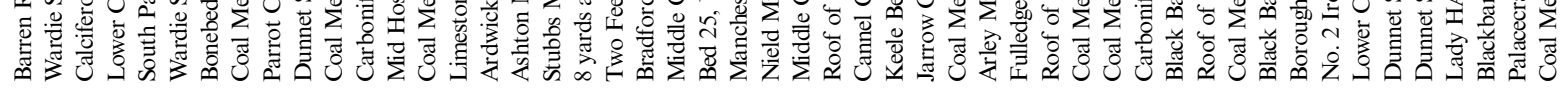




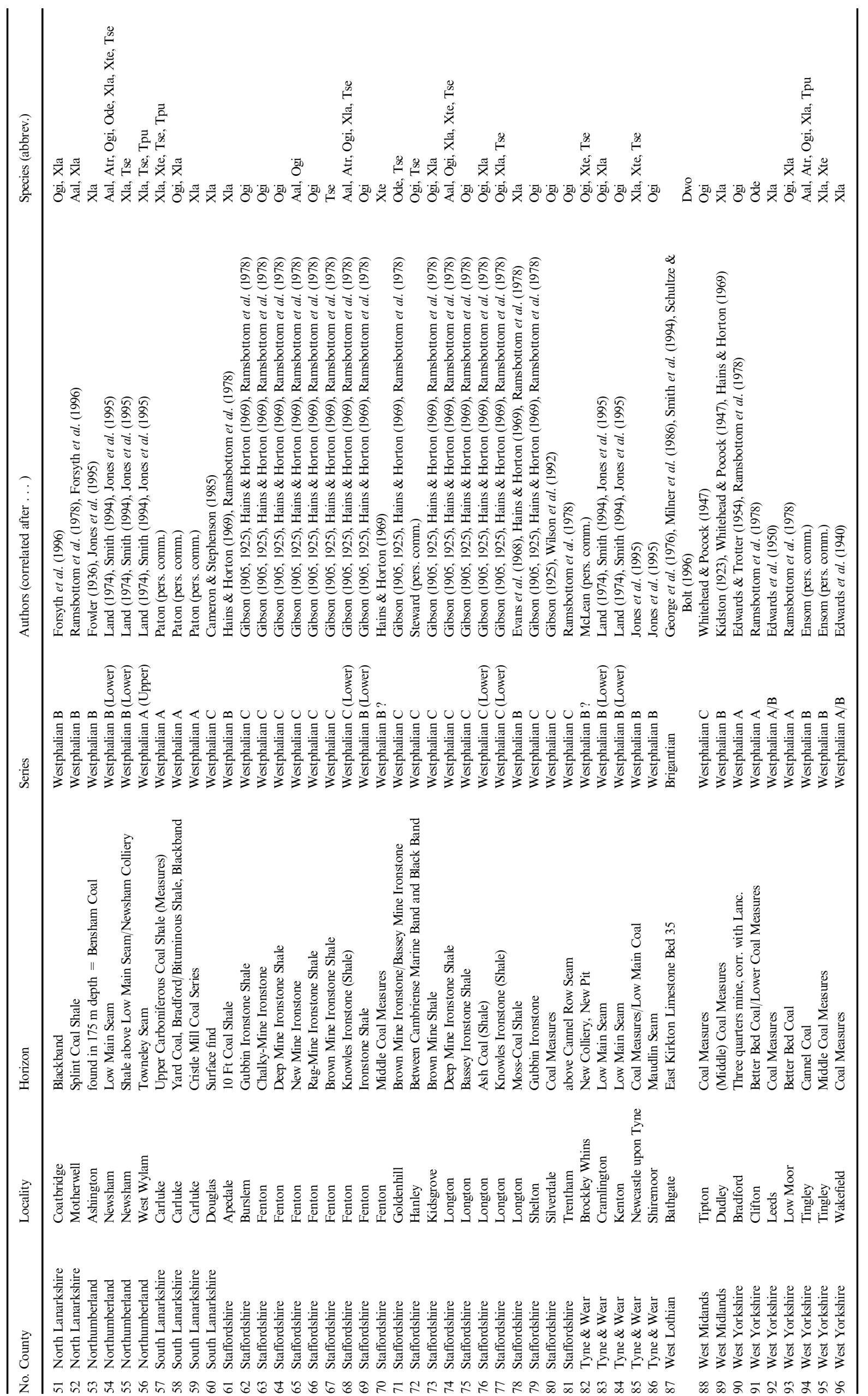



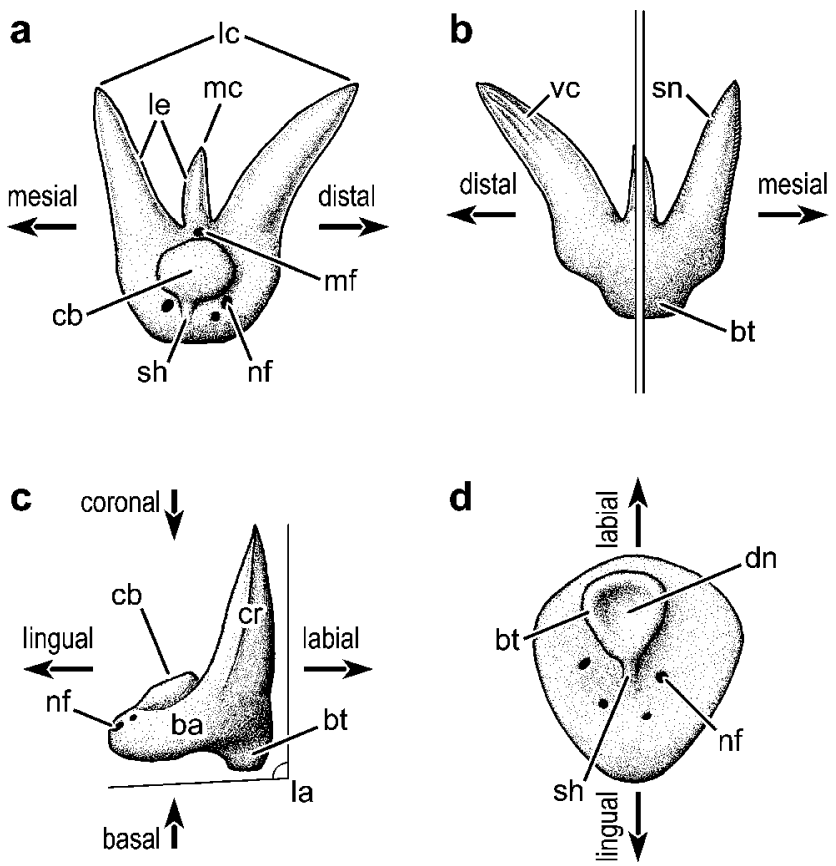

Figure 2 Nomenclature of xenacanthid teeth used in the text; for abbreviations see text.

$\begin{array}{ll}\mathrm{q} & - \text { source of light: mercury lamp } \\ \mathrm{t} & - \text { exposure time } \\ \mathrm{x} & - \text { magnification }\end{array}$

\section{The Victorian age- stratigraphical correlation problems}

The history of the discovery of the xenacanthids is intimately connected with the history of coal exploitation. The Upper Carboniferous is one of the most economically important parts of the geological column in Britain. This is due to the rich coal and iron reserves, which contributed to Britain becoming a major world power during the second half of the nineteenth century (Cleal \& Thomas 1996).

The broad lithostratigraphical division of the British Carboniferous (Carboniferous Limestone, Millstone Grit and Coal Measures) broadly corresponds to the Viséan, Namurian and Westphalian Series in the European regional chronostratigraphy (Wagner 1974; Ramsbottom et al. 1978). Various biostratigraphical schemes have been developed based mainly on conodonts, goniatites, foraminifera and spores (George et al. 1976; Riley 1993), whilst the non-marine bivalves and macrofloras have also been important in the Westphalian (Ramsbottom et al. 1978; Cleal \& Thomas 1994). A detailed review of recent stratigraphical research on the British Carboniferous is beyond the scope of this paper, but the following brief outline will help to place the fossils considered below into a broad geological context.

In the Early Carboniferous, Britain was located on the southwestern margin of the Laurasian continent close to the equator. An island known as St. George's Land ( WalesBrabant barrier) extended over Wales and Central England, and northern Scotland was part of the large Caledonian landmass. The remainder of Britain was covered by shallow seas (Cleal \& Thomas 1995). During the Namurian, fluvial deltaic systems prograded over northern and central Britain. By the Westphalian, these became covered by extensive and dense forests, which produced the peat that eventually gave rise to the productive coal of the Coal Measures (Cleal \& Thomas 1995). The youngest coal sequences probably range into the basal Cantabrian (early Stephanian), although the exact level of the Westphalian-Stephanian boundary is still a matter of debate (Cleal 1997).

Conditions in the six main areas where xenacanthids have been found (Fig. 3: Scottish Midland Valley, Northumberland/Tyne \& Wear area, the Pennines, Flintshire in N Wales, Central England and Kilkenny/Ireland) were quite similar.

The basal Carboniferous of the Midland Valley of Scotland represents a transition from the red, fluviatile and lacustrine sediments of the Upper Devonian, to the predominantly grey, fluvio-deltaic and shallow-marine beds of the remainder of the Lower Carboniferous (Cameron \& Stephenson 1985). These transitional beds are thick and lithologically variable cementstones (Calciferous Sandstone Group) formed in highly saline conditions in a lagoonal-coastal setting (George et al. 1976). The overlying Lower Limestone Group consists of limestones and mudstones, representing increasingly marine conditions (Cameron \& Stephenson 1985). The famous Wardie Shales were probably deposited under lagoonal and estuarine conditions (Carruthers et al. 1927).

The Westphalian of NE England (Northumberland/Tyne \& Wear) comprises about $900 \mathrm{~m}$ of deltaic sediments. Sandstones, siltstones and shales, deposited from sediment derived from the northern Caledonian landmass, predominate in the former near-shore environment. There are also numerous bituminous coal seams, each measuring up to $3 \mathrm{~m}$ thick (Jones et al. 1995).

The Westphalian of the Pennines is characterised by rhythmic sedimentation, especially in the Lancashire Coalfield, and represents tropical lowland swamps (Edwards \& Trotter 1954). Similar deposits also occur in central England $N$ of the Wales-Brabant barrier, where the most important coalfields are located in Staffordshire.

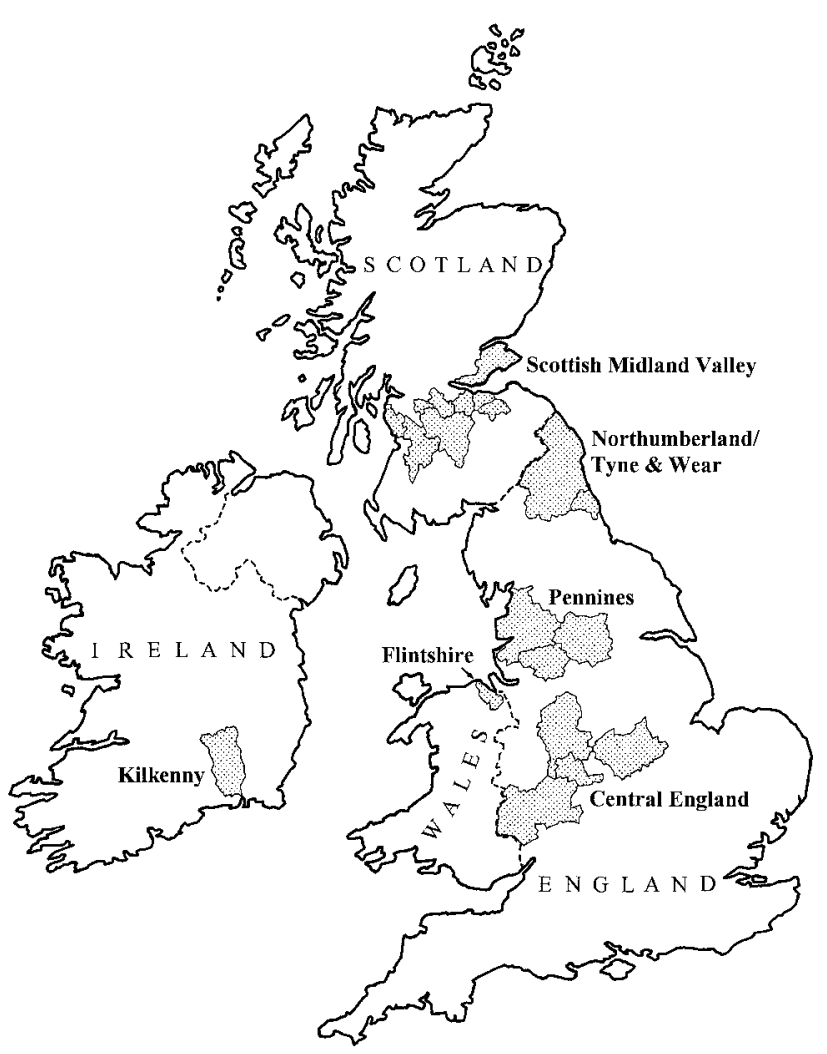

Figure 3 Map of Great Britain and Ireland showing the regions revealing determinable Carboniferous xenacanthid remains. 
The Carboniferous of $\mathrm{N}$ Wales also represents shallow-shelf seas and deltas, with a declining open-sea, neritic influence. During the Westphalian, the lagoons gradually silted up, and the environment became brackish and freshwater swamps (Smith \& George 1961).

The only Irish locality to have been identified as yielding determinable xenacanthid remains is the Jarrow Colliery, in the Leinster Coalfield, a site known for a rich vertebrate (tetrapod) fauna (Wright \& Huxley 1866; Huxley \& Wright 1867).

Recently, sequence stratigraphy has been used as a tool to try to elucidate the mechanisms of Westphalian coal deposition in Britain, especially the relationship between the raised mires and the periodic flooding events (e.g. Flint et al. 1995; Waters et al. 1996). Smith (1994) counted at least 40 cycles (cyclothems) for the Sunderland district, although most could be further subdivided into two or more subcyclothems. However, the cyclothems vary significantly from place to place, which has made it difficult to develop a consistent stratigraphical nomenclature between different districts and regions. This inconsistency was not helped by the geographical isolation of the former mining communities. Following nationalisation in 1947, however, the newly formed National Coal Board took control of the 70 collieries in Northumberland (see also closing data in Jones et al. 1995) and attempts were made to develop a more consistent nomenclature for the coals within each coalfield.

The British Coal Measures is a remarkably thick sequence: for instance, the Westphalian of Scotland is $1060 \mathrm{~m}$ thick, and that of the Pennines $3000 \mathrm{~m}$ (Owen 1976). With the decline in the economic importance of coal, the number of new xenacanthid finds diminished rapidly in the twentieth century. The following study deals with most of the xenacanthids that have been found in Great Britain and Ireland. Traquair (1901, p. 513) gave some additional occurrences for some species in Scotland, but it has not been possible to locate these specimens in the collections visited.

\section{Systematic palaeontology}

Class Chondrichthyes Huxley, 1880

Subclass Elasmobranchii Bonaparte, 1838

Order Xenacanthida Glikman, 1964

Type. Xenacanthus laevissimus (Agassiz 1837) from the Middle Coal Measures (Westphalian B) of Dudley, West Midlands.

Referred genera. Diplodoselache*, Dicentrodus*, Anodontacanthus*, Hagenoselache, Lebachacanthus, Orthacanthus*,

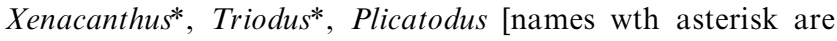
known from the British deposits].

Remarks. The generic names Pleuracanthus (Griffith et al. 1832 for a coleopteran from Brazil: Pleuracanthus sulcipennis) and Diplodus (Rafinesque Schmaltz 1810 for a sparid fish [Actinopterygii: Perciformes: Diplodus annularis]) are both preoccupied since the early nineteenth century. Expleuracanthus Heyler 1969 is equivalent ( $\supset$ junior synonym) to Xenacanthus Beyrich 1848. Bohemiacanthus Schneider \& Zajíc 1994 is a junior synonym for Triodus Jordan 1849. Misceracanthus Schneider \& Zajíc 1990 is a nomen nudum (only appearance in an unpublished abstract and in a comment of Zidek 1993a). The systematic position of Bransonella Harlton 1933 is not yet solved (see discussion in Ivanov \& Ginter 1996, p. 656). Further invalid names assigned to the reviewed British material are documented in the synonymy lists.
Family Diplodoselachidae Dick, 1981

Family diagnosis (emend. after Dick 1981). More primitive group of xenacanthids with dorsal spine always rounded in cross-section with ventrally arranged double row of denticles; skeleton of caudal fin inequilobate, non-diphycercal.

Included genera. Diplodoselache, Dicentrodus, Lebachacanthus, Orthacanthus, Hagenoselache.

Remarks. The recent cladistic analysis (see below) supports a unification of the more primitive xenacanthid taxa within one family. Schneider $(1988,1996)$ aleady discussed this taxonomical concept and placed species of the recently accepted genera Orthacanthus and Lebachacanthus into the Diplodoselachidae.

\section{Genus Diplodoselache Dick, 1981}

Type species. Diplodoselache woodi Dick, 1981, RSM 1972.27.447 A-C, an almost complete specimen from the Wardie Shales, Lower Oil Shale Group, Upper Arundian (Lower Viséan) of Wardie, Edinburgh.

Diagnosis (emend. after Dick 1981). Teeth with very short median cuspule(s); tendency to develop a saw-like blade between the lateral cusps; strong and highly constructed tooth base divided into a lower half bearing multiple pores and a smooth upper half.

\section{Diplodoselache woodi Dick 1981}

(Figs 4, 5, 7a-f)

1843 Diplodus minutus; Agassiz, p. 205, tab. 22b, figs 6-8: nomen nudum, insufficient diagnosis

1981 Diplodoselache woodi; Dick, pp. 99ff, figs 1-15

1982 Diplodus minutus [Diplodoselache woodi]; Andrews, p. 41

1986 Diplodoselache woodi; Dick et al., p. 83, fig. 2

1994 Diplodoselache woodi; Paton, pp. 329-30, fig. 2

Holotype. RSM 1972.27.447 A-C, an almost complete specimen preserved in an ironstone nodule with head, paired fins, plus anal and caudal fin exposed.

Type locality. Wardie, Edinburgh.

Type horizon. Wardie Shales, Lower Oil Shale Group, Upper Arundian (Lower Viséan).

Stratigraphical range. Upper Arundian to Brigantian.

Occurrence. Restricted to the Scottish basin: Bathgate (BR); Pittenweem, Straiton, Pentland (AS); ?Hailes (HO); Wardie, Granton (AR).

Diagnosis (emend. after Dick 1981). Elongated bodyform with terminal mouth opening; caudal fin internally heterocercal and of equilobate shape externally; tribasal articulation of pectoral fins with a long trapezoid metapterygium and segmented preaxial radials and very probably a broad insertion along the body wall; anal fin with broadly developed basal plate; straight and short, rounded dorsal spine inserting behind the shoulder girdle with rough striations on the anterior surface and a double row of denticles on the posterior face; teeth in general typically tricuspid with particularly short median cuspule.

Remarks. The teeth described by Agassiz (1843) from Burdiehouse appear to be lost. An enquiry at the Muséum d'Histore Naturelle, Neuchâtel resulted in a negative statement. The Burdiehouse Limestone is Asbian in age (see George et al. 1976), a section in which only the xenacanthid Diplodoselache woodi occurs. Andrews (1982) reidentified these specimens on Agassiz' plates as possibly belonging to $D$. woodi. The specimens described by Agassiz were poorly preserved, consisting mainly of isolated cusps, making an effective diagnosis impossible. 


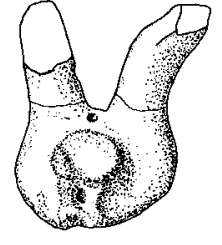

a
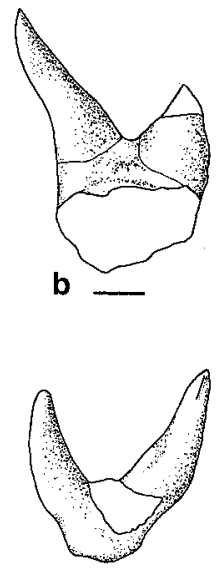

c

Figure 4 Teeth (a-j) and spine (k) of Diplodoselache woodi: (a) BMNH P 11317a, lingual view, Asbian of Pittenweem; (b) RSM 1974.23.7A, lingual view; (c) RSM 1972.27.447B, labial view; (d) RSM 1974.23.7B, labial view; (e) RSM 1972.27.447B, labial view, all upper Arundian of Wardie. (f) BMNH P 11318, labial view, Asbian of Straiton. (g) BMNH P 11317b, labial view, Asbian of Pittenweem. (h) RSM 1992.51.1, linguo-basal aspect, Brigantian of Bathgate. (i) HM G 182.69b, basal view, Asbian of Crail. (j) BMNH P 11317b, basal view, Asbian of Pittenweem. (k) RSM 1890.1.4, dorsal view of distal part, Asbian of Pentland. Scale bars, $1 \mathrm{~mm}$ (teeth), $10 \mathrm{~mm}$ (spine).

Description. Diplodoselache woodi is worldwide the oldest known fossil that can be confidently identified as a xenacanthid. It also represents the most complete elasmobranch of this order known from the British Isles. The skeletal remains lack only the details of the neurocranium. The braincase has a long otic region (Dick 1981) as is usual in xenacanthid sharks. There is nothing significant to add to the accurate, detailed description of the skeleton given by Dick (see Fig. 5). The following description concentrates on the morphology of the teeth, the spine and the distribution of the body scales.
The height of the teeth varies from $2 \mathrm{~mm}$ to $3.5 \mathrm{~mm}$ in smaller individuals to about $7 \mathrm{~mm}$ in larger individuals. The median cuspule is very short, sometimes measuring only one-tenth of the height of the lateral cusps (Fig. 4d). Accessory median cuspules occur relatively frequently, two or three being the usual number (Fig. 4f, g). It is also possible for median cuspules to be absent, in which case a little hump may be developed centrally between the lateral cusps. The cross-section of the cusps is oval to sometimes rhomboid. The lateral edges of the cusps are usually smooth. Occasionally, the edges are crenu-
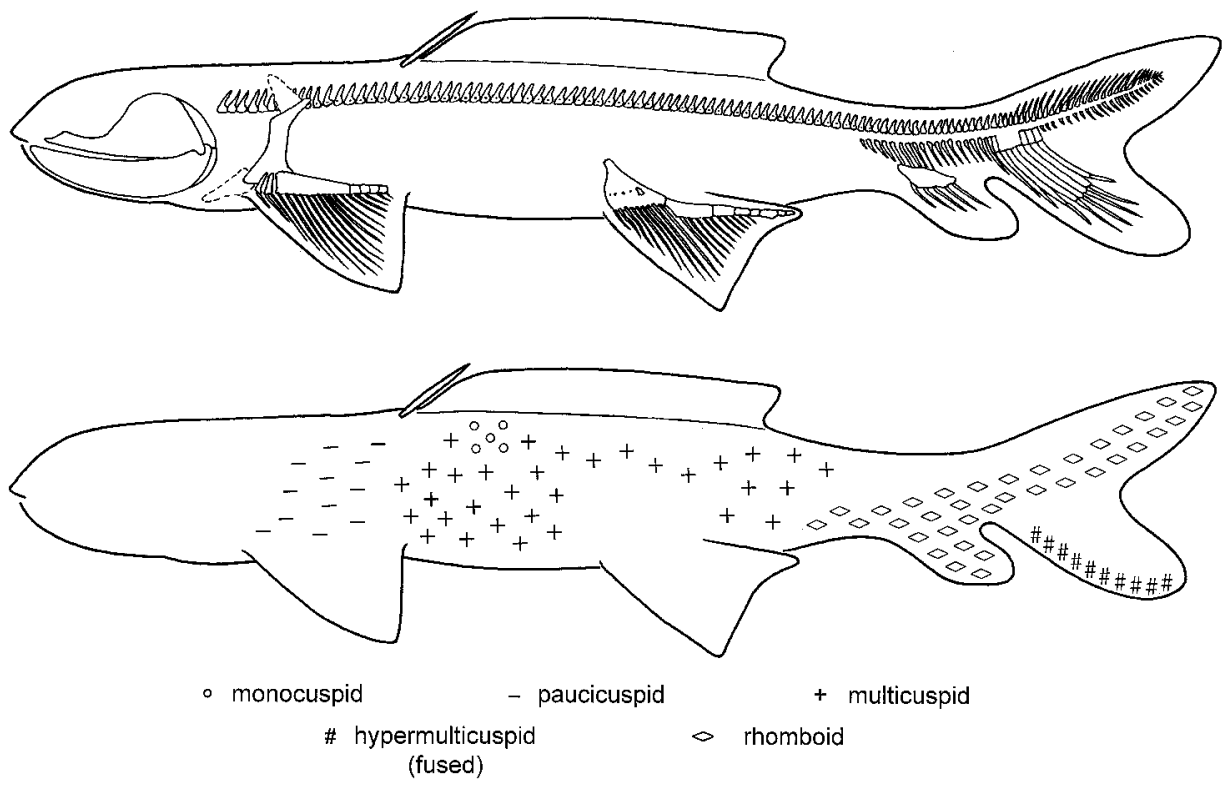

Figure 5 Reconstruction of Diplodoselache woodi (above), verified after Dick (1981) and scale distribution on the body surface (below). 
lated for the upper half of the cusp. In addition, one, or occasionally two vertical cristae occur on the lingual or labial surface of the lateral cusps (Fig. 4a, c) as can be clearly seen in horizontal section (Fig. 7e, f).

The base in Diplodoselache woodi is strong and elevated (Fig. 4). The outline of the base varies from a labio-lingually extended oval to occasionally rhomboid (Fig. 4i, j). The lower half of the base is punctuated with multiple pores; the upper half, including the transition with the crown, has a distinctly smoother surface (Fig. 4f). The upper side of the base always develops a central circular coronal button. A broad shaft can be developed on which a central nutrient foramen occasionally occurs (Fig. 4a). A median foramen is present in front of the median cusp (Fig. 4a). The bottom side of the base displays a maximum of six nutrient foramina. The basal tubercle, located adjacent to the labial margin, is very prominent and has a straight basally directed gentle concave depression (Fig. 4i, j).

The varying numbers of median cuspules, the variation in the development of cristae as well as the height variation indicates a heterodont dentition in this species. The lateral angle between the base and crown in lateral view is about $100^{\circ}$. RSM 1974.51.4A shows the presence of a row of replacement teeth behind the functional teeth (see reconstructions for the genera Xenacanthus and Triodus in Hampe 1988b, 1989).

The internal vascularisation system consists of pulp canals within the cusps, possessing relatively wide lumina. As in all xenacanthids, the cusp surface lacks enameloid. The crown is constructed with an internal socket of intrapulpous trabecular dentine of characteristically spongy character (Fig. 7b) identical to the condition in the tooth base (Fig. 7c). The trabecular sockets of the cusps are covered by centripetally deposited parallel layers of orthodentine (Owen's lines, fig. 7a). Dentine tubules are clearly visible in the orthodentine. They are arranged more or less parallel to each other and are more segregated in the peripheral zone (Fig. 7f). The lateral edges as well as occasional accessory cristae belong to the initial growth zone ('pallial' dentine, fig. 7f) formed when the basal membrane thickened and the odontoblasts were fully differentiated (see Schroeder 1992; Hampe \& Long 1999). Finally, dentine tubules are present in this superficial tissue forming the edge. The area of the coronal button (Fig. 7d) forms a trabecular dome enclosed by a few layers arranged parallel to each other (orthodentine).

The spines of $D$. woodi are straight and relatively short with a maximum width/total length ratio of 1:9 to 1:11 (for ease of comparison, the limit from robust to slender is adjusted to 1:12, following Soler-Gijón 1997b). The spines have an overall length of between $6 \mathrm{~cm}$ and $7.5 \mathrm{~cm}$. The skeleton shows clearly that the single dorsal spine is located behind the shoulder girdle as demonstrated by Dick (1981). Hampe (1997b) illustrated that this insertion is unique in the Xenacanthida. Other known genera have their point of insertion further forward (shoulder girdle area or head spine). The spine surface in $D$. woodi has a bark-like ornamentation giving the impression of strong corrosion (Fig. 4k). The cross-section is rendered elliptical by anterior-posterior compression and the posterior side carries a double row of small denticles. The central pulp canal is relatively wide, forming one-third to one-half of the entire diameter of the spine. The internal structure is composed exclusively of trabecular dentine as has already been described by Dick (1981).

Following the detailed description of scale types by Dick (1981), an attempt is made here to reconstruct the body squamation pattern (Fig. 5). Simple, paucicuspid scales can be found in front of the pectoral fin, followed with multicuspid scales covering almost the entire trunk of $D$. woodi. A field of stout, monocuspid denticles is present on the dorsal body surface beside the anterior half of the elongated dorsal fin. Rhomboid scales with a knob-like projection are located behind the pelvic fin including the surface of the anal fin, and reaching the epicaudal lobe of the tail. Some rather peculiar 'fused' scales are present on the lower margin of the ventral lobe of the tail. This character may be of functional significance: injuries of the dermis may have induced growth of these hypermulticuspid scales sustaining damage against a stony bottom. The structure of this type of scale resembles the 'growing-type' of Reif (1979).

\section{Diplodoselache parvulus (Traquair, 1881)} (Fig. 6)

1881 Diplodus parvulus, Traquair, p. 35

1889a Diplodus parvulus; Woodward, p. 12, pl. VI, figs 5-6

Syntypes. BMNH-P 4495, six teeth.

Type locality. Burghlee, Midlothian.

Type horizon. Middle Carboniferous Limestone, Pendleian (Lower Namurian A).

Stratigraphical range. Brigantian (Upper Viséan) to Pendleian (Namurian A).

Occurrence. Only in Scotland: Burghlee, Loanhead (PE); Cardonald (BR); Hyvots Bank (?BR).

Diagnosis (restricted to dentition; emend. after Traquair 1881). Teeth even more elevated than those of $D$. woodi; median cusp developed regularly as a labio-lingually compressed blunt hump; tendency to develop a saw-like blade of up to six miniature cusplets between the lateral cusps; presence of a vertical ridge on the labial side of the base; basal tubercle kidney-shaped; lateral angle between base and crown consistently $85^{\circ}$ to $90^{\circ}$.

Remarks. Traquair (1905) also reported Diplodus parvulus from the oil-shale of Pitcorthie in Eastern Fife.

Description. This species is known on the basis of teeth alone. Generally, they display more or less the same features as D. woodi. However, D. parvulus shows some significant morphological differences. The tooth height is increased and ranges from $2.5 \mathrm{~mm}$ to $10 \mathrm{~mm}$. The median 'cusp' is seldom strongly developed, but often comprises a labio-lingually compressed, blunt hump (Fig. 6b, c, e-j, m). Sporadically, two or three tiny cusplets can be detected (Fig. 61). A multiplicity of cusplets can result in a saw-like blade containing up to about six miniature cusplets between the two lateral cusps (Fig. 6n-p). This is abnormal for a xenacanthid. The lateral cusps have an oval cross-section, show minor divergence only (Fig. 6) and have delicately crenulated lateral edges ('grainy' in the proximal part). Otherwise the edges are smooth. Up to five additional vertical cristae are frequently present on the upper half of the cusps (Fig. 6c, g, i, j, m). Exceptionally, five cristae can be counted on the lingual side (Fig. 6b).

The base of the tooth has a circular outline (Fig. 7q-t) and, as in D. woodi, has a porous lower half. A 'vertical labial ridge' lying parallel to the median plane on the labial side is a distinctive feature (e.g. Fig. $6 f, h, j, 1)$. The upper end of the ridge begins below the median hump, cusp, or blade and terminates before reaching the porous lower part. A rounded, sometimes large coronal button is in most cases situated on the upper side (Fig. 6a-c). No shaft is present. The nutrient foramina, about one to three in number, are located mainly along the lingual margin of the base (Fig. 6a-c). One foramen typically lies directly in front of the coronal button (Fig. 6a, c). The bottom side shows generally about two to six, and rarely ten nutrient foramina placed in the inner circle of the basal surface (Fig. 6q-t). The basal tubercle is kidney-shaped but slightly depressed like an articulation cavity (Fig. 6q, s, t). The angle between base and crown is consistently $85^{\circ}$ to $90^{\circ}$ (Fig. $7 \mathrm{~d}$ ). 


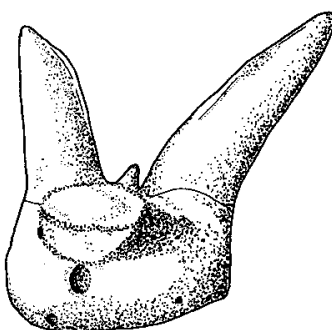

a

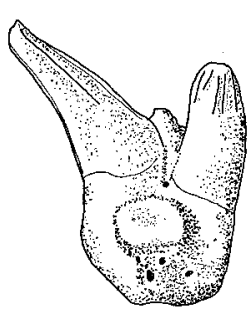

b

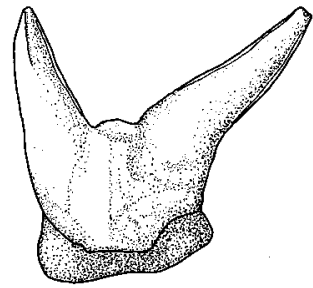

g

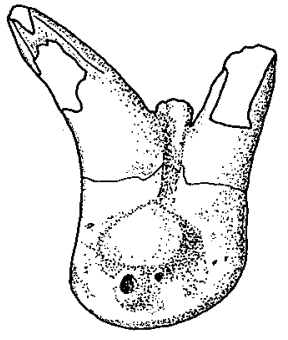

c

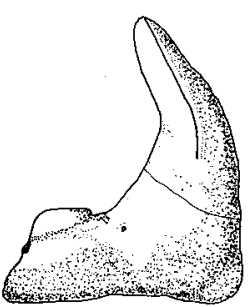

d

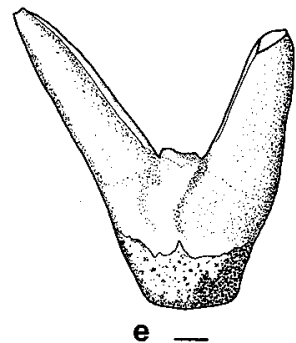

e -

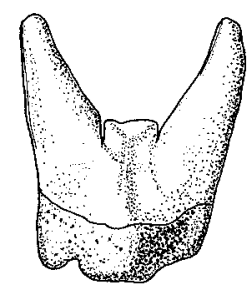

f

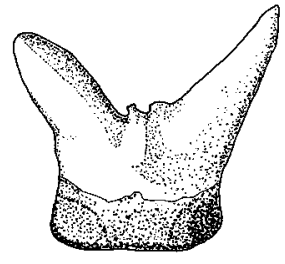

k

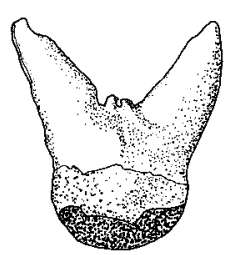

1 -

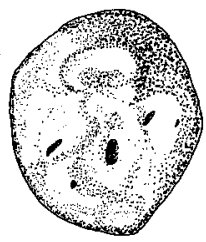

q -

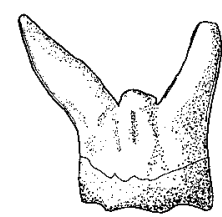

h

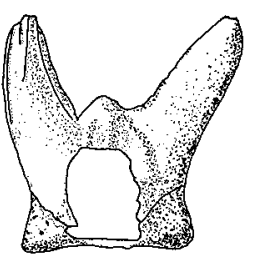

m

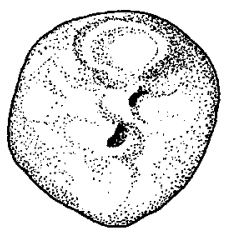

r -

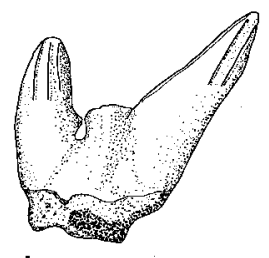

i

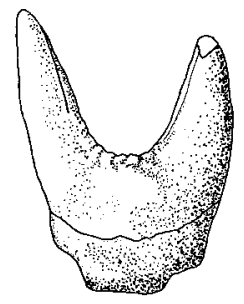

n -

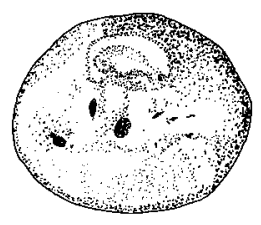

$\mathbf{s}$
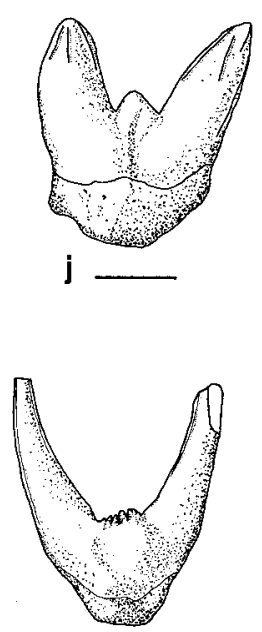

o -

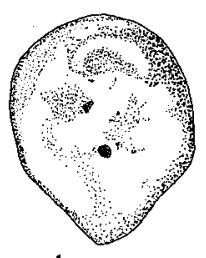

$\mathbf{t}$

Figure 6 Teeth of Diplodoselache parvulus: lingual (a-c), lateral (d), labial (e-p) and basal ( $\mathrm{q}-\mathrm{t})$ aspects: (a) HM G 70.36; (b) MM L.10444h; (c) MM L.10444l; (d) MM L.10444a; (e) HM G 70.36, (f) BMNH P 113211; (g) HM G 51.69; (h) BMNH P 11321 k; (i) MM L.10444i, all Pendleian of Loanhead. (j) NHM PW 1996/11-LS, Brigantian? of Hyvots Bank. (k) BMHN P 11321d, Pendleian of Loanhead. (l) BMNH P 4495.6, Pendleian of Burghlee. (m) BMNH P 8369, Brigantian of Cardonald. (n) BMNH P 11321j; (o) BMNH P 11321f, both Pendleian of Loanhead; (p) BMNH P 4495.5, Pendleian of Burghlee. (q) BMNH P 11321j; (r) BMNH P $11321 \mathrm{~h}$; (s) BMNH P 11321i; (t) BMNH P 11321k, all Pendleian of Loanhead. Scale bars, $1 \mathrm{~mm}$.

Discussion of Diplodoselache. Diplodoselache is the most primitive xenacanthid elasmobranch. The skeleton displays a mosaic of undoubted xenacanthid characteristics combined with features occuring in anacanthous (morphology of pectoral fin, e.g. Zangerl \& Case 1976 in Cobelodus; Williams 1985 in Symmorium) and ctenacanthoid sharks (tail; Moy-Thomas 1936 in Ctenacanthus and Goodrichthys). Xenacanthid characteristics include the elongated dorsal fin, and those of the spine, and the teeth (e.g. Schneider \& Zajíc 1994; Hampe \& Heidtke 1997).

The spine has some similarities with the early xenacanthid Dicentrodus (this paper) and with the Lower Permian Lebachacanthus from the SW German Saar-Nahe basin. The spines display the same arrangement of denticles (a double row on the posterior side) as well as identical proportions (Fritsch 1889; Soler-Gijón 1997b; Heidtke 1998). In Diplodoselache and Dicentrodus the spine surface is relatively rough without a definable pattern, whereas in Lebachacanthus a partial ornamentation of fine striations is present (see Heidtke 1998, fig. 7). The insertion of the spine in Diplodoselache is far behind the shoulder girdle, whereas the spine in Lebachacanthus has moved to a position near the shoulder girdle. In more derived xenacanthids, the spine is connected with the occipital region of the cranium (see Hampe 1997b, fig. 4).

The teeth of Diplodoselache woodi are typically xenacanthid, having a lingually extended base with a coronal button on the upper side and basal tubercle on the bottom. Nutrient foramina never occur on the labial surface of the base. The crown is usually tricuspid with longer lateral cusps and a smaller median cusp. In contrast, the younger species Diplodoselache parvulus exhibits unique characters in tooth morphology: the area of the median cusp is developed into a saw-like blade, a strong ridge on the labial side of the base appears, the number of vertical cristae increases, and the degree of heterodonty increases. With the exception of the latter two features, the other attributes are very unlike those of other xenacanthids, particularly in comparison to the younger forms of the Late Carboniferous and Permian. This circumstance leads to the 
assumption that the successor of $D$. woodi, D. parvulus, marks a dead end in the Diplodoselachidae and in xenacanthid evolution in general.

Recently Lebedev (1996) described a new species which he assigned to ?Diplodoselache as ?D. antiqua from the Lower Tournaisian of the Tula region S of Moscow. The teeth (Lebedev 1996, fig. 9a-d) show a long, and for Diplodoselache unusual, median cusp. However, the smooth lateral edges of the cusps as well as the not-uncommon accessory vertical cristae are similar to those in the Scottish species. The low base in the Russian species is a unique characteristic.

The spines of '?D. antiqua' (Lebedev 1996, fig. 9G, H) have a relatively clearly visible ornamentation of fine longitudinal striations which is not present in Diplodoselache woodi. Also, the maximum width/total length ratio is above the 1:12 limit used to specify Diplodoselache. This throws doubt on the generic assignation of the Russian form to Diplodoselache.

From the Early Carboniferous of central Queensland, Turner (1993, figs 4, 5) has described teeth as 'Xenacanthoid cf. Diplodoselache woodi'. However, these specimens are more closely related to the genus Hagenoselache Hampe \& Heidtke (1997), a nearly complete xenacanthid from the Namurian B of the Sauerland region in Germany. The Australian teeth are smaller than those of Hagenoselache sippeli, but share with them very short vertical cristae at the most distal part of the cusps, as well as identical numbers and distribution pattern of nutrient foramina on both the upper and lower surfaces of the base (Hampe \& Heidtke 1997, fig. 4C-E). Most of the teeth figured by Turner (1993, fig. 4C-G) have an extended mesio-distal diameter in the base which is not exposed in Diplodoselache.

The basal xenacanthid Diplodoselache is so far known only from the Scottish deposits and cannot be related to the discoveries in Russia and Australia.

The paired fins of Diplodoselache woodi resemble those of Ctenacanthus costellatus (Moy-Thomas 1936, text-fig. 5) with its long metapterygoidal axis bearing preaxial radials. However, the tribasal articulation is also found in the xenacanthids Orthacanthus (O. bohemicus, Fritsch 1889, fig. 173, pl. 81) and Lebachacanthus (e.g. Heidtke 1982, fig. 9, Klausewitz 1986, fig. 4, as Orthacanthus senckenbergianus). Bibasal (Xenacanthus, Triodus, e.g. X. meisenheimensis, Schwind 1991, p. 66, 67, fig. 2, pl. 69, fig. 1; X. decheni, Schneider \& Zajíc 1994, fig. 1, 7, 13b; T. palatinus, Schwind 1991, pl. 49, fig. 2; T. carinatus, Fritsch 1890, pl. 97) and monobasal (Hagenoselache sippeli, Hampe \& Heidtke 1997, fig. 7C) articulations together with the change to a biserial archipterygium represent one of the most typical characters of more derived xenacanthids.

The caudal fin of Diplodoselache is nearly symmetrical. Late Carboniferous and Early Permian xenacanthids developed increased epicaudal portions as in Hagenoselache and Lebachacanthus, and extremely reduced ventral lobes as in Xenacanthus and Triodus. The latter both reflect a more or less diphycercal tail outline (see reconstructions in Schneider 1996, fig. 7; Hampe \& Heidtke 1997, fig. 10C-G).

The morphology of the dermal scales, documented in Diplodoselache woodi, is relatively primitive: nearly all types are multicuspid and belong to the growing type which is usual in anacanthous sharks (Reif 1978, 1979) and which can be found amongst other cladodont sharks, such as Ctenacanthus costellatus and the protacrodontid elasmobranch ?Holmesella (see discussion in Dick 1981). More derived xenacanthids have monocuspid body scales of the non-growing type, as in Lebachacanthus senckenbergianus and Triodus palatinus as investigated from the Lower Permian of the SW-German Saar-Nahe basin (Hampe 1997b).

At this point, it must be mentioned that Janvier (1996, fig. 4.34. A1) figured a reconstruction of the Middle Devonian
Antarctilamna prisca using the body of Diplodoselache with integrated elements of Young's (1982) original specimens (braincase, spine). This means a composition made up from parts of two extremely different elasmobranchs. Antarctilamna has a markedly different braincase to that of any xenacanthid (see Fig. 17). The spine is of typical phalacanthous design with a wide posterior-basal opening of the pulp cavity (Young 1982, text-fig. 5; pl. 87, figs 2-5) and with strong ribs which Young himself claims as characteristic for ctenacanthoid sharks (see Maisey 1975).

\section{Genus Dicentrodus Traquair, 1888}

Type species. Dicentrodus bicuspidatus Traquair, 1881, BMNH-P 2295 (neotype), a single tooth from the Edge Coal Group, Carboniferous Limestone, Pendleian (Lower Namurian A).

Diagnosis (emend. after Traquair 1881). Asymmetrical bicuspid teeth reaching a height of between $3.5 \mathrm{~mm}$ and $20 \mathrm{~mm}$; large mesial and small distal cusp, both diverging distally having lanceolate cross-section and fine serrated edges; flat base always mesio-distally elongated; no median foramen between the cusps; histological structure: centre of cusps of trabecular dentine covered with orthodentine; dorsal spine stout and robust; double row of denticles on the posterior side.

\section{Dicentrodus bicuspidatus (Traquair, 1881)}

(Figs $7 \mathrm{~g}-\mathrm{j}, 8,13 \mathrm{a}, 19 \mathrm{a}$ )

1881 Cladodus bicuspidatus; Traquair, p. 34 (issued in January)

1881 Anodontacanthus fastigiatus; Davis, p. 428, pl. XXII, fig. 12 (read in May)

1888a Dicentrodus bicuspidatus; Traquair, pp. $420 \mathrm{ff}$

1889a Dicentrodus bicuspidatus; Woodward, p. 26, pl. 6, figs 7-9

Neotype. BMNH-P 2295, first figured tooth of this species, published by Woodward 1889a.

Type locality. Burghlee, Midlothian.

Type horizon. Edge Coal Group, Carboniferous Limestone, Pendleian (Lower Namurian A).

Stratigraphical range. Pendleian (Lower Namurian A).

Occurrence. Only in Scotland: Burghlee, Loanhead, Cowdenbeath.

Diagnosis. As for genus.

Remarks. There was no type specimen defined in the first description of teeth by Traquair (1881). Traquair (1888b) wrote that he had a large number of spines resembling those of the fastigiatus type in his collection, which he originally allocated to Anodontacanthus. Some have, however, 'undoubted stumps of denticles' (Traquair 1888b, p. 421), a confirmation that they belong to Dicentrodus.

Description. At first sight, teeth of Dicentrodus bicuspidatus look quite different compared to those of other xenacanthids. This may be the reason why Traquair originally determined them as belonging to cladodonts. The height of the teeth, measured at the longest cusp, ranges from $3.5 \mathrm{~mm}$ (in juveniles) up to $20 \mathrm{~mm}$. As the name suggests, the teeth are generally bicuspid with a large and strongly developed main mesial cusp and a distinctly smaller distal cusp which is about onequarter of the height of the bigger one (Fig. 8). The cusps diverge distally and have a lanceolate cross-section with fine serrated edges (Figs 8i, 19a). Occasionally, one or two accessory cusps occur between them (Fig. 8m).

The base is consistently elongated mesio-distally and has an almost diamond-shaped outline (Fig. 8g, h). From the lower margin to the base of the crown (cusps) the base shows a gradi- 

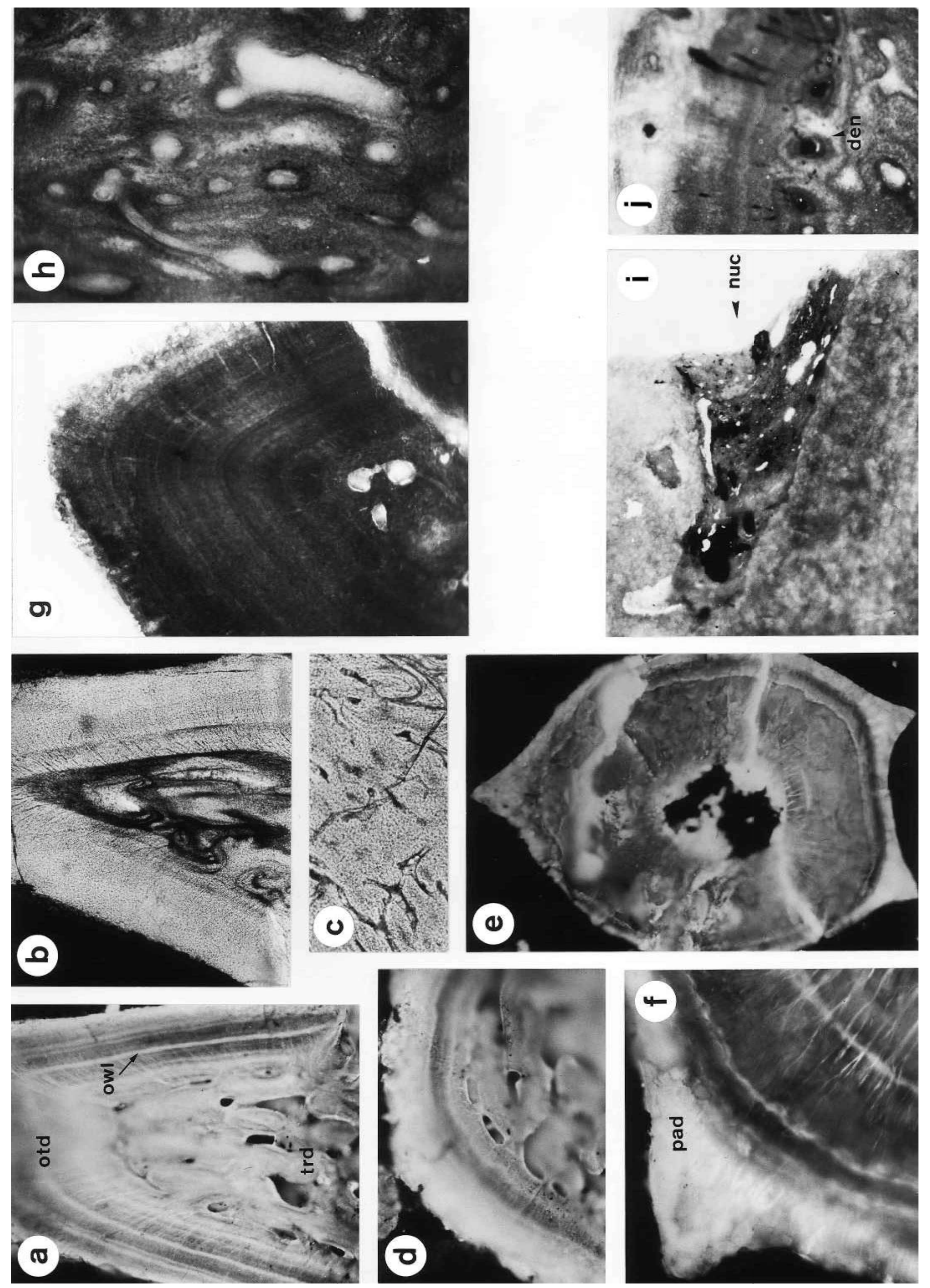


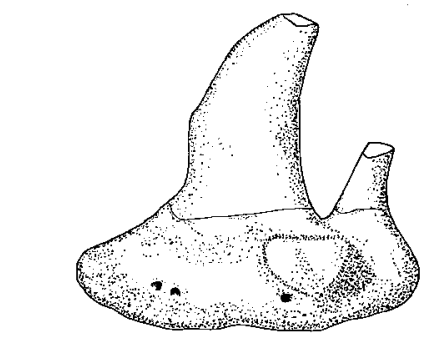

a -
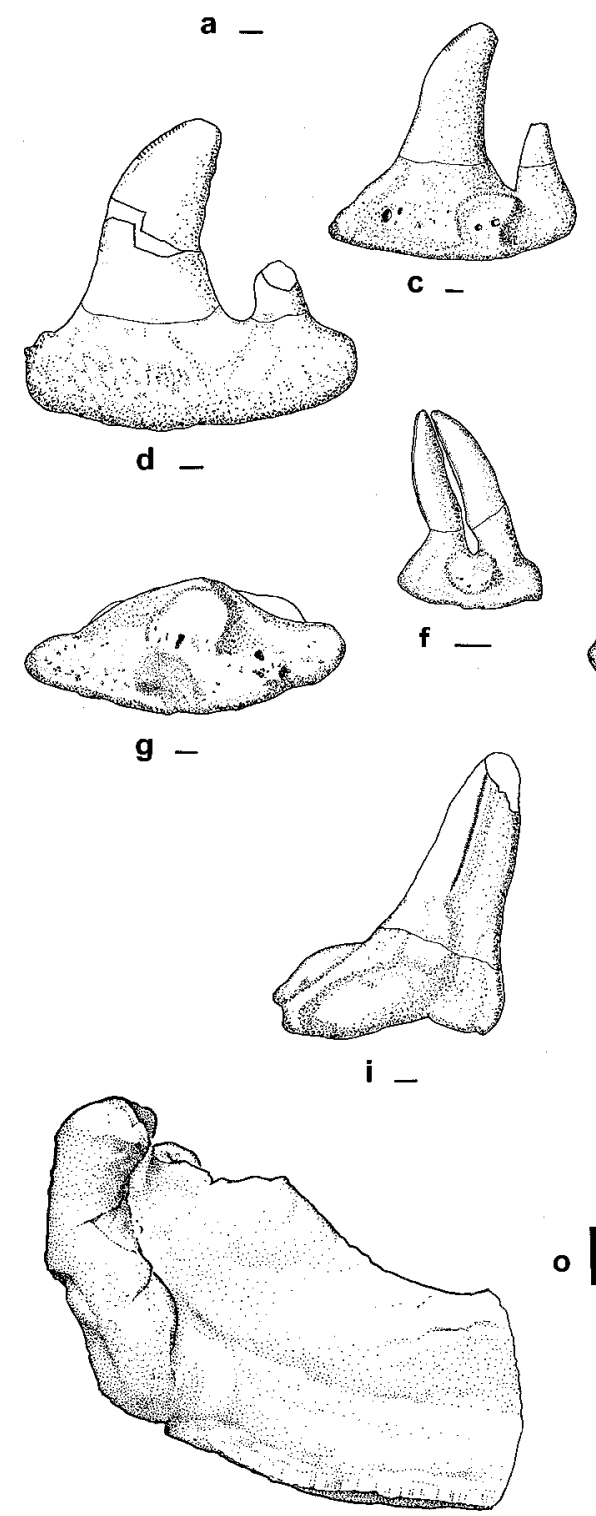

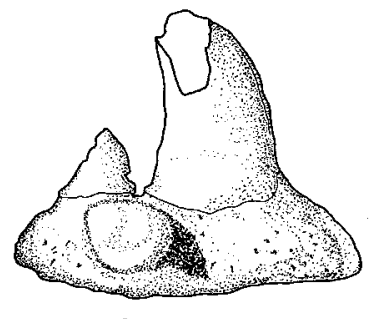

b -

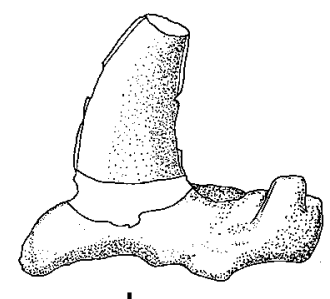

k -

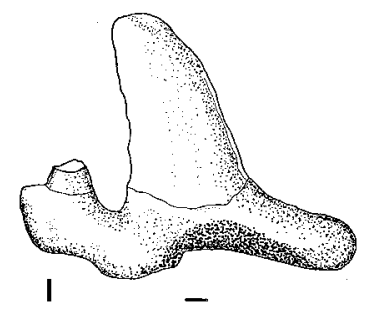

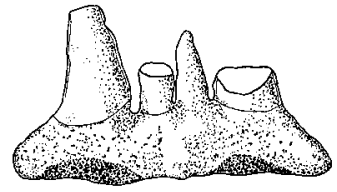

m -

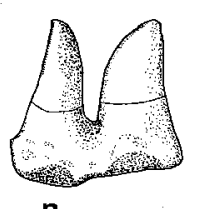

n

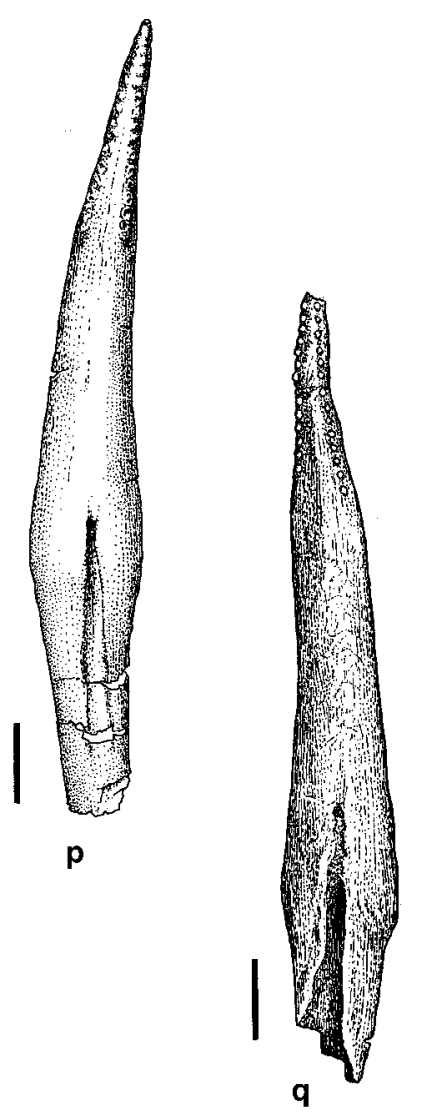

Figure 8 Dicentrodus bicuspidatus: teeth in lingual $(\mathrm{a}-\mathrm{f}, \mathrm{j})$, basal $(\mathrm{g}, \mathrm{h})$, lateral (i) and labial $(\mathrm{k}-\mathrm{n})$ aspects, a proximal fragment of a ceratohyal with internal (left) and external aspect (right) (o), and spines in ventral view (p, q): (a) NHM PW 1996/2-LS; (b) RSM 1975.5.27 Nr. 5; (c) BMNH P 59071; (d) NHM PW 1996/3-LS; (e) NMS G 1994.141.2, all Pendleian of Cowdenbeath. (f) BMNH P 11309b, Pendleian of Loanhead. (g) NMS G 1994.141.1; (h) NMS G 1994.141.4; (i) RSM 1975.5.27 Nr. 5, all Pendleian of Cowdenbeath. (j) BMNH P 11309a, a monocuspid tooth, Pendleian of Loanhead. (k) RSM 1975.5.27 Nr. 4; (l) RSM 1975.5.27 Nr. 2; (m) NMS G 1994.141.1, a quadricuspidate tooth, all Pendleian of Cowdenbeath. (n) BMNH P 11312, a commissural, Pendleian of Loanhead. (o) RSM 1975.48.12;(p) RSM 1978.4.1; (q) NMS G 1994.141.5, all Pendleian of Cowdenbeath. Scale bars, $1 \mathrm{~mm}(\mathrm{a}-\mathrm{n})$ and $1 \mathrm{~cm}(\mathrm{o}-\mathrm{q})$.

Figure 7 Tooth histology of Diplodoselache woodi (a-f) and Dicentrodus bicuspidatus ( $\mathrm{g}-\mathrm{j}$ ) revealed by fluorescence microscopy with incident light: (a) RSM 1894.186.2A-II, vertical section through a lateral cusp showing parallel layers of circumpulpargrown orthodentine (Owen's lines) surrounding the internal socket of trabecular dentine, B h, $\mathrm{t} \supset 2.34$ min, magnification $\times 53$; (b) RSM 1974.23.7, vertical section through a lateral cusp; transmitted light observation through a thin section, $\mathrm{t} \supset 1.68$ sec, magnification $\times 53$; (c) RSM 1974.23.7, vertical section through the base with typical trabecular dentine; transmitted light, $\mathrm{t} \supset 1.50 \mathrm{sec}$, magnification $\times 53$; (d) RSM 1894.186.2A-II, vertical section through a coronal button exhibiting a trabecular dome mantled by a few parallel oriented layers of orthodentine; B h, $\mathrm{t} \supset 2.15$ min, magnification $\times 53$; (e) RSM $1894.186 .2 \mathrm{~A}-\mathrm{IV}$, horizontal section from the top of a cusp showing lateral edges plus additional crista; B h, t $\supset 1.55$ min, magnification $\times 85$; (f) RSM 1894.186.2A-IX, enlargement of the lateral edge in a horizontal section of a cusp, constructed of 'pallial' dentine with dentine tubules arranged perpendicular to the growth lines; B h, t $\supset 3.29$ min, magnification $\times 210$; (g) NMS G 1994.141.3a, vertical section of a mesial cusp with dense trabecular dentine filled centre, covered with orthodentine crossed with parallely arranged dentine tubules; B h, t $\supset 3.06$ min, $\times 53$; (h) NMS G $1994.141 .3 \mathrm{~d}$, horizontal section through centre of a base with regular trabecular dentine having mesio-distally stretched spaces; B h, t $\supset 19.28 \mathrm{~min}, \times 53$; (i) NMS G 1994.141.3c, vertical section of a canal at the margin of the coronal button; B q, t $\supset 2.47 \mathrm{sec}, \times 134$; (j) NMS G 1994.141.3c, vertical section through the upper part of a base showing concentric depositions, denteons; B h, t $\supset 6.50 \mathrm{~min}, \times 53$. For abbreviations see text. 
ent slope on the lingual side (Fig. 8a-c) which is unique. On the upper side, a relatively flat, rounded or egg-shaped coronal button (Fig. 8a-c), sometimes pointed lingually and usually lacking a shaft (Fig. 8a) is situated in the centre of the lingual side. The number of nutrient foramina is difficult to verify because of the scarred surface. There seems to be from one to a maximum of four foramina present. They are not confined to the periphery of the coronal button. There is no median foramen located between the two cusps. The lower side has a more numerous, smaller foramina (plus scars) and a rounded, flat and less prominent basal tubercle which opens lingually to the surface of the base (Fig. 8g, h). The basal tubercle is slightly depressed. Overall, the dentition is heterodont.

Teeth with two more or less equal-sized cusps can be interpreted as probable commissurals or symphyseals (Fig. 8f, n). A broad base with a straight single cusp bearing serrated edges may be an accessory tooth (Fig. 8j), whose role was to protect soft tissue by filling up a gap between several tooth files (Reif 1980; Hampe 1997a).

The base of Dicentrodus bicuspidatus is composed of trabecular dentine with many vascular cavities (Fig. 7h). Units of concentrically deposited dentine, so-called denteons, are prominent in vertical section (Fig. 7j) near the upper surface of the base. The coronal button has the same structure as the base. Fig. $7 \mathrm{i}$ shows a vertical section through a nutrient canal below the coronal button. The centre of the cusps is also filled with trabecular dentine, covered with orthodentine, typified by the parallel arrangement of growth lines, or Owen's lines (Fig. 7g). The lateral edges of the cusps are not highlighted in a specific way. The vascular structure in the centre of each cusp is relatively dense with only narrow vascular spaces. No distinct pulp canal is exposed. Dentine tubules, closely in parallel and reaching the outermost layer, can be observed in horizontal sections of the cusps. An enameloid layer is absent.

The dorsal spines of Dicentrodus bicuspidatus have a length of about $8-10 \mathrm{~cm}$. They are more or less straight, although some specimens are slightly curved (Fig. 8p, q). Their crosssection is rounded (distally) to broadly oval-shaped (proximally). The posterior wall of the spine is open for the proximal third of its length. (Fig. 8p, q). From its proximal end the spine increases in width to a point which corresponds relatively to the closure of that opening. From this point the spine tapers gradually toward the distal tip. The maximum width/length ratio is $1: 7$ to $1: 10$ and the spine displays a stout and robust form. The surface has a bark-like structure overall. Small denticles are situated in a double row on the distal part of the posterior side.

Further preserved material is restricted to a few jaw cartilages. Isolated mandibulars and hyoid arch fragments show heights of $5 \mathrm{~cm}$ (ceratohyal, fig. 80 ) to $8.5 \mathrm{~cm}$ (mandibular $\supset$ Meckel's cartilage) as measured from the lower margin to the articular process for the hyomandibula (ceratohyal) and the palatoquadrate (mandibular), respectively.

Discussion of Dicentrodus. As mentioned above, Traquair (1881), in his first paper discussing Dicentrodus, suggested a resemblance of the teeth to those of Cladodus. He compared them with Cladodus pattersoni from the Waverly Black Shale of Ohio as illustrated in Newberry (1875, pl. LVIII, fig. 6). C. pattersoni 'teeth', however, were recently reidentified as modified dermal denticles of the dorsal surface of the head and the posterodorsal surface of the peculiar brush in stethacanthid sharks (see Williams 1985, p. 117; Coates \& Sequeira 2001, p. 451, fig. 12). C. pattersoni represents monocuspid elements and the flat base is the only character in common with Dicentrodus bicuspidatus teeth. Other features are distinctly different. The general morphology of the teeth of D. bicuspidatus is undoubtedly xenacanthid. The only exceptional character is the consistent lack of a median cusp. The histological structure of the cusps, with a trabecular core, is primitive and somewhat similar to the condition seen in Diplodoselache woodi.

No other xenacanthid teeth are directly comparable to this genus. The massive lateral cusps with distinct serration are similar to those of Lebachacanthus and species of Orthacanthus (except for O. platypternus from the Lower Permian of Texas, Oklahoma and West Virginia, see Johnson 1999). The latter species, however, has the greatest similarity with $D$. bicuspidatus. O. platypternus also has crescent-shaped cusps which always diverge distally. The proportions between the three cusps are not identical either; the mesial cusp is often clearly larger than the distal cusp. The median cusp is always very short. The base of $O$. platypternus is comparatively flat as in D. bicuspidatus (Johnson 1999, fig. 11G). Similar bases can be found in several other xenacanthid species, including Xenacanthus remigiusbergensis from the lowermost Permian of the Saar-Nahe basin (Hampe 1994, figs 8, 9) and Xenacanthus slaughteri (see Johnson 1999, figs 21, 22). Teeth described as 'Pleuracanthus' albuquerquei from the Permo-Carboniferous deposits of Pastos Bons, Estado do Maranhão, Brazil (Silva Santos 1946, pl. II) show some similarity with D. bicuspidatus in having one dominant lateral cusp. Also, the base is relatively flat in the Brazilian species. However, ' $P$.' albuquerquei is always tricuspid and has a parallel arrangement of vertical cristae on the cusp surface, indicating a relationship with Triodus. One of the jaw fragments from Cowdenbeath has been identified as a ceratohyal of D. bicuspidatus (cf. Hotton 1952, pl. 58, fig. 2B for O. platypternus). Isolated cartilage elements, especially mandibular and hyoid arch fragments, are less diagnostic and only useful for comparison if preserved in articulated specimens.

The spines of Dicentrodus bicuspidatus resemble very closely those of Lebachacanthus senckenbergianus from the Lower Permian of the intensively studied SW-German Saar-Nahe basin (Heidtke 1998). They are almost identical to Lebachacanthus in terms of proportions, denticulation and surface structure (Klausewitz 1987, fig. 7, Soler-Gijón 1997b, figs 1-3, Heidtke 1998, fig. 7). The site of insertion is unknown in Dicentrodus, together with the morphology of other important skeletal features such as the shape and structure of the fins. The record of D. bicuspidatus is too sparse to be able to relate them to a known xenacanthid. The distinctly younger Lebachacanthus senckenbergianus, on the other hand, is one of the best known of all xenacanthids.

Fritsch (1889, pl. 86, fig. 5) described a spine from the Stephanian B of Bohemia as 'Platyacanthus' ventricosus which Heidtke (1998) placed for good reasons into Lebachacanthus (Heidtke as subgenus, see discussions in Heidtke 1998, 1999a; Soler-Gijón 1997b, 2000). The spine of ' $P$.' ventricosus has no denticles, a phenomenon which sometimes also occurs in L. senckenbergianus. From his recent studies on histology and growth mechanisms, Soler-Gijon (1999) confirmed that the denticles were added proximally as independent dermal elements through the ontogeny of the spine. The denticles grew and mineralised in the germinal area of the skin. When the spine erupted through the skin, the denticles became fused to the spine surface. Nevertheless, different lengths of denticulation, gaps in the denticle row or even a complete lack of denticles can occur (asynchronous arrangement, cyclical variation in the growth rate). Supernumerary rows can also be observed, e.g. in Orthacanthusmeridionalis from the Uppermost Carboniferous (Stephanian C) of the Puertollano basin, Spain (SolerGijón 1997a, fig. 7B, 1999, fig. 22E, F).

This discussion suggests that Dicentrodus has greatest similarity with Lebachacanthus. Unfortunately, this opinion is based only on the spine morphology of the senckenbergianus 
and ventricosus species. Dicentrodus, like Diplodoselache, is known solely from Scotland.

Further doubts spring from the descriptions of 'Anodontacanthus' belemnoides from the Upper Pennsylvanian of Oklahoma (Zidek 1978, text-fig. 2A). Zidek's specimen shares many characteristics with $D$. bicuspidatus. It is the same size ( $7.5 \mathrm{~cm}$ length), the cross-section is circular distally to oval proximally, and the posterior notch occupies the proximal third of the spine length. Differences include the fact that the D. bicuspidatus spines can be slightly curved distally, the maximum width/length ratio is a little higher (1:7 to $1: 10)$ than in 'A.' belemnoides $(1: 6 \cdot 2)$, and the ornamentation is rougher in $D$. bicuspidatus (bark-like) than in 'A.' belemnoides (longitudinal striae). The fact that $D$. bicuspidatus definitely developed denticles in contrast to 'A.' belemnoides is not a reliable character to separate the latter as belonging to another genus (as demonstrated by Soler-Gijón's observations; see above). It seems likely that 'A.' belemnoides belongs to Dicentrodus.

Zangerl (1981) listed Dicentrodus as a junior synonym of Lambdodus, a genus based on monocuspid elements (scales?) from the Lower Carboniferous of Illinois and Iowa. However, the type species Lambdodus costatus from the upper Burlington limestone of Iowa and Illinois (St. John \& Worthen 1875, p. 280f, pl. 5, fig. 3) shows significant differences to Dicentrodus teeth: a single, slightly sigmoidal cusp with more or less distinct cutting edges as opposed to a bicuspid crown, irregular vertical cristae not occuring in Dicentrodus, and a base of oval or subcircular outline as opposed to a regularly diamond-shaped, mesio-distally elongated outline.

\section{Genus Orthacanthus Agassiz, 1843}

Type species. Orthacanthuscylindricus ( $\supset$ O.gibbosus), spine figured in Agassiz (1843, pl. 45, figs 7-9); whereabouts unknown.

Diagnosis (limited to teeth and spines; emend. after Fritsch 1889). Teeth tricuspid, characterised by large lateral cusps and consistently minute median cusp; at least serration on the lanceolate, dagger-shaped lateral cusps; median foramen on the upper side in front of the median cusp; basal tubercle without concave depression; histological structure: cusps constructed of orthodentine; dorsal spine straight and slender.

Remarks. Heyler \& Poplin (1989) erected for Orthacanthus the new familiy Orthacanthidae. However, their familial diagnosis, also used by Hampe (1994) and Heidtke (1998, 1999a) is considered to be no longer valid because it was based on 'O.' senckenbergians from the Lower Permian of the SWGerman Saar-Nahe basin which has now been ascribed to Lebachacanthus (see Soler-Gijón 1997b; Schneider et al. 2000). Articulated remains of Orthacanthus are extremely rare; cranial fragments are known in O. bohemicus from the Westphalian D of Bohemia (Fritsch 1889), O. buxieri from the Lower Permian of the French Massif Central (Heyler \& Poplin 1989, 1990; Poplin \& Heyler 1989) and O. texensis from the Lower Permian of Texas (Schaeffer 1981); almost nothing is known of the structure of the paired and the caudal fins. Remains of $O$. platypternus (Zidek 1993b) and O. bohemicus (Fritsch 1879, 1889) are assumed to belong to juveniles (Zidek 1993a).

\section{Orthacanthus gibbosus (Binney, 1840)}

(Figs 9, 10a-g, 11a-e, 13f, g, 19b)

1840 Diplodus gibbosus Binney, p. 169, pl. 5, figs 17, 18

1843 Diplodus gibbosus Agassiz, p. 204, pl. 22b, figs 1, 5 [non fig. 4]

Orthacanthus cylindricus Agassiz, p. 330, pl. 45, figs 7-9

1867
1873 Ochlodus crassus Barkas, p. 17, pl. 1, fig. 12 Orthocanthus Barkas, p. 20, pl. 1, figs 39-42

1880b Pleuracanthus cylindricus Davis, p. 332, fig. 8 Pleuracanthus wardi Davis, p. 334, fig. 9, pl. XII, fig. 6

1880 Lophacanthus taylori Stock, p. 217f, fig. 1

1889a Pleuracanthus cylindricus Woodward, p. 8 [in part] Diplodus gibbosus Woodward, p. 10f [in part]

1890 Orthacanthus cylindricus Ward, p. 137f Diplodus equilateralis Ward, p. 139f, pl. II, fig. 2

1892 Pleuracanthus wardi Davis, p. 732, pl. LXXII, fig. 15 Pleuracanthus cylindricus Davis, p. 740, pl. LXXIII, figs $1-4$

Pleuracanthus (Lophacanthus) taylori Davis, p. 745, pl. LXXIII, figs 22, 23

Pleuracanthus equilateralis Davis, p. 747, pl. 73, fig. 27

1994 Xenacanthus (Diplodus) gibbosus Steward, p. 11 Xenacanthus (Orthacanthus) cylindricus Steward, p. 11

1996 Xenacanthus taylori Newman et al., p. 8

1998 Orthacanthus gibbosus Heidtke, p. 137f, fig. 1, 2

Lectotype. BMNH-P 497, one isolated tooth. The holotype described by Binney (1840), from Pendleton coal field, Greater Manchester, is now apparently lost. Woodward (1889a) designated the tooth from Silverdale in Staffordshire as the type specimen, which must therefore be considered as a lectotype.

Type locality. Silverdale, Staffordshire.

Type horizon. Coal Measures (Westphalian C).

Stratigraphical range. Langsettian to Bolsovian (Westphalian A to C).

Occurrence. Teeth from Fallowfield (WC/D), Longton, Silverdale, Shelton, Collyhurst, Fenton, Tipton, Burslem, Hanley (all WC), Manchester and Ashton-under-Lyne (WB C), Kenton, Pendleton, Collyhurst, Newsham, Coatbridge, Tingley, Cramlington (all WB), Brockley Whins (WB?), Moira, Bradford, Low Moor, Carluke, Bardsley, Oldham (all WA); spines from Trentham, Fenton, Longton, Collyhurst, Kidsgrove (all WC), Peel/Little Hulton (WB/C), Tingley, Airdrie, Fenton, Dalkeith, Cambuslang, Newsham, Shiremoor, Eastfield (all WB), Low Moor (WA).

Diagnosis (emend. after Binney 1840, Agassiz 1843, Woodward 1889a). Median cusp of teeth with a length of one-fifth to one-third that of the lateral cusps; serration can occur also on the median cusp; presumed juvenile teeth lack serration; robust base with scarred surface; dorsal spine very long; maximum width/length ratio of about 1:19; double row of denticles separated by a central ridge.

Description. The teeth are characterised by a height of between $4 \mathrm{~mm}$ and $14 \mathrm{~mm}$; commissural teeth reach $3 \mathrm{~mm}$ to $4 \mathrm{~mm}$ in height. The median cusp has a length of one-fifth to one-third that of the lateral cusps (Figs 9, 10a-g, 19b). The cross-section of the cusps is typically lanceolate usually with serrated edges (Figs 9d-o; 10a, b, f). This serration can also be observed on the median cusp (Fig. 9j, k). Some specimens lack serration; these smaller and more gracile specimens probably belong to juveniles (Fig. 10e).

The base is robust and has, in most cases, a rounded outline (Fig. 9r-t), sometimes extended into an oval by labio-lingual elongation (Fig. 9p, q). Characteristic for this species is the scarred surface of the base (Fig. 19b). The coronal button on the upper side of the base varies significantly in shape, probably corresponding to individual positions in the jaws. Buttons vary from small rounded forms (Fig. 9a), through labio-lingually stretched (Fig. 9c), heart-shaped (Figs 9e; 10a) to big, more or less rectangular buttons (Fig. 9b). A lingual shaft is seldom developed; when present it is generally confined to the heart-shaped buttons (Fig. 9e). Between two and four nutrient foramina are situated on the lingual and lateral margins of the 


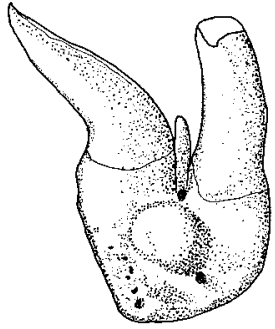

a

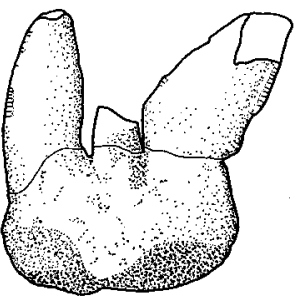

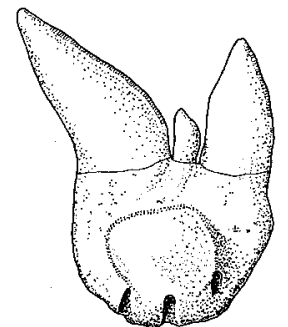

b

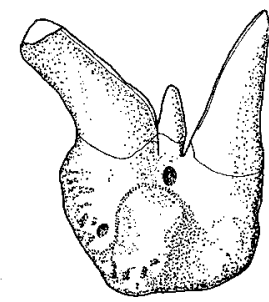

c

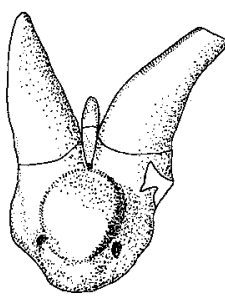

d -

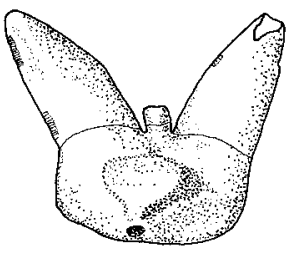

e -

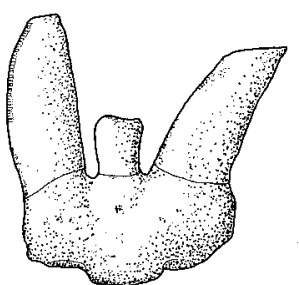

g

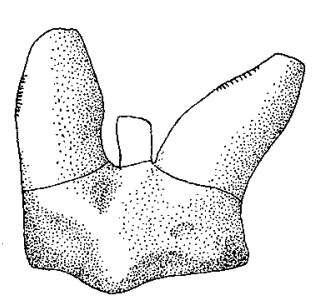

h

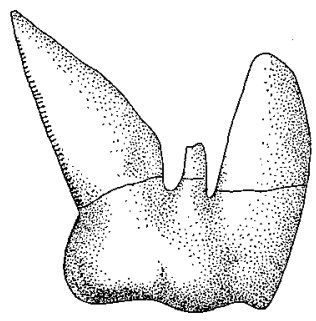

i -

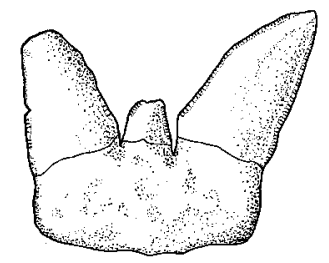

i -

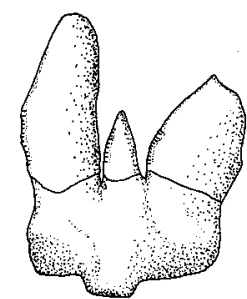

k -

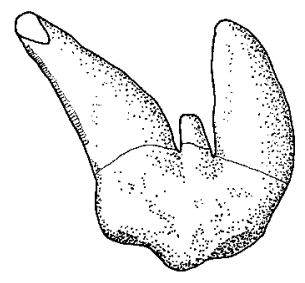

I

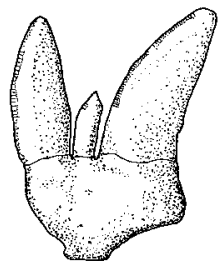

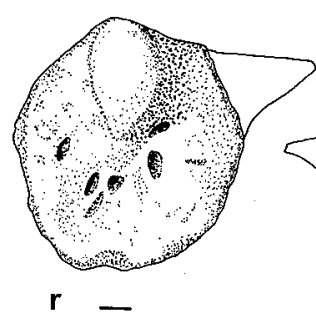

r

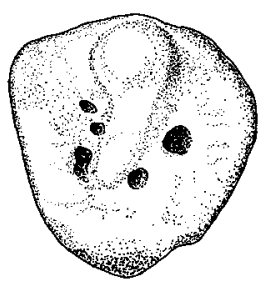

p -

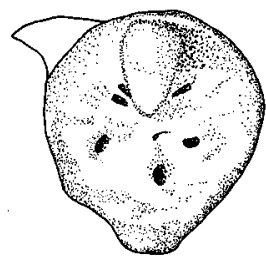

q -

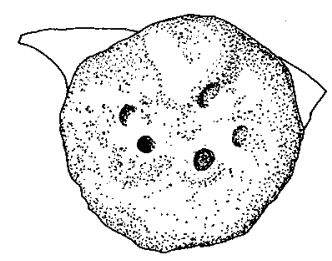

$\mathbf{s}$

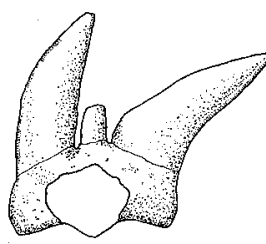

n -

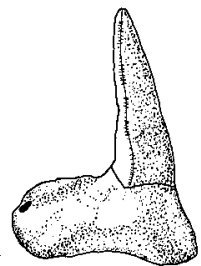

$\circ$ -

\begin{abstract}
Figure 9 Teeth of Orthacanthus gibbosus in lingual (a-e), labial (f-n), lateral (o), and basal (p-t) aspects: (a) MM W.901a, Westphalian A of Bardsley. (b) BMNH 44865a, Westphalian B of Pendleton, Manchester. (c) HM G 178.00, Lower Westphalian B of Kenton. (d) MM LL.11602a, Westphalian B of Collyhurst. (e) BMNH P 8408 Nr. 1, Westphalian C of Collyhurst. (f) BMNH P 8158 Nr. 23, Westphalian C of Longton. (g) BMNH P 52469, Westphalian B/C of Ashton-under-Lyne. (h) MB f.5491; (i) MB f.5490, both Westphalian C of Tipton. (j) MM LL.11603b, Westphalian C of Collyhurst. (k) MM LL.11602g, Westphalian B of Collyhurst. (1) BMNH P 8555 Nr. 2, Westphalian C of Shelton. (m) BMNH P 8158 Nr. 33, Westphalian C of Longton. (n) BMNH P 497 (lectotype), Westphalian C of Silverdale. (o) BMNH P 8408 Nr. 4. (p) MM LL.11603a, both Westphalian C of Collyhurst. (q) MM LL.11602b, Westphalian B of Collyhurst. (r) BMNH P 8158 Nr. 39. (s) BMNH P 8158 Nr. 49, both Westphalian C of Longton. (t) MB f.5491, Westphalian C of Tipton. Scale bars, $1 \mathrm{~mm}$.
\end{abstract}

coronal button (Figs 9a-e; 10a). An additional median foramen is present in front of the median cusp (Fig. 9a, c, d). On the crown underside a very prominent basal tubercle with a balllike head is occasionally found (Figs 91, p; 10c), sometimes becoming flat and tongue-shaped, and connected with a lingually directed shaft (Fig. $9 \mathrm{f}-\mathrm{n}, \mathrm{t})$. Between two and six nutrient foramina are present on the bottom side (Fig. 9p-t). The dentition can be referred to as heterodont, especially in view of the variation in height and degree of serration. Commissurals are typically only bicuspid with short cusps (Fig. 10d). The inner edges of one small tooth are relatively straight whereas the outer edges are curved as in a short broad-bladed knife (Fig. 10c). This tooth has also relatively blunt, parallel cusps. The latter feature suggests a possible symphyseal position. In both types of teeth the serration can vary and the base looks undifferentiated with barely developed buttons.

The histological features of Orthacanthus gibbosus teeth do not differ from those of other species of the same genus and Lebachacanthus senckenbergianus. The base is constructed of diffuse vascular trabeculardentine (Fig. 11e). The cusps consist of orthodentine with characteristic parallel arranged growth lines (Owen's lines). Vertical sections through lateral cusps suggest the laminar structure (Fig. 11a, b; see also Hampe 1991, pl. 1, fig. 2 for Lebachacanthus senckenbergianus). The dentine tubules are close together and strongly parallel (Fig. 11b, c, d). The main pulp canal has a relatively narrow lumen. An enameloid layer is absent.

The dorsal spines of Orthacanthus 'cylindricus' can be correlated with teeth of Orthacanthus gibbosus with some certainty. 


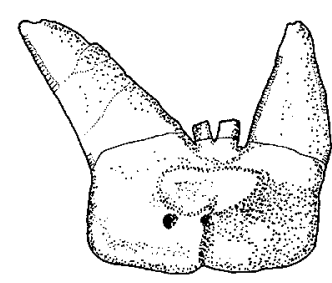

a -
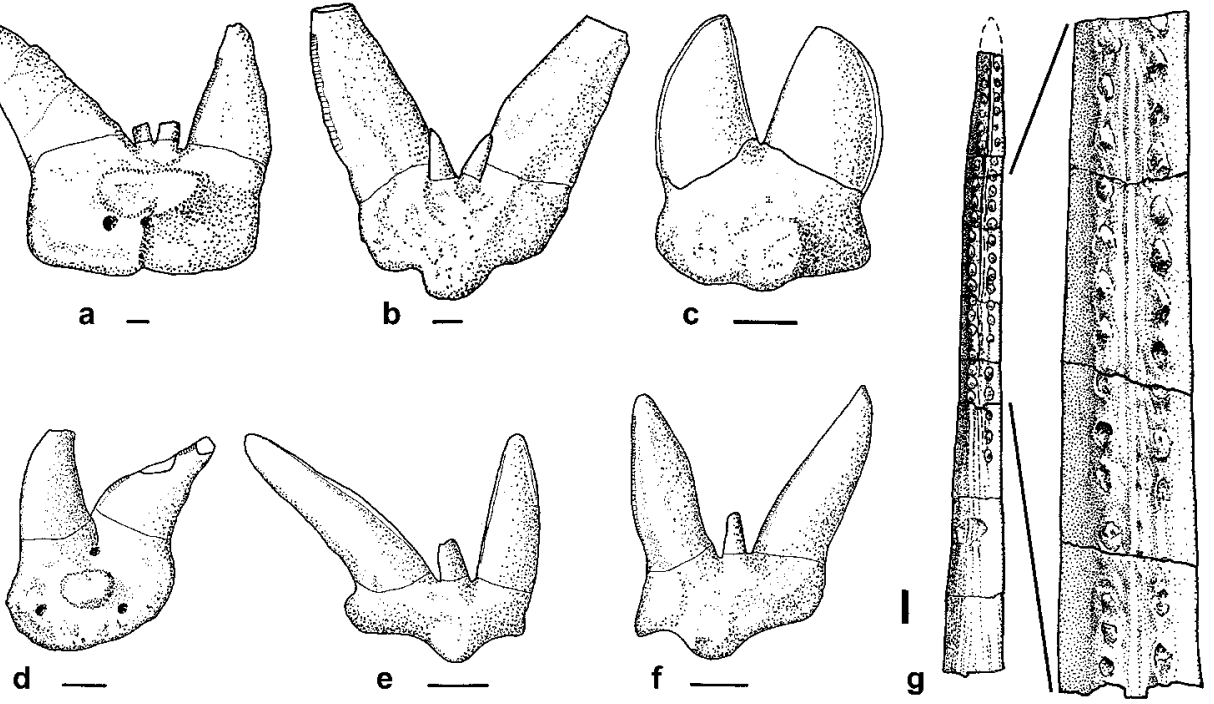

g
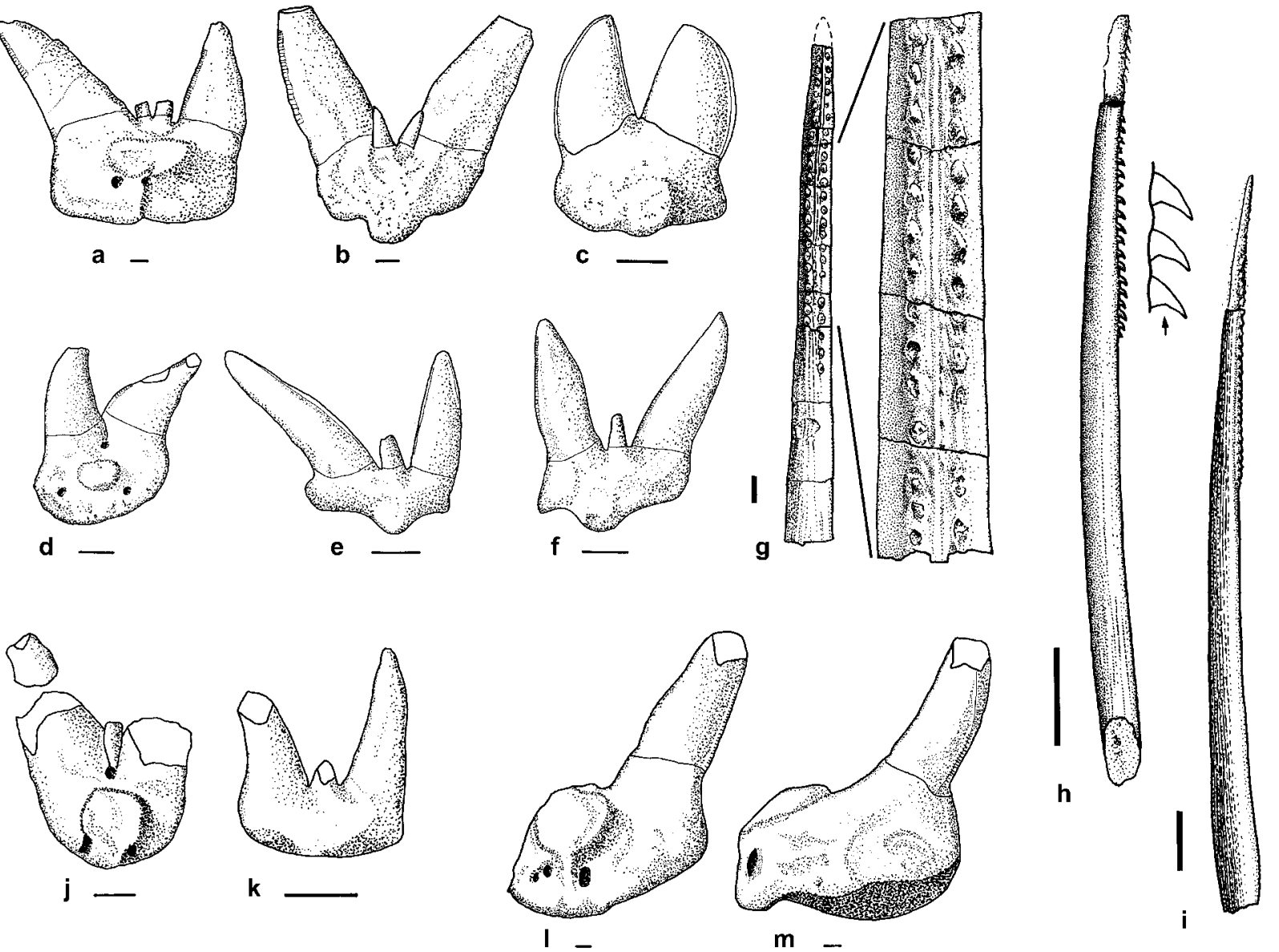

\begin{abstract}
Figure 10 Orthacanthus species: O. gibbosus (a-g), O. denticulatus (h, i), O. cf. gracilis (j, k), O. cf. kounoviensis (l, m): (a) BMNH P 8408 Nr. 3, quadricuspidate tooth in lingual view, Westphalian C of Collyhurst. (b) BMNH P 8162, quadricuspidate tooth in labial view, Westphalian $\mathrm{C}$ of Longton, formerly described as 'equilateralis' by Ward (1890) and Davis (1892). (c) MM LL.11607, probably a commissural tooth in labial view, Westphalian A of Bradford. (d) MM LL.116021, a biscuspid tooth in lingual view, Westphalian B of Collyhurst. (e) MM LL.11605b, Westphalian A of Bradford, (f) BMNH 46029, Westphalian C of Longton, both possible juvenile teeth in labial view. (g) BMNH P 6689, close-up of the ventral surface of a spine, Lower Westphalian B of Fenton. (h) HM G 24.22, spine in dorso-lateral aspect with detail of the denticles displaying the distinct bend pronouncing the backward orientation of the apex; (i) HM G 34.24, spine also in dorso-lateral aspect, both Lower Westphalian B of Newsham. (j) BMNH P 14021a, fragmentary tooth in lingual view; (k) BMNH P 14021b, labial aspect, both Westphalian D/Stephanian boundary of Hagley. (1) MM LL.11608, broken tooth in lingual view, Westphalian D of Ardwick; (m) same in lateral view. Scale bars, $1 \mathrm{~mm}(\mathrm{a}-\mathrm{f}, \mathrm{j}-\mathrm{m})$ and $1 \mathrm{~cm}(\mathrm{~g}-\mathrm{i})$.
\end{abstract}

A piece of shale from the Knowles Ironstone Shale (Lower Westphalian B) of Longton reveals seven teeth in association with the characteristic spine fragment (BMNH-P 8152). The spines (formerly described under the name $O$. cylindricus by British authors) are usually straight and erect. Some can be slightly curved (formerly classified under the species names wardi and taylori). The spines can reach over $40 \mathrm{~cm}$ in length. The maximum width/length ratio based on a few complete spines (most of the preserved specimens are fragmentary) is about $1: 19$, indicating that the spines of $O$. gibbosus were comparatively slender. The cross-section is generally rounded with the diameter decreasing gradually towards the apex (Fig. 13f). The central pulp cavity comprises about one-quarter of the entire cross-section of the spine. The surface is striated along the entire length of the spine, becoming a little less prominent on the most distal part (Fig. 13f). Two rows of small denticles are present on the upper half of the posterior side of the spine and are separated by a thin ridge which extends beyond the denticulated area (Figs 10g; 13f).

From the proportions and size of the spine, it can be estimated that individuals of $O$. gibbosus belong to the largest xenacanthid sharks known.
Orthacanthus denticulatus Davis, 1880

(Fig. 10h, i)

1880b Pleuracanthus denticulatus Davis, p. 334, fig. 10, pl. XII, fig. 7

1892 Pleuracanthus denticulatus Davis, p. 734, pl. LXXII, figs $18-20$

Pleuracanthus howsei Davis, p. 735, pl. LXXII, fig. 21

1996 Xenacanthus howsei Newman et al., p. 2 Xenacanthus denticulatus Newman et al., p. 4

Holotype. BMNH-P 7694, an isolated spine.

Type locality. Clifton, W Yorkshire.

Type horizon. Better Bed Coal, Langsettian(Westphalian A).

Stratigraphical range. Langsettian to Bolsovian (Westphalian $\mathrm{A}$ to $\mathrm{C}$ ).

Occurrence. Goldenhill (WC), Newsham (WB), Clifton, Burnley (both WA).

Diagnosis (emend. after Davis 1880b, 1892). Spines always curved, and slender with maximum width/length ratio between $1: 18$ and 1:20; denticles sharply pointed, slender and recurved; surface between the double row of denticles planar. 

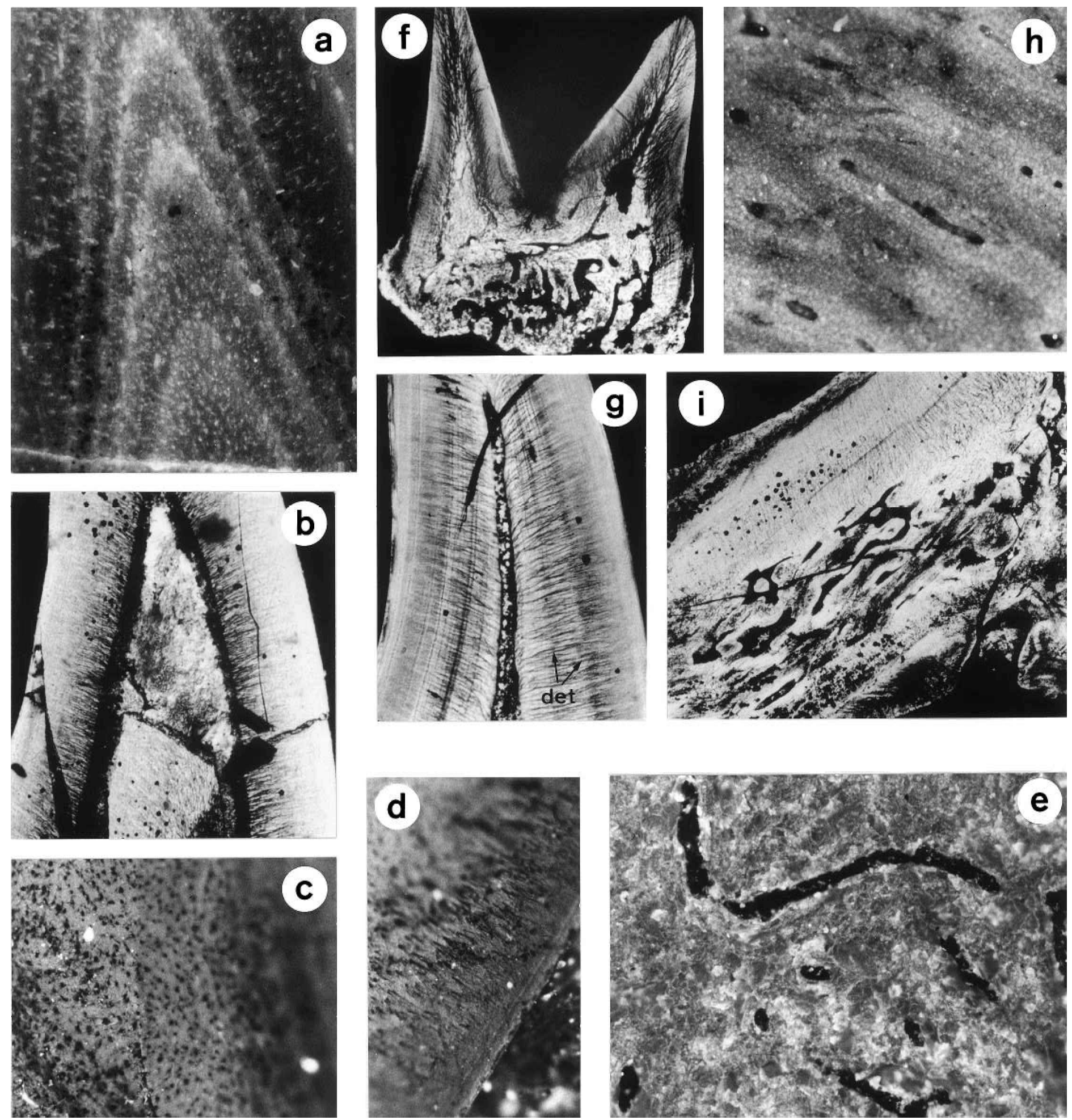

Figure 11 Tooth histology of Orthacanthus gibbosus (a-e) and Xenacanthus laevissimus (f-i): (a) BMNH P 8408 b, vertical section through a lateral cusp with parallel growth lines of orthodentine which covers the entire cusps; B q, t $\supset 7.59$ sec, $\times 88$; (b) BMNH P 40208, vertical section through cusp with orthodentine and dentine tubules arranged in parallel; transmitted light from a thin section [originally described as Ochlodus crassus by Owen 1867], UV Vh q, t $\supset 0.22 \mathrm{sec}, \times 43$; (c) MM L.5176, transversal section of the proximal part of a cusp with dentine tubules crossing the orthodentine; B q, t $\supset$ 13.67 sec, $\times 88$; (d) MM L.5176, vertical section of a lateral cusp, outer zone with dentine tubules set close together and parallel; B q, t $\supset 16.32 \mathrm{sec}, \times 88$; (e) STOT F 1406, vertical section through base with normal diffuse vascular trabecular dentine; B q, t $\supset 9.56 \mathrm{sec}, \times 88$; (f) BMNH P 6238, vertical section through a complete tooth in labio-lingual projection (median cusp broken?) showing a trabecular dentine core in the proximal part of the cusps covered with orthodentine; transmitted light from a thin section [originally as Dittodus divergens, Owen 1867], UVh q, t $\supset 0.30 \mathrm{sec}, \times 43$; (g) BMNH P 6245, vertical section through a cusp exhibiting the bushy dentine tubules arranged closely in parallel and a very narrow pulp canal, transmitted light from a thin section [originally as Pternodus productus, Owen 1867], UV Vh q, t $\supset 1.76$ sec, $\times 43$; (h) SM F 15005 , tranversal section through base with typical trabecular dentine, B q, t $\supset 3.55 \mathrm{sec}$, $\times 88$; (i) BMNH P 6245 , vertical section in the transitional area between base and crown showing the mantle of orthodentine which follows the upper surface of the base in lingual direction; internal structure of trabecular dentine; transmitted light, UV Vh q, t $\supset 0.50 \mathrm{sec}, \times 43$. 
Remarks. Only the spines of this species are known to date; no specimens show teeth associated with spines or spine fragments. It is possible that teeth of $O$. gibbosus may belong to $O$. denticulatus (perhaps the 'juveniles' which are distinctly developed more gracile than the regular teeth of $O$. gibbosus). However, this suggestion is purely conjectural at present.

Description. The dorsal spines are evidently shorter than the spines of $O$. gibbosus. Spine lengths vary from $7 \cdot 4 \mathrm{~cm}$ to $12 \mathrm{~cm}$. The cross-section is rounded. In contrast to O. gibbosus, the spines of $O$. denticulatus are always curved posteriorly (Fig. 10h, i). The maximum width/length ratio lies between $1: 18$ and $1: 20$ and indicates slender proportions. The surface is ornamented by longitudinal striations which are strongly developed in the proximal, non-denticulated area, and become weaker but still discernible in the distal, denticulated part. Between the double row of denticles the surface is an almost flat plane. The denticles are separated by a distance more or less equal to half the diameter of the spine. The form of the denticles is very characteristic: they are sharply pointed, slender and recurved. On the posterior margin the denticles have a distinct bend emphasising the backward orientation of the apex (Fig. 10h). Denticles are not developed in the howsei specimen; they are not connected to the spine during ontogeny (see Soler-Gijón 1999). A double row of knobs arranged in a wave-like pattern shows the former articulation points for the denticles (Fig. 10i). These knobs indicate prolonged centrifugal accretion of dentine without the formation of new denticles (Soler-Gijón 1999). Davis (1892) cited the resemblance of howsei to denticulatus. The only difference he noted between them is the number of denticles, which is fewer in the howsei type.

\section{Orthacanthus cf. kounoviensis Fritsch, 1889}

(Fig. 101, m)

Syntypes of $\boldsymbol{O}$. kounoviensis. Národni Muzeum, Prague, all originals figured in Fritsch $(1889$, pl. 83, fig. 1; pls 84, 85; pl. 86 , figs $1-4$; pl. 87 , figs $1,2,5,7$; pl. 90), teeth and spines, head and branchial arch fragments.

Type locality. Kounová, Plzen basin, Bohemia (Czech Republic).

Type horizon. Kounová member, Upper Stephanian B.

Stratigraphical range. ?Saale depression (Central Germany): Stephanian C; Plzen basin (Bohemia, Czech Republic): Stephanian B; SW-Germany (Saar-Nahe basin): Stephanian A; Manchester Coalfield: Westphalian D.

Occurrence in Britain. Ardwick (WD).

Diagnosis. After descriptions of Fritsch (1889) and Hampe (1994) unchanged.

Description. The British teeth are characterised by their immense height of $16 \mathrm{~mm}$ to $17 \mathrm{~mm}$ minimum (!). Teeth of this size are known only from the $\mathrm{N}$ American species $O$. texensis and from the Bohemian O. bohemicus and O. kounoviensis. The median cusp is not complete in any of the Ardwick specimens. The lateral cusps are of lanceolate cross-section and are equipped with an usually weak but distinctive serration (Fig. 101, m). A serration of the serration, typical for O. kounoviensis (Fritsch 1889, pl. 85, fig. 18; Hampe 1994, p. 65), is not present in the specimens from Ardwick. This may be the result of variation within the species.

The base is extremely strong and robust and relatively high in comparison to the height of the complete teeth. In lateral view, the base displays a hump-like protuberance (Fig. 10m). The coronal button on the upper side is rounded and comparatively small with a narrow lingual shaft (Fig. 101). Three lingually oriented nutrient foramina are situated on the upper side of the base (Fig. 10m). Details of the base underside are not available in the British specimens.

The broken teeth reveal a typically Orthacanthus histology, with a base constructed of trabecular dentine and orthodentine in the crown.

\section{Orthacanthus cf. gracilis (Giebel, 1848)} (Fig. 10j, k)

1926 Diplodus Cox, p. 404

Holotype of $\boldsymbol{O}$. gracilis. GTM 1095, tooth figured in Giebel (1849, pl. XXIX, fig. 2) as 'Chilodus' gracilis.

Type locality. Wettin, N Halle/Saale, Saxony-Anhalt, Central Germany.

Type horizon. Brandschiefer, Wettin member, Stephanian C.

Stratigraphical range. Central Germany (Saale depression): Stephanian C; SW-Germany (Saar-Nahe basin): Stephanian A and C (facies correlated hiatus in Stephanian B); Hereford \& Worcester, Britain: Westphalian D/Stephanian boundary.

Occurrence in Britain. Hagley (W/S).

Diagnosis. See Hampe (1994, p. 61).

Remarks. Newberry (1875, p. 56f) allocated isolated spines to $O$. gracilis from the Linton locality in Ohio. They are very short and slender with a flattened dorsal surface and denticles of uncertain position (?double row or on each lateral side; Newberry 1875, pl. LIX, fig. 7). Although Orthacanthus teeth are known from Linton ( $\supset O$. compressus), it is not certain whether the spines belong to that species. A relationship to the European $O$. gracilis is questionable.

Description. Only three teeth of this species have been located in British collections, and come from Hereford \& Worcester. They were mentioned in a footnote in Cox (1926) but not figured. Cox referred to the teeth while describing gastropods from the Hunnington Calcareous Beds of the so-called Keele beds at a locality identified as Hagley Wood.

Information concerning these specimens is relatively sparse. One tooth has a height of $2 \mathrm{~mm}$, and a second tooth is $4 \mathrm{~mm}$ high. The lateral edges of the cusps are serrated as usual. The median cusp is always short (Fig. 10j, k). The base is rounded but mesio-distally extended. On the upper side there is a rounded coronal button of almost rectangular outline (Fig. 10j). The button extends into a broad lingual shaft. One nutrient foramen is positioned directly in each corner between the button and the shaft (Fig. 10j). An Orthacanthus-type median foramen is present in front of the median cuspule. The basal tubercle on the bottom side of the base is not very prominent; the basal surface is almost planar. Three to four nutrient foramina can be detected on the bottom side. One commissural tooth is also known in the material. This small tooth $(1.8 \mathrm{~mm}$ high) is characterised by the typical lack of a median cusp.

Discussion of Orthacanthus. O. gibbosus shows the largest spines known so far for xenacanthids, with distinctive characteristics including the median ridge between the denticle rows. On the other hand, the teeth look rather primitive, with a unique scarred surface to the base. O. gibbosus shows irregular cusp serration, sometimes weakly developed, and sometimes lacking altogether. The development of the cusp edges shows similarities with $O$. gracilis in some cases.

$O$. gracilis from the Pennsylvanian of $\mathrm{N}$ America, and described by Newberry (1856) under the name 'Didymodus', is not conspecific with the European material. The European species, erected by Giebel (1848, as 'Chilodus' gracilis) has priority and is thus valid. The $\mathrm{N}$ American teeth are characterised after Olson (1946) by the lack of cusp serration, minor 
lanceolate cusp cross-section and a small base. However, Hotton (1952) believed that $O$. latus and $O$. gracilis were

conspecific with and synonyms of $O$. compressus, the three nominal species merely illustrating intraspecific variation. Newberry (1875, pl. LVIII, figs 1-3) remarked that the differences between these 'species' are neither strongly marked nor very constant and may be variants within a single taxon.

$O$. compressus appears mainly in eastern $\mathrm{N}$ America and is a species which in some cases is difficult to distinguish from the teeth of O. texensis and O. platypternus (Johnson 1999, figs 15-19). Johnson described immense variation but notes general similarities between the teeth of $O$. compressus and $O$. texensis. It is not clear, however, whether $O$. compressus is just a stratigraphically younger variant of $O$. texensis. The latter (Hotton 1952, figs 2B, 3, 4; Schneider 1988, text-fig. 3.3, pl. 1, fig. 5; Johnson 1999, figs 5-8) occurs in the Early Permian of mainly southern and western $\mathrm{N}$ America (type material named 'Didymodus' compressus Cope, $1884 \rightarrow$ not $O$. compressus Newberry 1856). Teeth from Archer County, McGregor Ranch, Texas, housed at the University of Mainz, show coarsely serrated edges, serration of the median cusp, the frequent occurrence of accessory or intermediate median cusps, an S-shaped divergence of the lateral cusp in larger teeth, and nutrient foramina on the bottom side of the base preferentially arranged in a mesio-distal line. This vascularisation is not figured in Johnson (1999, fig. 4) for material from Waggoner Ranch. The serration of the median cusp also occurs in the British O. gibbosus.

O. platypternus (Cope 1884), known by visceral cartilages and teeth only, has been suggested as belonging to Xenacanthus platypternus by Olson (1956), Hampe (1988b, 1994), and Schneider $(1988,1996)$ based especially on the non-serrated lateral edges of the cusps and the high number of nutrient foramina in the base (Hampe 1994). However, Hotton (1952), Lund (1976), Zidek (1993b, describing a poorly preserved spine juvenile from the Upper Carboniferous of Hamilton, Kansas) and Johnson $(1995,1996)$ include the species in Orthacanthus. From recent work, the latter authors seem to be correct in their interpretation, although some disregard characteristic features which are common with Xenacanthus. The best evidence to date is provided by spines collected from the Lower Permian Craddock Bonebed in Baylor County, Texas (Donelan \& Johnson 1997). Here typical Orthacanthus spine fragments and spines with a posterior double row of denticles are found in a locality where $X$. platypternus is the only xenacanthid species so far recovered. The denticle rows in the proximal area of the spine are more ventro-laterally positioned as is characteristic for Anodontacanthus, but the maximum width/ length ratio is about 1:16, and therefore significantly higher than in Anodontacanthus. The teeth are distinct from those of all other known species of Orthacanthus, in the divergence of the cusps and the mesio-distally extended, pancakeshaped flat base as well as the form of the basal tubercle, which sometimes shows a slight depression. In a recent review of $\mathrm{N}$ American Orthacanthus dentitions, Johnson (1999) pointed out that $O$. platypternus sometimes develop serrations (Johnson 1999, fig. 12N). Nonetheless, lateral cusps equipped with serration on the proximal half were recently observed in larger lateral teeth of an articulated specimen of Xenacanthus meisenheimensis from the Lower Permian of the Saar-Nahe basin (NHM-PW 1992/1378-LS).

$O$. huberi from the Late Pennsylvanian of New Mexico (Zidek 1992, fig. 1) represents an organ species. The spines are extremely slender with maximum width/length ratio of 1:26. They are straight and have very closely spaced denticles (in excess of 100 in each row). The denticles themselves are stubby and the surface of the spine between the denticle rows is concave and depressed. O. kounoviensis (Fritsch 1889, pl. 87, fig. 2) and $O$. denticulatus also show very closely spaced denticulation. A slight curvature of the spine exists in both species. The concavity of the ventral (posterior) surface is limited to $O$. huberi, however.

The maximum width/length ratio of the spines of $O$. kounoviensis is around 1:20 based on the figure in Fritsch $(1889$, pl. 87, fig. 2) and therefore does not differ from $O$. denticulatus and O. gibbosus. Fritsch described no ventral ridge comparable to that in $O$. gibbosus.

The head spine of O. buxieri (Poplin \& Heyler 1989, pl. 1, fig. 4a) is also very similar to that of $O$. kounoviensis, so differences cannot be defined on the basis of the Bohemian and French specimens. Almost complete spines show a maximum width/length ratio of about 1:16 (coll. P. Gond, Chateauroux) which is slightly less than in O. kounoviensis. It seems, however, that these species are closely related on the basis of a phylogenetic analysis based on teeth (Hampe 1994, fig. 7).

Spines of $O$. pinguis from the Stephanian B of Bohemia (Fritsch 1889, pl. 87, figs 3, 4, 6) show no unique characters. Heidtke (1998) assumed that they represented an 'aberrant' variant of $O$. kounoviensis.

The teeth of $O$. kounoviensis show characteristic features including the common extreme divergence of the lateral cusps, the minute median cusp, a 'serration of the serration' and the comparatively small coronal button. The absence of this secondary serration in the British specimens may represent local variation. This feature is also known in O. buxieri from the Lower Permian of the French Massif Central. The massive, robust base is also rather similar to the French species. The minute median cusp is comparable with $O$. texensis.

$O$. bohemicus teeth from the Westphalian D of the Plzen basin (Bohemia) display less divergence of the lateral cusps compared with teeth of $O$. kounoviensis. The median cusp is generally longer in $O$. bohemicus, a character which is also observed in $O$. gibbosus. The crown of O. bohemicus is more massive (Fritsch 1889, pl. 82) than the base. The features of the base (coronal button, basal tubercle, nutrient foramina) are practically indistinguishable from those of Lebachacanthus senckenbergianus. The dental morphology of $O$. bohemicus shows no further relationships to the British forms. The few preserved head spines from Bohemia are not very characteristic, because they belong to juveniles (Fritsch 1889; Zidek 1993a). The denticulation of the spines seems to be restricted to the distal third. A maximum width/length ratio of about $1: 15$ for the spines shows them to be distinctly shorter than those of $O$. gibbosus and $O$. denticulatus.

O. meridionalis teeth (Soler-Gijón 1997a, figs 4-6) from the Stephanian C of Puertollano basin, Central Spain, have no significant characters in common with the British specimens. Soler-Gijón described one tooth showing a lingual vertical crista which has not been observed in any other Orthacanthus species. The serration of the median cusp may be similar to that in $O$. gibbosus, however. The spine of $O$. meridionalis has a regular rounded to oval cross-section and is most similar to O. pinguis (Soler-Gijón 1997a) which is considered to be a variant of O. kounoviensis (maximum width/length ratio of 1:15). However, there is no spine from the Westphalian D of Britain which is related to O. kounoviensis (see above). The spines of $O$. gibbosus and $O$. denticulatus are more slender in proportion and show comparatively smaller denticles. Soler-Gijón (1997a, fig. 7B) also documented supernumeral denticles for $O$. meridionalis. A fine median ventral (or posterior) ridge between the denticle rows can be observed and is also strongly developed in $O$. gibbosus.

Generally, the tooth morphologies of the genera Orthacanthus and Lebachacanthus are extremely similar (Fritsch 
1889; Hampe 1988a; Schneider 1988, 1996; Johnson 1999). L. senckenbergianus is clearly different from O. gibbosus in having a non-scarred base with regular rhomboid to hexagonal outline and well-defined saddle- to heart-shaped coronal button and basal tubercle as well as the pattern of nutrient foramina. Juvenile teeth lack serrations in contrast to L. senckenbergianus (Hampe 1988a as Orthacanthus senckenbergianus, fig. 2). They share with $O$. gibbosus serration of the median cusp, and the median foramen which is characteristic of the genus.

L. senckenbergianus teeth are smaller than O. kounoviensis and have a bigger coronal button on the upper side of the base. Usually L. senckenbergianus has no 'serration of the serration', the diameter of nutrient foramina is higher and the lateral cusps show a lower degree of mesio-distal divergence. As described above, spines of L senckenbergianus resemble very closely those of Dicentrodus bicuspidatus. The position of the dorsal spine in L. senckenbergianus and its proportions were a subject of considerable controversy in relation to its taxonomic status between the authors Soler-Gijón (1997b, 2000: genus and family definition) and Heidtke (1998, 1999a: consideration as a subgenus of Orthacanthus).

Other isolated teeth of Orthacanthus as yet undetermined to species level are present in the Upper Pennsylvanian of Cape Breton Island, Nova Scotia (Masson \& Rust 1984), the Lower Permian near Oslo, Norway (Heintz 1934, pl. I, figs 15), and the Upper Permian in Motoyoshi Town, NE Japan (Goto et al. 2000, figs 3, 4). It is not certain whether all the teeth from eastern Canada belong to Orthacanthus (see Hampe 1988a). The tooth figured in Masson \& Rust (1984, pl. I, fig. 1) is very stout. This is perhaps a function of the perspective of the picture (occlusal view). The serration of the cusps is weakly developed or abraded and the coronal button is relatively small. Six nutrient foramina can be counted along the lingual margin of the upper side and one broad median foramen is present behind the coronal button. The latter has an outline somewhat like the symbol for infinity. It probably represents the entrance to two separate canals (see for comparison vascularisation system of L. senckenbergianus in Hampe 1988a, fig. 3a; Hampe 1993, fig. 4a). The higher number of nutrient foramina shows affinities to the British $O$. gibbosus, and to the mid-European $O$. gracilis. Both also sometimes develop irregular serrations. O. gracilis teeth are, depending upon position in the jaws, occasionally quite stout (Hampe 1994, fig. 2g). Resemblance with one of these two species is quite probable. The Canadian Atlantic Provinces belonged to the European continental area during the Late Carboniferous (Scotese 2001; Flügel et al. 2001).

The only Norwegian tooth is indistinguishablefrom the wellknown teeth of Lebachacanthus senckenbergianus from SW Germany (Hampe 1988a as O. senckenbergianus). The single Japanese specimen consists of one cusp only. It is extremely slender, strongly serrated and sigmoidally curved, measuring $12.4 \mathrm{~mm}$ high, with a maximum width of $2 \cdot 1 \mathrm{~mm}$. These proportions are not comparable with those of other species of Orthacanthus. There is, however, no other convenient systematic consideration currently available. The specimen from Japan provides the youngest record of Orthacanthus to date.

Ecologically, Orthacanthus represents the top predator of Carboniferous and Permian aquatic environments (Hampe 1994; Boy \& Schindler 2000) with a dentition characterised by 'scissor teeth with broad dagger-shaped lateral cusps' (Schneider 1996).

These comparisons lead to the following conclusions:

(1) North American species of Orthacanthus are quite different to those of Europe. They evolved independently from a xenacanthid stock separated from the European popula- tions by the barrier of the Appalachian-Hercynian mountain range (Johnson 1999).

(2) The occurrence of Orthacanthus kounoviensis in the Pennines, the Saar-Nahe basin, Saale depression and in Bohemia indicates the probability of interbasinal migrations. Prevailing connections through the Westphalian and Stephanian must have allowed faunal exchanges between intra-montaine basins as well as between single basins and the Palaeo-Tethys sea (Schneider et al. 2000). For example, Schindler \& Hampe (1996) noted a southern connection between the Zöbing area in Austria and the Boskovice furrow in Bohemia to marine deposits of the Alps (after Schönlaub 1979 on plant biogeographicalimplications and tectonics).

(3) Consequently, it remains questionable whether the French O. buxieri erected by Heyler \& Poplin (1989), which has many similarities in tooth and spine structure with $O$. kounoviensis, is a species in its own right, or is only a geographic variant of the latter.

\section{Family incertae sedis}

Genus Anodontacanthus Davis, 1881

Type species. BMNH-P 7675, Anodontacanthus 'acutus' ( $\supset$ A. alatus), a single isolated spine.

Diagnosis. Relatively short xenacanthid spines, sometimes slightly curved ventrally; maximum width/length ratio intermediate around 1:12; two rows of denticles are arranged ventro-laterally.

Remarks. It is important to mention, that 'anodonta' does not generally mean lacking denticulation in xenacanthid spines (see Heidtke 1998; Soler-Gijón 1999).

\section{Anodontacanthus alatus (Davis, 1880)}

(Figs 12a-c, 13b, c)

1880b Pleuracanthusalatus; Davis, p. 329, fig. 6, pl. XII, fig. 4 1881 Anodontacanthusacutus; Davis, p. 428, pl. XXII, fig. 10 1881 Anodontacanthusobtusus; Davis, p. 428, pl. XXII, fig. 11 1890 Pleuracanthus alatus; Ward, p. 136, pl. III, fig. 7

1892 Pleuracanthusalatus; Davis, p. 736, pl. LXXIII, figs 5-13

1892 Anodontacanthus acutus; Davis, p. 748, pl. LXXIII, fig. 25

1892 Anodontacanthus obtusus; Davis, p. 748, pl. LXXIII, fig. 26

1994 Xenacanthus (Pleuracanthus) alatus; Steward, p. 11

1996 Xenacanthus alatus; Newman et al., p. 2 [not the holotype], 3,4

Holotype. BMNH-P 7690, a single isolated spine.

Type locality. Tingley, W Yorkshire.

Type horizon. Cannel Coal, Duckmantian (Westphalian B). Stratigraphical range. Langsettian to Bolsovian (Westphalian A to C).

Occurrence. Fenton, Longton, Collyhurst (all WC), Motherwell, Newsham, Tingley (all WB), Bacup, Burnley (both WA), Dalkeith (W).

Diagnosis (emend. after Davis 1880b, 1881). Spines of more or less elliptical cross-section, ventrally flattened; maximum width/length ratio constantly 1:12; central pulp cavity less than half of the entire diameter; denticle rows oriented ventrolaterally.

Remarks. 'Xenacanthus' alatus, listed in the catalogue of the type, figured and cited fossil vertebrates in the Hancock Museum (Newman et al. 1996) is referred to incorrectly as the holotype. 

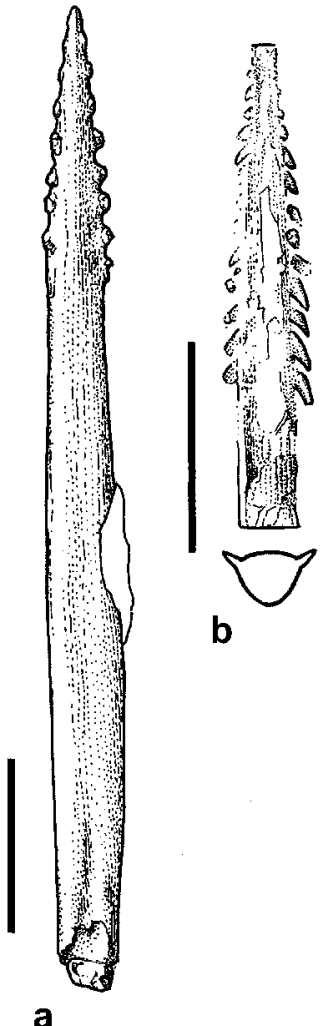

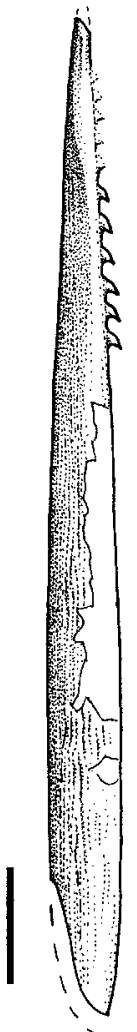

d

Figure 12 Spines of Anodontacanthus alatus (a-c) and Anodontacanthus triangularis (d): (a) BMNH P 8134, Lower Westphalian C of Fenton; (b) HM G 34.22, Lower Westphalian B of Newsham; (c) BMNH P 1733, Westphalian $\mathrm{C}$ of Longton, all in ventral view. (d) HM G 34.13, Lower Westphalian B of Newsham, dorso-lateral view. Scale bars, $1 \mathrm{~cm}$.

Description. The overall length of the generally wellpreserved, straight spines ranges from about $4.5 \mathrm{~cm}$ to $8 \mathrm{~cm}$.

The cross-section is more or less elliptical, with a ventral flattening and a delicate longitudinal groove (Fig. 12b). The maximum width is situated in the lower third of the gradually distally tapering spine. The spines have a consistent maximum width/length ratio of 1:12 in almost all referred specimens. A relatively broad insertion notch is present at the base, where the spines are often crushed. The proximal spine surface is characterised by simple, fine striations which are correlated with numerous vascular canals (Soler-Gijon 1999) up to the beginning of the denticulated area; the ventral surface is covered with small pits giving rise to a 'rough', sand-paperlike surface in non-denticulated specimens (Fig. 13b). The denticles, if present, are pointed and directed proximally with partly slender (Fig. 12b, c) and partly obtuse pointed cusps (Fig. 12a). The two denticle rows do not form a posterior double row as in Orthacanthus, and are not laterally situated as in Xenacanthus, but are arranged in two ventro-lateral lines (Fig. 12b).

The central pulp cavity measures a little less than half of the whole diameter/radius. The dentine is normally constructed of trabecular dentine.

The holotype probably represents a juvenile. The species name erected by Davis (1881) under the name A. obtusus is nothing more than a variation of alatus.

1880a Compsacanthus triangularis Davis, p. 62, fig. 1 (read in November 1879)

1880b Pleuracanthusrobustus Davis, p. 330, fig. 7, pl. XII, fig. 5 (read in January 1880)

1889a Pleuracanthus robustus Woodward, p. 7 [in part]

1892 Pleuracanthusrobustus Davis, p. 730, pl. LXXII, figs 10 14

1892 Pleuracanthus (Compsacanthus) triangularis Davis, p. 746 , pl. LXXIII, fig. 24

Holotype. BMNH-P 7678, one isolated spine.

Type locality. Tingley, W Yorkshire.

Type horizon. Cannel Coal, Duckmantian (Westphalian B).

Stratigraphical range. Duckmantian and Bolsovian (Westphalian B and C).

Occurrence. Fenton (WC), Tingley, Newsham (both WB).

Diagnosis (emend. after Davis 1880a, b). Spines of rounded cross-section with a distinct planar dorsal area at the distal third; sometimes slightly curved ventrally; striated ornament covering the entire spine; denticles very slender and extremely pointed; denticle rows oriented ventrolaterally.

Remarks. The generic name Compsacanthus was originally erected by Newberry $(1856$, p. 100) for spines of small size and 'very neat in form and finish'. These spines are round in cross-section with a single row of comparatively large denticles. The figure presented in Newberry (1874, pl. XL, fig. 5) from Linton, Ohio, cannot definitely be correlated with xenacanthid sharks, although during individual development the dentition can open with one initial row (limited to a few denticles).

Description. The spines of this species are included in Anodontacanthus because they display a suite of characteristics which is so far limited to this genus. The total lengths of the specimens vary between $6 \mathrm{~cm}$ and $9 \mathrm{~cm}$. The cross-section is rounded proximally with a distinct plane dorsal surface in the distal part of about the upper third of the spine (Figs 12d, $13 \mathrm{e}$ ). This character unifies ' $C$.' triangularis with specimens of ' $P$.' robustus. The spines, although largely straight, can sometimes be slightly curved ventrally (Fig. 13d).

The comparatively short length with a maximum width/ length ratio average of about 1:11 is another distinct character to determine these spines as Anodontacanthus. A short tongueshaped insertion notch is present proximally. The surface of the spines has a striated ornamentation which covers practically the entire spine (Fig. 13d). The ornamentation becomes less prominent distally and consists of impersistent striae. Longitudinal growth lines which meet in the tapered point of the distal end are visible on the planar dorsal part. The spine denticles are very characteristic: they are extremely pointed with slender cusps exhibiting a sharp bend on their posterior edge (Figs 12d, 13d). The denticles are positioned ventro-laterally, a position intermediate to that shown by Orthacanthus and Xenacanthus spines. The presence of knobs in the holotype of 'Compsacanthus' triangularis (Fig. 13e, see enlargement) indicates continuous centrifugal accretion of dentine without the formation of new denticles in its individual development (interpreted after Soler-Gijón 1999). The hump-like knob shape may result from tensional forces developed by the anchoring fibres connecting the spine to the dermis and which promoted the deposition of hard tissue in a slowly growing spine.

Discussion of Anodontacanthus. Anodontacanthus species are distinct from other xenacanthid genera in the spine proportions and in the position of the denticles. The maximum width/length ratio is different from slender spines like those of Orthacanthus, Xenacanthus and Triodus, and the short, compact spines of the basal Diplodoselache and Dicentrodus. The frequent lack of denticles in comparison to other xenacanthid genera is also 
characteristic. The reason for this phenomenon remains unclear and speculative. Perhaps it is the result of a distinct physiology in these elasmobranchs, possibly caused by ecological peculiarities. Ontogenetic explanations are discussed by Soler-Gijón (1999, see above). It is interesting that Woodward (1889a) suggested that 'Compsacanthus' triangularis and 'Pleuracanthus' robustus are probably conspecific. He considered triangularis as merely being an abraded version of a robustus spine. However, after recent investigations into the development and histology of xenacanthid spines (Soler-Gijón 1999), it can be estimated that the triangularis spine (holotype) had a very low growth rate. The arrangement of the denticles is different to that in other genera, as mentioned above. They are not placed on the lateral surfaces as in Xenacanthus or Triodus and they are not situated in a narrow separated double row as in Orthacanthus, for example.

A. americanus, a species erected by Hussakof (1911, pl. 26, fig. 5), from the Wichita beds of Texas, is only known from fragmentary elements. However, Romer (1942, pl. 1, fig. 5) pointed out that numerous similar spine fragments from Texan deposits in the MCZ collection and comparable to the material of Hussakof sometimes display denticles, and sometimes do not. They have a striated ornament which is characteristic of A. triangularis. They differ from the British species in possessing a significant ventral ridge distally, as figured by Romer. The relatively closely arranged denticle rows are similar to the arrangement in other genera (Dicentrodus, Lebachacanthus, Orthacanthus). Zidek (1978) eliminated the species americanus from Anodontacanthus with good reason. He shows that the material possesses features characteristic for the genus Platyacanthus.

'Platyacanthus' ventricosus from the Stephanian B of Bohemia (Fritsch 1889, pl. 86, fig. 5; redrawn Zidek 1978, textfig. 2C) is another single spine lacking denticulation. This species was designated as Lebachacanthus by Heidtke (1998) because of its stout appearance (max.width/length ratio of $1: 7.7)$ and the absence of a well-defined longitudinal striation. The fragmentarypreservationpreventsconfident determination.

Anodontacanthus is so far only known from spines. The scanty fossil record of this genus makes familial designation impossible for the moment.

A third species from Britain was described as 'Anodontacanthus' fastigiatus (Davis 1881, pl. XXII, fig. 12) from the Pendleian of Loanhead. Recent observations indicate that this spine undoubtedly belongs to Dicentrodus bicuspidatus.

Remains of questionable origin but also named Anodontacanthus are known from the Late Permian (Kazanian) of Ejuga river/Russia (Chabakov 1928, fig. 1, 'A.' ruthenorum). The Russian spine has a strong triangular outline and an almost smooth surface. It is slightly curved and seems to taper both proximally and distally (the ends were broken prior to fossilisation, after Chabakov). The clearly triangular outline throughout the length of the spine is, for example, different to A. triangularis and does not conform with the English species. The cross-section is more reminiscent of that of ctenacanth and hybodont spines.

\section{Family Xenacanthidae Fritsch, 1889}

Type genus. Xenacanthus Beyrich, 1848.

Family diagnosis (emend. after Schneider \& Zajíc 1994). Tricuspid, non-serrated teeth; cusps often equipped with vertical cristae; basal tubercle with depression; dorsal spine with one row of denticles on each lateral side inserts at the neurocranium; pectoral fins bibasal, axial and biserial; caudal fin pseudo-diphycercal ( $\supset$ modified heterocercal: epicaudal lobe enlarged, elongated in longitudinal axis); paired fins can be supported by ceratotrichia.

Included genera. Xenacanthus, Triodus, Plicatodus.

Genus Xenacanthus Beyrich, 1848

Type species. Xenacanthus decheni (Goldfuss, 1847), MB.f.1433 ( $\supset$ counterpart of the holotype; the main slab, originally held in the Institute of Geology and Palaeontology of the University in Bonn, is now lost), a complete articulated specimen from the Lower Permian (latest Autunian: Olivětín member, Broumov formation) of Ruprechtice, Intrasudetic basin, Czech Republic.

Diagnosis (limited to teeth and spines; emend. after Schneider \& Zajíc 1994). Teeth with cusps of usually lanceolate crosssection with smooth lateral edges; consistently larger number of nutrient foramina perforating the base (see Hampe 1997a, fig. 1); length of spine considerably larger than one-sixth of body length (often reaching one-quarter).

\section{Xenacanthus elegans (Traquair, 1881)}

(Figs 13h, 14a-h)

1881 Pleuracanthus elegans Traquair, p. 35

1954 Xenacanthus elegans Waterston, p. 36

Neotype. BMNH-P 11364, a nearly complete isolated spine. Type locality. Loanhead, Midlothian.

Type horizon. No. 2 Ironstone, Carboniferous Limestone, Pendleian.

Stratigraphical range. Only Pendleian (Lower Namurian A).

Occurrence. Only in Scotland: teeth from Burghlee; spines from Burghlee, Loanhead, Niddrie, Possil Park (all PE).

Diagnosis (emend. after Traquair 1881). Teeth small measuring $1.8-2.5 \mathrm{~mm}$ with more or less parallel arrangement of cusps bearing smooth lateral edges; base sub-rounded, coronal button tongue-shaped with a lateral constriction; one to four nutrient foramina on the upper side; median foramen present; bottom side completely concave; basal tubercle deeply depressed with broad, lingually directed shaft; one larger nutrient foramen flanks the shaft on each side; usually two, and sometimes up to eight nutrient foramina located on the bottom side of the shaft; lateral angle between crown and base around $130^{\circ}$ to $135^{\circ}$; dentition homodont; dorsal spine always straight, extremely slender with a rounded cross-section proximally and becoming dorso-ventrally compressed distally; maximum width/total length ratio about 1:25; denticulation closely packed; denticles pointed directly posteriorly.

Remarks. A holotype was not figured by Traquair. Waterston (1954), however, identified the type as RSM-1950.38.47. The search for this specimen in Edinburgh was without success. It belongs to a group of specimens which were the property of private collectors (in this case, Robert Kidston) and which were never stored in the Royal Scottish Museum (R. Paton, pers. comm.).

Description. Only nine teeth from the excavation and collecting activities of the nineteenth century have so far been identified as $X$. elegans. The small teeth are very significant. Their height measures between $1.8 \mathrm{~mm}$ and $2.5 \mathrm{~mm}$. The lateral cusps are arranged more or less in parallel, a divergence (Fig. 14a-f). The median cusp reaches half to two-thirds the height of the lateral cusps. The cusps are more or less rounded in cross-section, being only slightly labio-lingually compressed, and bear lateral edges and cusp surfaces which are totally smooth.

The base is rounded to a mesio-distally extended oval. The coronal button on the upper side is somewhat tongue-shaped, labio-lingually elongated and shows a lateral constriction 


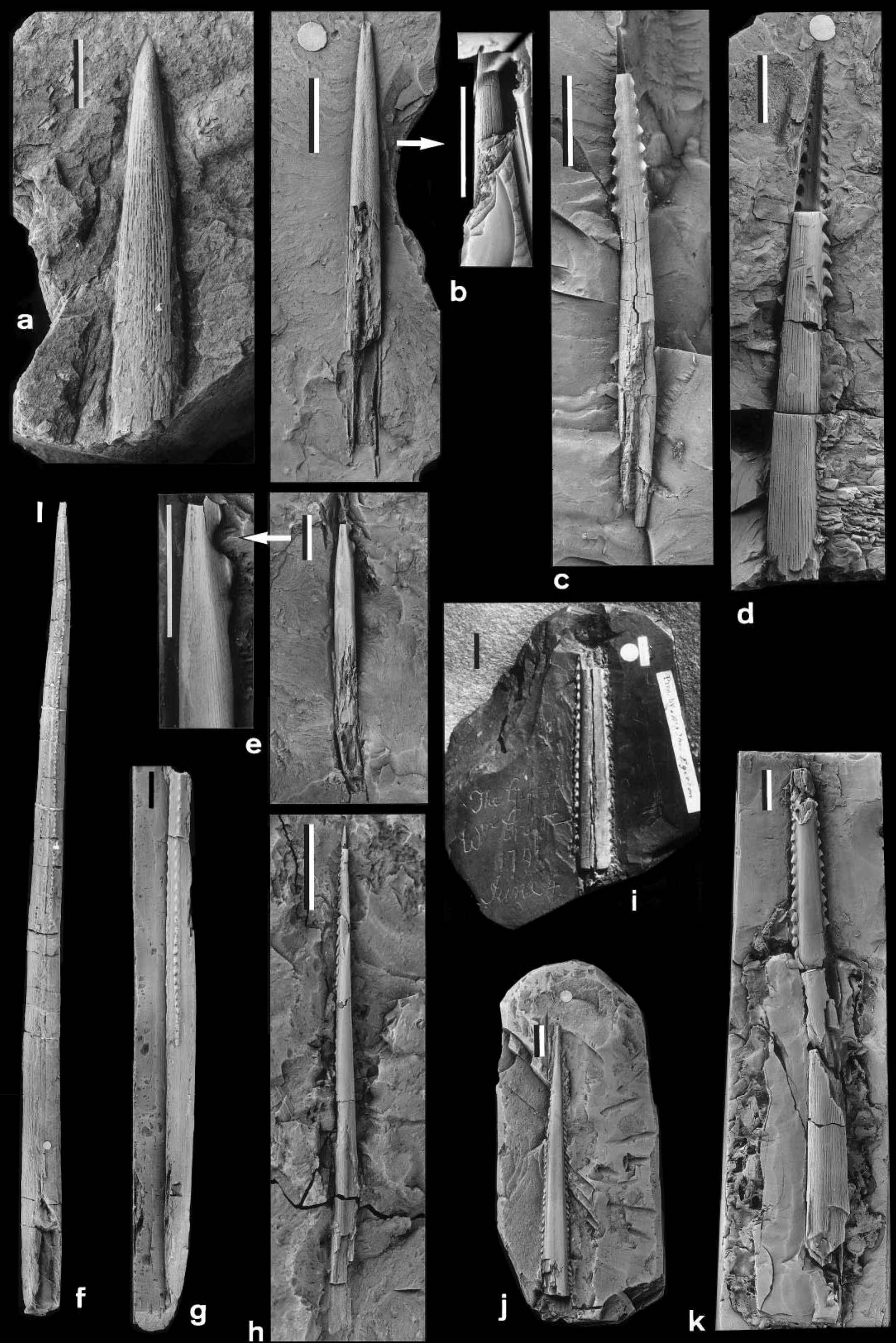


demarcating it from the shaft which displays the lower, broad part of the 'tongue' (Fig. 14f). One to four nutrient foramina are located along the lingual margin, usually in a position directly adjacent to the constriction. A median foramen is present in front of the median cusp (Fig. 14f). The entire basal surface forms a concave depression. The basal tubercle has a rounded outline and is characteristically deeply depressed (Fig. 14b, c). The degree of prominence of the basal tubercle is irregular. A broad lingually directed shaft is always developed (Fig. 14a-d). One larger nutrient foramen flanks the shaft on each side. Usually two, and sometimes up to eight smaller openings can occur.

The lateral angle between crown and base is large, varying from about $130^{\circ}$ to $135^{\circ}$. X. elegans has a virtually homodont dentition, however. Histological investigations of broken teeth indicate that the cusps consist of normal orthodentine.

The spines are straight without exception and extremely slender, sometimes appearing fragile. One almost complete spine measures $9 \cdot 1 \mathrm{~cm}$ long. Proximally, the spines are finely striated, a feature which disappears in the denticulated section (Fig. 13h). The cross-section is rounded proximally; distally, it becomes slightly dorso-ventrally compressed and a low median rim can make an appearance (Fig. 14g, h). The maximum width/total length ratio is around 1:25. The central pulp cavity measures around one-quarter of the entire diameter.

The laterally placed rows of denticles comprise very delicate elements surmounting an elongate base, which are closely arranged and directed posteriorly (Fig. 14g). The anterior edge tends to be nearly parallel to the surface of the spine corpus. The proximal denticles show an almost trapezoid outline in lateral view (Fig. 14h). 'Pleuracanthus' gracillimus, described by Traquair (1882) belongs very probably to $X$. elegans. Only three fragmentary spines are in public collections.

\section{Xenacanthus laevissimus (Agassiz, 1837)}

(Figs 11f-i, 13i-k, 15)

1837 Pleuracanthus laevissimus Agassiz, p. 66, pl. 45, figs 4-6

1867 Dittodus divergens Owen, pp. 334ff, pl. II

Pternodus productus Owen, pp. 363ff, pl. XI

1873 Pternodus productus Barkas, p. 17, pl. I, fig. 10

1880a Compsacanthus major Davis, pp. 62ff, fig. 2

1880b Pleuracanthus laevissimus Davis, pp. 325ff, fig. 1

Pleuracanthus erectus Davis, p. 326, fig. 2

Pleuracanthus planus Davis, p. 329

1889a Pleuracanthus laevissimus Woodward, pp. 5ff [in part] Diplodus gibbosus Woodward, pp. 10ff [in part]

1890 Diplodus tenuis Ward, p. 140, pl. II, fig. 1

1892 Pleuracanthus laevissimus Davis, pp. 724ff [in part]

Diplodus gibbosus Davis, pp. $725 \mathrm{ff}$ [in part]
Pleuracanthus (Diplodus) laevissimus Davis, pl. LXIX, LXX, LXXI, fig. 1, LXXII, figs 1, 3, 6-8

Pleuracanthus erectus Davis, p. 738, pl. LXXIII, figs $14-16$

Pleuracanthus woodwardi Davis, p. 741, pl. LXXIII, fig. 21

1979 Pleuracanthus laevissimus Pyrah, p. 419

1986 Expleuracanthus laevissimus Heyler \& Debriette, pp. $90 \mathrm{ff}$

1996 Xenacanthus erectus Newman et al., pp. 4, 5 Xenacanthus laevissimus Newman et al., pp. 5-7

Holotype. YM 480, median spine fragment with denticulation, donated by Mrs. Thos. Egerton (gift of Wm. Croft, 4 June 1791).

Type locality. Dudley, W Midlands.

Type horizon. (Middle) Coal Measures, Westphalian B.

Stratigraphical range. Entire Westphalian (Langsettian to Westphalian D).

Occurrence. Teeth of morphotype 1 ( $\left.\supset \mathrm{Mt}^{1} \frac{1}{2}\right)$ from Kilmarnock (WC/D); Longton (WC); Dalkeith, Newcastle upon Tyne, Newsham, Bardsley, Airdrie (all WB); Wakefield (WA/ B); Burnley, Low Moor, Wigan, Carluke (all WA); teeth of morphotype 2 ( $\supset$ Mt1) from Longton (WC); Newcastle upon Tyne, Tingley (both WB); Wakefield (WA/B); Queensferry (WA); teeth of morphotype 3 ( $\supset$ Mtc) in Newsham (WB); Carluke, Wigan (both WA); spines from Fenton, Longton, Kidsgrove, Collyhurst, Douglas (all WC); Cambuslang, Dalkeith, Motherwell, Tingley, Newsham, Longton, Dudley, Ashington, Cramlington, Apedale (all WB); Leeds (WA/B); Montgreenan, Burnley, Clogh, Carluke, West Wylam, Bardsley (all WA).

Diagnosis. Bottom of tooth base with strong relief; lingually directed shaft of coronal button and basal tubercle absent; cusps have trabecular dentine socket in the proximal part; orthodentine covers parts of the upper surface of the base below the cusps; spines of rectangular cross-section with dorso-ventral compression.

Remarks. Heyler (1969) introduced the generic name 'Expleuracanthus' (adopted throughout the French literature) in place of Pleuracanthus because of its preoccupation and related it to the material described by Agassiz (1837). Nomenclatural emendations using a prefix are unjustified [ICZN (1999), Art. 33.2.3.]. Unfortunately, the designation 'Expleuracanthus' occasionally appeared in non-francophone publications (Zidek 1988, corrected Zidek 1993b; Zajíc 1989). The descriptions presented below indicate that the type specimen undoubtedly belongs to the genus Xenacanthus. Furthermore, a recent discovery from Germany indicates similar body shape between $X$. meisenheimensis and 'Expleuracanthus'

Figure 13 Xenacanthid spines from England and Scotland: (a) Dicentrodus bicuspidatus, BMNH P 7674, distal part of the holotype of the former Anodontacanthus fastigiatus, Pendleian of Loanhead. (b) Anodontacanthus alatus, BMNH P 7675, ventral side of the holotype of the former A. acutus, with detail of recently prepared dorsal side. (c) Anodontacanthus alatus, BMNH P 7690, ventral side. (d) Anodontacanthus triangularis, BMNH P 7691, proximal part of the holotype of the former 'Pleuracanthus' robustus, all Westphalian B of Tingley. (e) Anodontacanthus triangularis, BMNH P 7678, dorsal view of holotype, with detail of the tip showing the presence of knobs indicating continued centrifugal accretion of dentine without formation of denticles. The humps probably resulted from tensile forces of the anchoring fibers connecting the spine to the dermis in a slowly growing spine. (f) Orthacanthus gibbosus, BMNH P 8115 , ventral view (formerly $O$. cylindricus), Westphalian C of Fenton. (g) Orthacanthus gibbosus, BMNH 42035, ventro-lateral view of former holotype of 'Pleuracanthus' taylori, Westphalian B? of Airdrie. (h) Xenacanthus elegans, BMNH P 11364, dorsal view of ?paratype, Pendleian of Loanhead. (i) Xenacanthus laevissimus, YM 480, holotype, spine fragment from the (Middle) Coal Measures (Westphalian B) of Dudley, W Midlands. (j) Xenacanthus laevissimus, BMNH P 8124, dorsal view of distal part, Westphalian C of Fenton. (k) Xenacanthus laevissimus, BMNH 36175, ventral view of proximal part, Westphalian (B?) of Dalkeith. Scale bars, $1 \mathrm{~cm}$. 


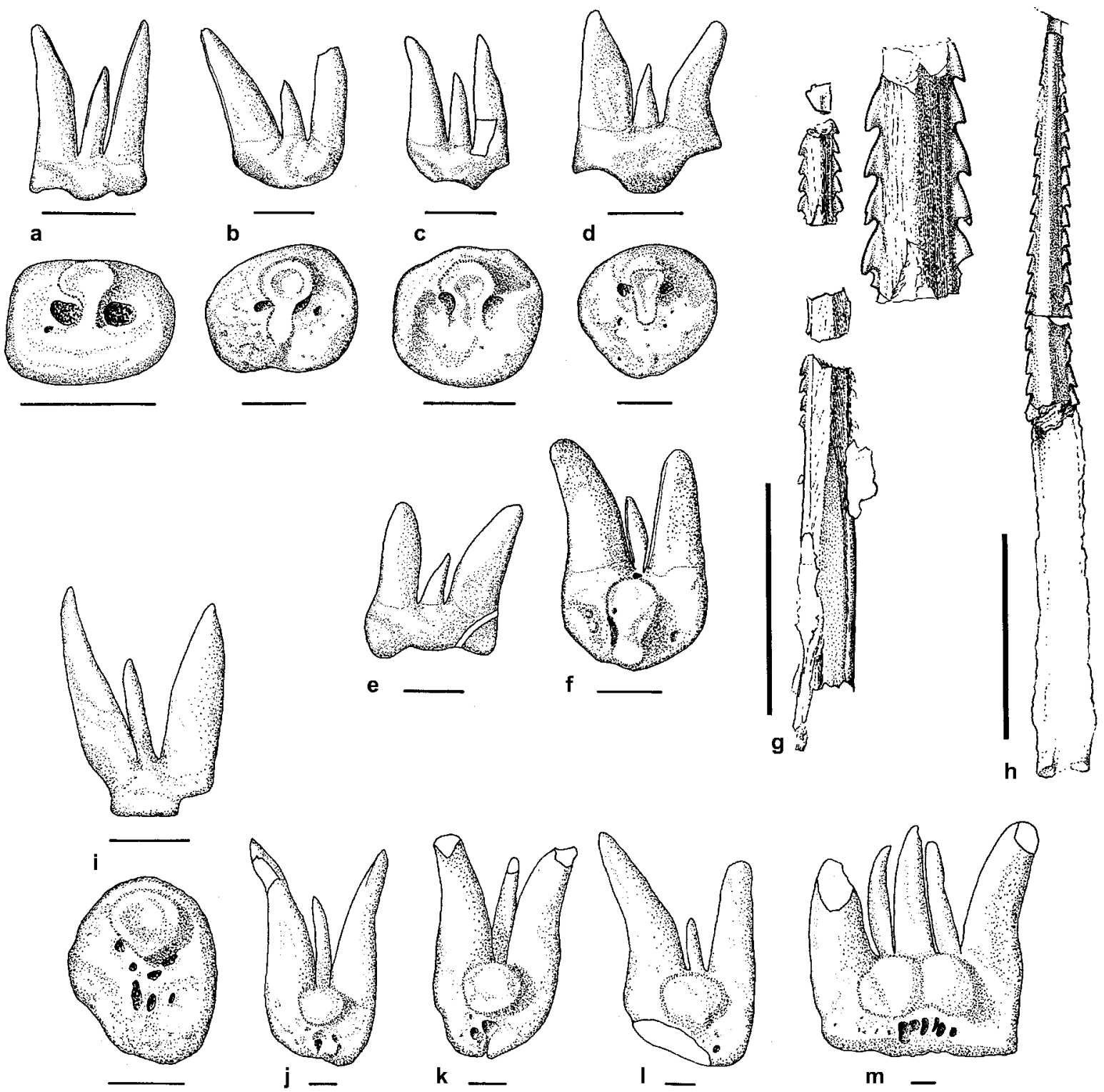

Figure 14 Xenacanthus species: X. elegans $(\mathrm{a}-\mathrm{h}), X$. tenuis (i-m): (a) BMNH P 11316a, labial and basal aspect. (b) BMNH P 11316b, labial and basal aspect. (c) BMNH P 11316e, labial and basal aspect. (d) BMNH P $11316 \mathrm{~d}$, labial and basal aspect. (e) BMNH P $11316 \mathrm{c}$, labial aspect; (f) BMNH P $11316 \mathrm{f}$, lingual aspect, all teeth from Pendleian of Burghlee. (g) HM G 51.67, spine from Pendleian of Loanhead. (h) MM LL.11611, Pendleian of Burghlee, both in dorsal view. (i) HM G 177.99, labial and basal aspect, Westphalian B? of Brockley Whins. (j) BMNH 20695 Nr. 1, lingual aspect; (k) BMNH 20695 Nr. 2, lingual aspect, both syntypes of $X$. tenuis from the Westphalian A of Carluke. (1) BMNH P 1725a, lingual aspect, Westphalian C of Longton. (m) HM G 8.80 , abnormally generated fused teeth in lingual aspect from the Lower Westphalian B of Newsham. Scale bars, $1 \mathrm{~mm}(\mathrm{a}-\mathrm{f}, \mathrm{i}-\mathrm{m}), 1 \mathrm{~cm}(\mathrm{~g}, \mathrm{~h})$.

gaudryi based on the preserved outline of the skin (Heidtke 1999b).

Description. Many teeth of this species previously described in the literature or recorded in collections as 'Diplodus' gibbosus belong with the frequently occurring spines typical of this species (see, for example, HM G051.24, figured in Davis 1892, LXX, fig. 1).

The height of teeth ranges between $1.5 \mathrm{~mm}$ in juveniles and $15 \mathrm{~mm}$ in the largest specimens. The median cusp of the tricuspid teeth reaches about half to two-thirds and occasionally three-quarters that of the lateral cusps (Fig. 15a-h). The cusp cross-section can be more or less rounded but is mainly lanceolate. A slight sigmoidal divergence or lingual orientation of the lateral cusps (Fig. 15a) is possible. All teeth have smooth edges which are of variable development: often the edges are restricted to the upper half (maximum three-quarters) of the cusps ( $\supset$ morphotype 1, fig. 15b, c, e , n). Here, an edge can sometimes bifurcate at its very proximal end. A minor group of teeth displays edges extending down the entire length of the cusp ( $\supset$ morphotype 2 , fig. 15a, f, g). Normally, no vertical cristae are developed. However, those teeth with an edge along the upper half of the cusp often have a short vertical crista on the lingual face ( $\supset$ morphotype 3 , fig. $15 \mathrm{~d}, \mathrm{~h}$ ). The crista can occur on each cusp including the median one (Fig. 15d).

The base has a scarred surface. The outline of the base is, in most cases, circular, or occasionally oval by a slight mesiodistal compression (Fig. 15i). The coronal button on the upper side of the base is rounded, knob-like, and never has a shaft (Fig. 15a-d). Generally, one to three nutrient foramina are situated lingual to the coronal button. A median foramen is present in front of the median cusp (Fig. 15d) and sometimes shaped like a slot. The bottom side shows a strong relief 


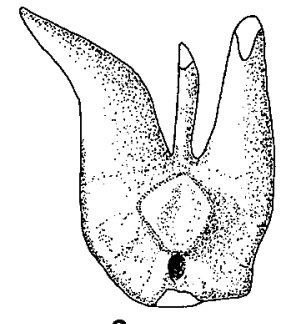

a

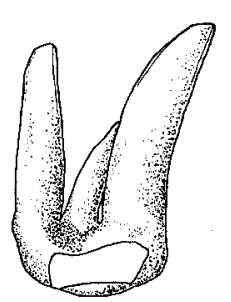

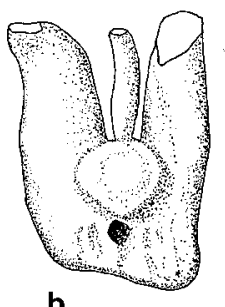

b

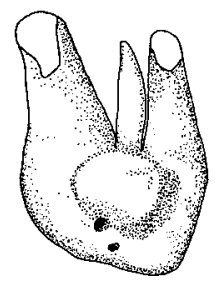

c
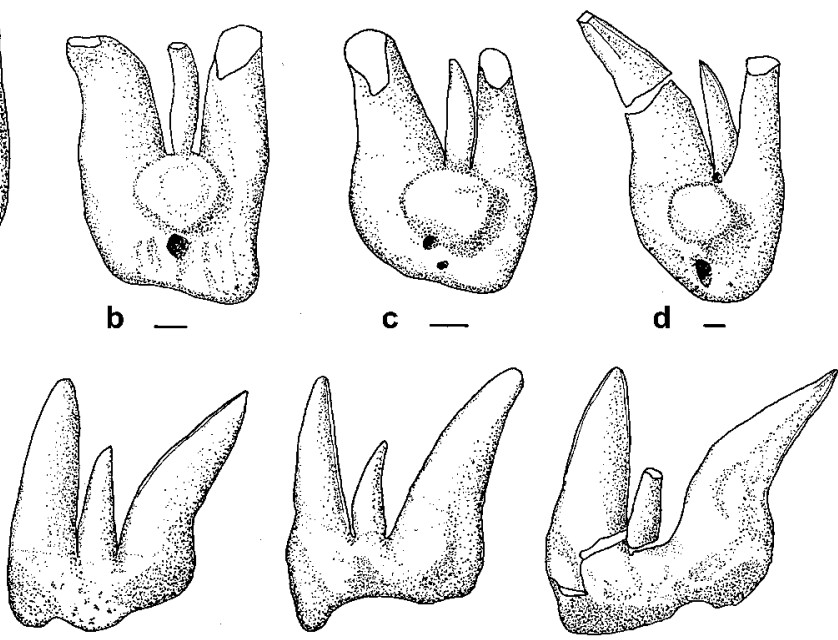

g -

h -

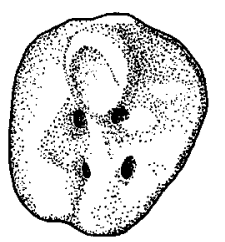

i

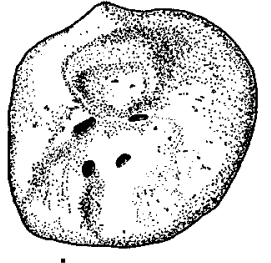

j -

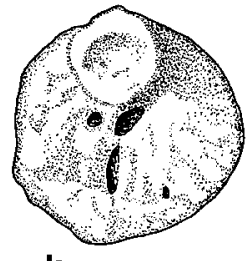

k
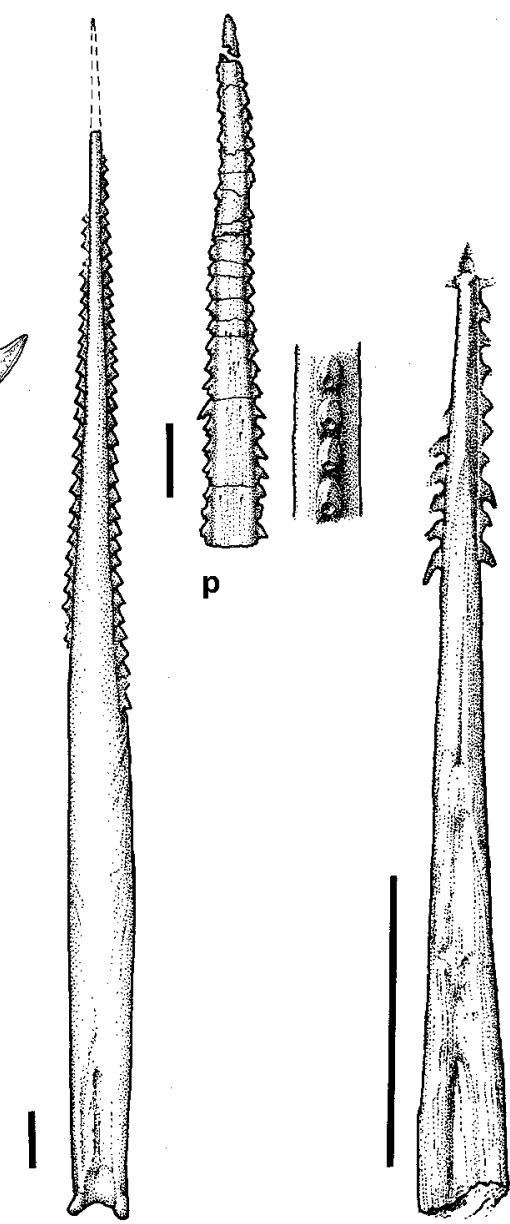

q

Figure 15 Xenacanthus laevissimus: teeth in lingual $(\mathrm{a}-\mathrm{d})$, labial $(\mathrm{e}-\mathrm{h})$, basal $(\mathrm{i}-\mathrm{m})$, and lateral $(\mathrm{n})$ aspects, and spines (o-q): (a) BMNH P 1182 ( $\supset$ Mt1), Westphalian B of Tingley. (b) BMNH P 52467 ( $\supset$ Mt $1 / 2$ ), Westphalian A of Low Moor. (c) MM W 901a ( $\supset \mathrm{Mt}^{1} \frac{1}{2}$ ), Lower Westphalian B of Bardsley. (d) HM G 55.58 (つ Mtc); (e) HM G

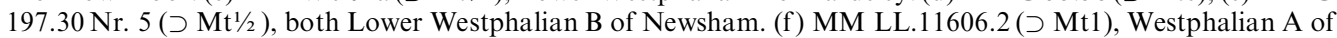
Burnley. (g) BMNH 41635 ( $\supset$ Mt1), Westphalian B of Newcastle upon Tyne. (h) HM G 197.41 (つ Mtc), Lower Westphalian B of Newsham. (i) MM LL.11606.2, Westphalian A of Burnley. (j) BMNH 41635, Westphalian B of Newcastle upon Tyne. (k) HM G 197.30 Nr. 2; (1) HM G 197.30 Nr. 1; (m) HM G 197.30 Nr. 3; (n) HM G 55.58 ( $\left.\supset \mathrm{Mt}^{1} / 2\right)$, all Lower Westphalian B of Newsham [morphotype abbreviations and explanations, see text]. (o) HM G 147.59 in ventral view, Lower Westphalian B of Newsham. (p) NHM PW 1996/1-LS dorsal aspect and detail of the lateral side, Westphalian C of Douglas. (q) BMNH 21423a, a juvenile spine in ventral view, Westphalian A of Carluke. Scale bars, $1 \mathrm{~mm}(\mathrm{a}-\mathrm{n}), 1 \mathrm{~cm}(\mathrm{o}-\mathrm{q})$.

(Fig. 15i-m) and is often depressed like a shovel (Fig. 151). The basal tubercle has a concave depression of variable depth. Four to seven nutrient foramina can be counted on this side. The lateral angle between the base and the crown ranges between $95^{\circ}$ and $120^{\circ}$ (Fig. 15n).

The histology of $X$. laevissimus is primitive in comparison with other derived xenacanthid genera. It is significant that teeth of this species have a trabecular dentine socket in the proximal part of the cusps (Fig. 11f) which is atypical for advanced xenacanthids (Lebachacanthus, Orthacanthus, Hagenoselache, Triodus, Plicatodus) as well as for other species of Xenacanthus. A characteristc feature is the mantle of orthodentine which covers parts of the upper surface of the base, from the base of the cusps lingually (Fig. 11i). The structure of the entire base including the coronal button is composed of trabecular dentine as usual (Fig. 11f, h), which appears to be relatively dense with narrow spaces (lumina, canals) in parts. The main pulp canal is a narrow tube (Fig. 11g). The cusps are made of orthodentine and show a parallel arrange- ment of closely spaced dentine tubules (Fig. 11g). As in all xenacanthids, no enameloid can be distinguished.

The spines of Xenacanthus laevissimus have a characteristic morphology which is relatively easily distinguished from that of other species. The longest measured spine in the British material is $22 \mathrm{~cm}$. The spines are always straight with a broad base (Fig. 15o, q). From the proximal region, the spines taper to a pointed distal tip (Figs 13j, 15o). The rectangular form of the cross-section, with greater width, is characteristic for X. laevissimus (Fig. 13j, k, 15p) . A distinct, ventrally situated groove is located about one-sixth of the way along the spine in many specimens (Fig. 13i). This position is an estimate owing to the fragmentary nature of most spines, with broken proximal and distal portions being common. The maximum width/length ratio is always over $1: 15$. The surface of the spines shows a delicate striation ( $\supset$ vascular grooves) of the lower, non-denticulated part (Fig. 13k), becoming smooth with occasional dot-like foramina distally (Fig. 15p). The denticles form one row on each lateral side. They are pointed back- 
wards and are crescentic, or shaped like the dorsal fin of a carcharinid shark (e.g. Fig. 13k). The denticle bases often overlap each other (the succeeding proximal overlaps the distal one; Fig. 15o, p lateral close-up). Some specimens (formerly designated as the species erectus, see Davis 1880 b, fig. 2) have only a wavy structure on the lateral sides. These eruptions are accretions of dentine caused by the tensile forces generated by fibres anchoring the spine to the dermis during life. In these cases, denticle formation was not completed (Soler-Gijón 1999). Traquair (1888b) recognised erectus as an eroded specimen of $X$. laevissimus using a different line of argument.

$X$. laevissimus is also known from a few slabs with partial skeletons, especially from Northumberland (see Davis 1892, pls LXV, LXVI, LXIX, LXX, LXXI). These specimens include head and jaw fragments and mostly fin radials. Isolated pterygopodials and parts of braincases cannot be ascribed to $X$. laevissimus without doubt. The neurocranium, possibly belonging to $X$. laevissimus, discovered in the collection of the Hancock Museum (Figs 16, 17) will be discussed in 6.

\section{Xenacanthus tenuis (Woodward, 1889) \\ non 'Pleuracanthus' tenuis Davis, $1880 \mathrm{~b}$ \\ (Figs 14i-m, 19c)}

1843 Diplodus gibbosus Agassiz, p. 204, pl. 22b, fig. 4

1867 Diplodus gibbosus Owen, p. 333, fig. 1B

1889a Diplodus tenuis Woodward, p. 11, pl. VI, figs 2-4

1982 Diplodus gibbosus [D. tenuis] Andrews, p. 41

Syntypes. BMNH-P 3026 and 20695, associated, numerous isolated teeth.
Type locality. Carluke, S Lanarkshire.

Type horizon. Upper Carboniferous Coal Measures, Langsettian (Westphalian A).

Stratigraphical range. Langsettian to Bolsovian (Westphalian A to C).

Occurrence. Only teeth distinguishable from Longton (WC); Newsham, Tingley, Fenton, Brockley Whins (WB?); Carluke (WA).

Diagnosis. 'The two principal cones of the dental crown slender, round in section, slightly compressed and divergent towards the extremities; intermediate denticle very long and slender' (Woodward 1889a).

Description. $X$. tenuis is a determinable species, if attention is paid to the description given by Woodward (1889a, p. 11). Although the teeth are sometimes difficult to distinguish from $X$. laevissmus, they do possess some distinct characters. The height of the teeth varies regularly between $4.5 \mathrm{~mm}$ and $8 \mathrm{~mm}$. The lateral cusps are arranged more or less in parallel, with only their apices curved slightly inwards (Fig. 14j, k). The median cusp reaches about half to two-thirds that of the lateral cusps and is very slender (Fig. 14i, j). The rounded cross-section of the cusps and the general absence of lateral edges is characteristic. If edges occur, they are developed only extremely labio-laterally, indicating a planar labial surface of the cusps. The edges are weakly developed and always smooth. No accessory vertical cristae are present.

The rounded base carries a coronal button of rounded and knob-like shape without a shaft (Fig. 14j-1). One to three nutrient foramina are located along the lingual margin of the teeth; no central foramen is developed in front of the median cusp.
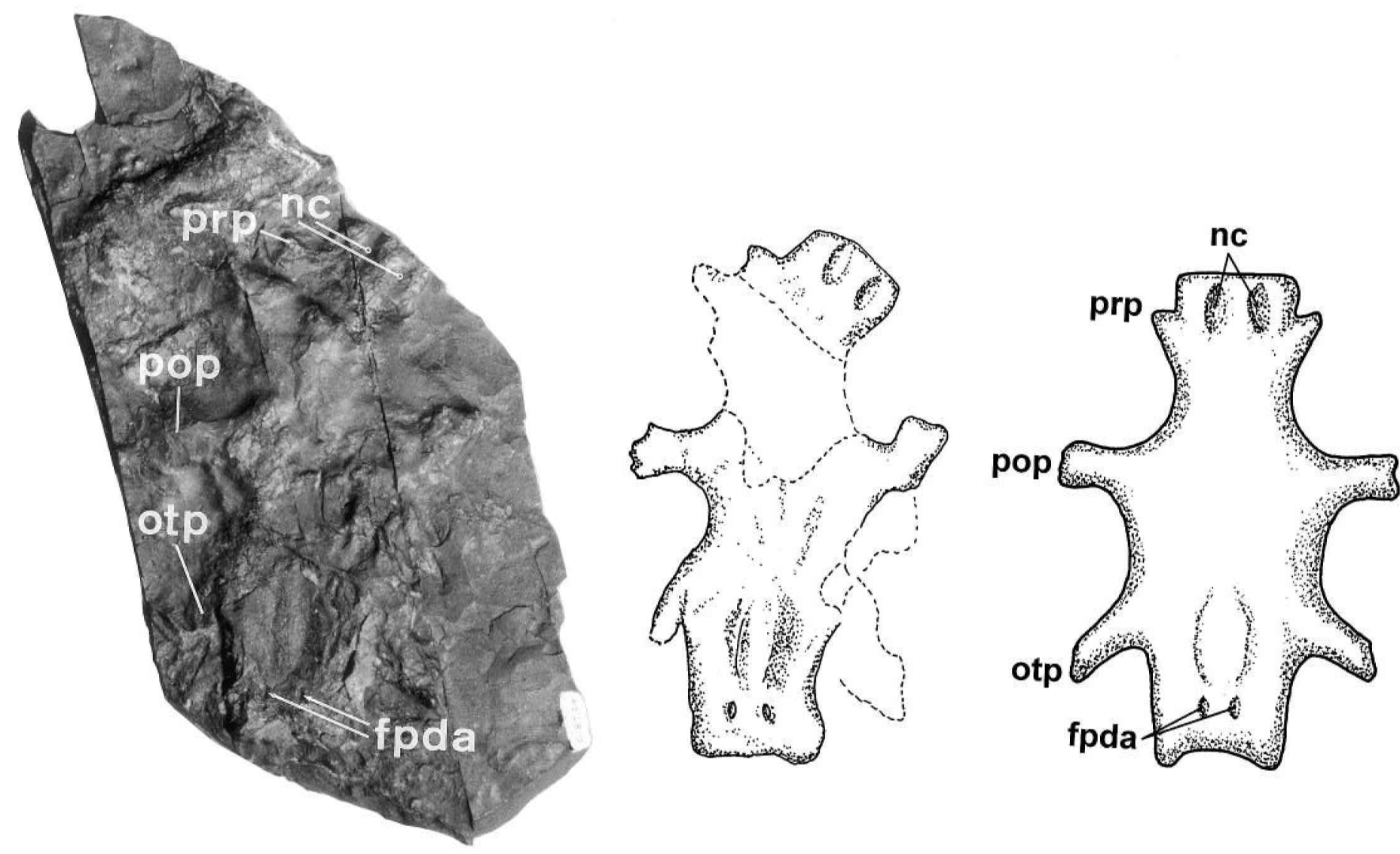

$3 \mathrm{~cm}$

Figure 16 Neurocranium possibly belonging to Xenacanthus laevissimus, HM G187.24, in ventral preservation: photograph of the original slab (left), camera lucida interpretation (middle), and reconstruction (right). Found probably in Northumberland. 


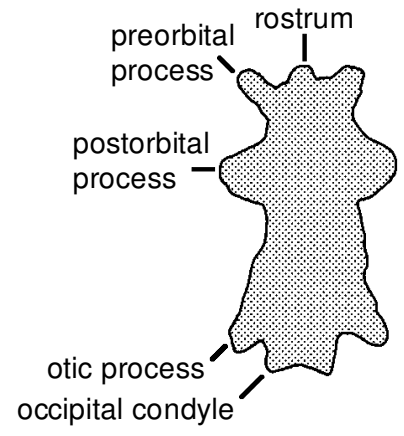

Orthacanthus texensis

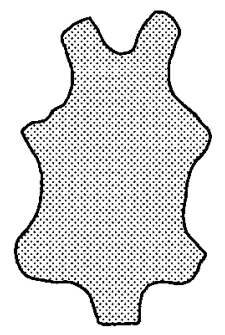

Xenacanthus decheni Xenacanthus humbergensis

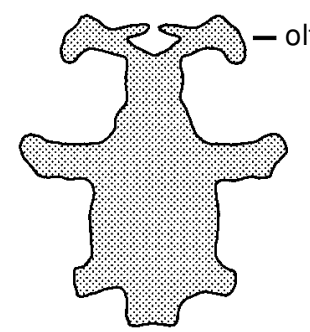

Bibractopiscis niger
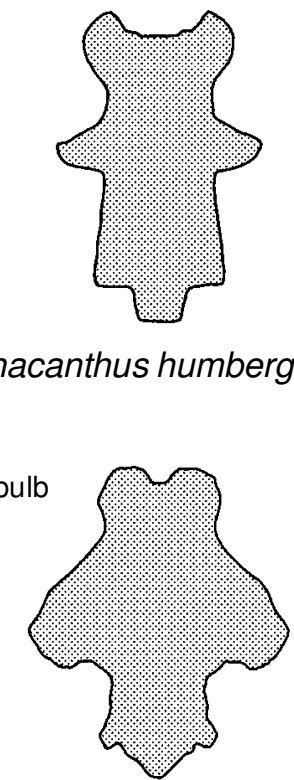

Akmonistion zangerli
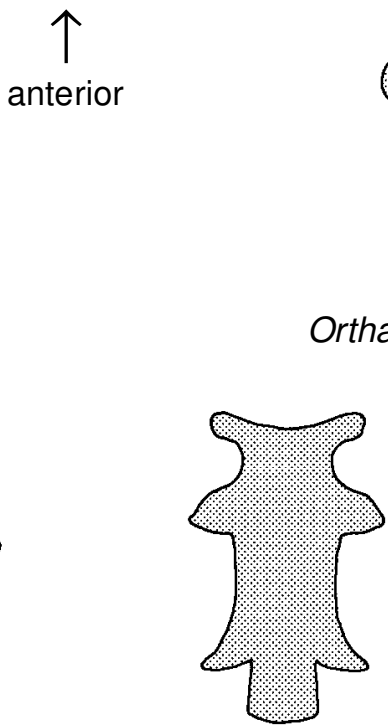

Triodus ?frossardi

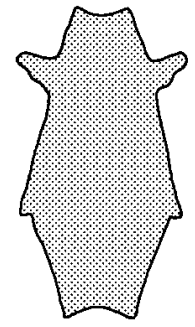

Antarctilamna prisca

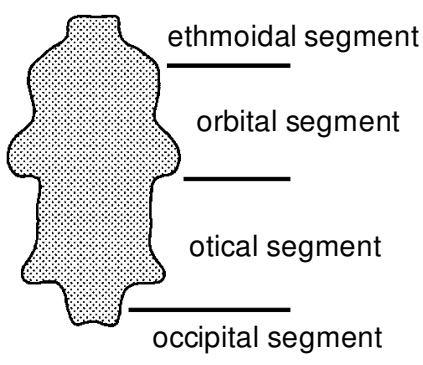

Orthacanthus buxieri

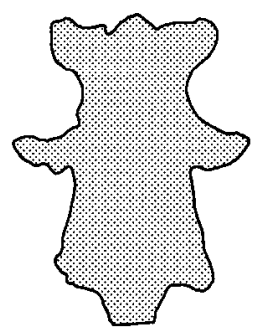

Triodus sessilis $\$$

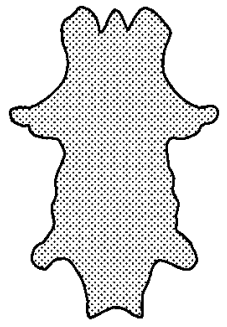

Tamiobatis vetustus

Figure 17 Outlines of different xenacanthid and other Palaeozoic elasmobranch braincases. Orthacanthus texensis (after Schaeffer 1981, fig. 3 as Xenacanthus sp.), Lower Permian of Texas; Orthacanthus buxieri ( $\supset$ ?O. kounoviensis, after Heyler \& Poplin 1989, fig. 1), Autunian of Buxière-les-Mines, Central Massif; Xenacanthus decheni (after Schneider \& Zajíc 1994, fig. 1), Lower Permian of the Intrasudetic basin, Bohemia; Xenacanthus humbergensis (after Schwind 1991, pl. 59), Lower Permian of the Saar-Nahe basin, SW-Germany; Triodus ?frossardi (after Soler-Gijón \& Hampe 1998, fig. 3), Lower Permian of Autun basin, France; female Triodus sessilis (after Schwind 1991, pl. 1), Lower Permian of the Saar-Nahe basin; Bibractopiscis niger, an elasmobranch of unknown systematic position (after Heyler \& Poplin 1982, fig. 2), Lower Permian of Autun basin; symmoriid Akmonistion zangerli (after Coates \& Sequeira 1998, fig. 5), lowermost Namurian (Pendleian) of Bearsden, Glasgow; possible phoebodontid (see Hampe \& Long 1999) Antarctilamna prisca (after Young 1982, fig. 7), Middle Devonian of South Victoria Land, Antarctica; ctenacanthoid (see Williams 1998) Tamiobatis vetustus (after Romer 1964, fig. 4), Lower Mississippian of Kentucky.

Four to seven foramina are present on the bottom of the base (Fig. 14i). The basal tubercle has a flat to slightly concave depressed basal surface.

Broken teeth give a suggestion of the histological structure (Fig. 19c). Trabecular dentine appears only within the base. The crown is constructed of orthodentine as usual. Figure $14 \mathrm{~m}$ shows a pathological development, 'siamese twins'. It is inferred that two teeth were fused together forming a strong median cusp representing a lateral cusp of both halves of the twin. The coronal buttons are not completely separated, while the nutrient foramina are duplicated, indicating that two embryonic germs were not isolated during ontogeny. This could be due to damage of the dental anlage, probably during feeding (see discussion in Duffin 1993, p. 15).

Discussion of Xenacanthus. Xenacanthus is known from nearly all British localities with suitable Carboniferous deposits. Xenacanthus laevissimus is the only Irish xenacanthid discovered from Jarrow Colliery in Kilkenny, a locality especially famous for its rich amphibian fauna (e.g. Huxley \& Wright 1867; Milner 1980).

$X$. laevissimus is unique within the genus with its dorsoventrally compressed rectangular cross-section of the cranial spine (see also Davis 1892, pl. LXXII, figs 6, 8). It is important to mention here that the use of the term 'cranial spine' in xenacanthids means an insertion of the dorsal spine in the region of the occipital part of the head or the neck. It is not homologous with the paired 'cephalic spines' of hybodonts (e.g. Maisey 1982, 1987)! The xenacanthid spines are mostly more or less oval in cross-section. The spines of the Bohemian $X$. decheni from the uppermost Autunian of the Intrasudetic basin taper, as is usual for the genus, and have closely packed denticulation (Fritsch 1890, pl. 96, fig. 3; pl. 98, fig. 2; Schneider \& Zajíc 1994, fig. 5) with backward pointing denticles identical to those of 
X. laevissimus (see Fritsch 1890, pl. 100, fig. 7 and Davis 1880b, fig. 1). The Bohemian species is the type species of the genus and probably comprised smaller individuals than $X$. laevissimus. This can be interpolated after Schneider \& Zajíc (1994) who calculated the average length of a $X$. decheni spine to be about one and one-third to one and two-thirds that of the length of the head. Fritsch (1890, pl. 96, fig. 3) cited, for example, a length of $7.8 \mathrm{~cm}$; the longest measured spine of $X$. laevissimus is $22 \mathrm{~cm}$ (almost three times longer than in the Bohemian shark). The teeth of $X$. decheni (Fritsch 1890, pl. 100, fig. 6; pl. 102, fig. 1; Schneider \& Zajíc 1994, fig. 13c-g) are also distinctly smaller, varying from $1.5 \mathrm{~mm}$ to only $2.5 \mathrm{~mm}$. Another difference is the coronal button, which in $X$. decheni is flat, pear-shaped and usually possesses a shaft, which never occurs in the material of $X$. laevissimus. The basal tubercle in $X$. decheni is tongue-shaped and only very slightly depressed, instead of having a variable concave depression as in X. laevissimus. The angle between the base and the crown in lateral view ranges from $95^{\circ}$ to $120^{\circ}$ in $X$. laevissimus and is thus larger than the usually constant $90^{\circ}$ of $X$. decheni (author's observations; characters not displayed in Fritsch 1890 and Schneider \& Zajíc 1994). The teeth of $X$. oelbergensis, also from the uppermost Autunian of Bohemia (Intrasudetic basin), differ from $X$. decheni only in the lower number of nutrient foramina on the bottom of the base.

$X$. parallelus from the Westphalian D of the Plzen basin is one of the dwarf members of the genus. It has oval-shaped spines (Fritsch 1890, fig. 191) with acutely angled denticles (Fritsch 1890, pl. 91, figs 1-4). These features distinguish the species from $X$. laevissimus and the lower Namurian $X$. elegans from Scotland, which displays a rounded spine with a slight median rim. The proximally trapezoid-shaped denticles indicate a distant relationship with the acutely angled forms of $X$. parallelus. The teeth of $X$. parallelus (Fritsch 1890, pl. 91, figs 1b, c, 5; pl. 94, fig. 9; Schneider \& Zajíc 1994, fig. 17) are very similar to those of $X$. elegans. They both have cusps of more or less rounded cross-section with weakly developed smooth lateral edges. The coronal button carries a lingual shaft in both species and the basal tubercle has a broad lingually directed shaft flanked by a larger nutrient foramen on either side. A difference is shown in the higher number of foramina on the upper side of the teeth in $X$. parallelus (two to six). The lateral angle varies from $130^{\circ}$ to $135^{\circ}$, distinctly higher in $X$. elegans than in $X$. parallelus with its range of $90^{\circ}$ to $100^{\circ}$.

Another extremely small species is $X$. ovalis from the upper Stephanian B of the Plzen basin. This shark also shows an oval cross-sectioned spine with a ventral groove (Fritsch 1890, fig. 201, pl. 91, figs 9, 10), and bearing small backwardly oriented denticles unlike the British species. The dot-like foramina of $X$. ovalis (Fritsch 1890, pl. 91, fig. 10a, b) can also occur in $X$. laevissimus on the surface of the denticulated part of the spine. Teeth of $X$. ovalis are always either fragmentary or in low number (Fritsch 1890, pl. 91, figs 7b, 8b; Schneider \& Zajíc 1994, fig. 18b), therefore limiting discussion. To date, no significant differences can be proposed between this species and $X$. parallelus. Schneider \& Zajíc (1994) noted minor differences (e.g. high number of smaller foramina on the lower side in $X$. ovalis could be confirmed by the author) between the two and mentioned the possibility of intraspecific variation.

Xenacanthus gaudryi was the second articulated xenacanthid to be published (Brongniart \& Sauvage 1888) following the description of Xenacanthus decheni by Goldfuss (1847). The lack of articulated material from Britain concentrates the comparison on the cranial spine. The French species usually has a dorso-ventrally compressed spine with rows of very closely spaced denticles (Brongniart \& Sauvage 1888, pl. IV; Heyler
\& Debriette 1986, pl. III, figs 3, 4; Poplin \& Heyler 1989, pl. I, fig. 4c), indicating closer similarity with the German X. meisenheimensis and the Bohemian $X$. decheni than with the British xenacanthids. The length of the spine extends from one-quarter to one-fifth that of the entire body length, resembling Xenacanthus rather than Triodus in this respect. However, the type specimen, MNHN-COM 140, has a closed mouth, obscuring the dentition. Often, isolated teeth are badly preserved and unsuitable for determination to species level in the French localities. Some broken teeth can be confidently ascribed to Triodus on the basis of their histology (see 'Discussion of Triodus' below).

Although the teeth of $X$. laevissimus are quite different from other species in toto, they show some similarities with the German species from the Saar-Nahe basin. X. laevissimus shares with X. meisenheimensis (Boy 1976, fig. 11e-g as Xenacanthus sp. B; Hampe 1988b, fig. 2; 1993, fig. 2g-i as Xenacanthus sp. ME; 1994, fig. 11) the degree of the lateral angle between base and crown in common, about $95^{\circ}$ to $120^{\circ}$ (X. meisenheimensis $90^{\circ}$ to $120^{\circ}$ ). The number of nutrient foramina in $X$. meisenheimensis is distinctly higher. The German species usually has over 20 foramina on the bottom side, as opposed to between four and seven in $X$. laevissimus. The coronal button can have a lingual shaft, which never occurs in either $X$. laevissimus, or in $X$. tenuis. The median foramen in front of the median cusp is present in $X$. laevissimus, but missing in $X$. meisenheimensis and $X$. tenuis. On average, $X$. laevissimus teeth are twice the height $(1 \cdot 5-15 \mathrm{~mm})$ of $X$. meisenheimensis $(3-7 \mathrm{~mm})$ and the length of the median cusp is shorter (one-fifth to two-thirds that of lateral cusps) than in $X$. laevissimus (half to two-thirds, occasionally threequarters).

Morphotype 3 of $X$. laevissimus shows interesting transitions with a second SW German species, to $X$. humbergensis (Hampe 1988b, fig. 4; 1994, fig. 13). This species can have one to three additional vertical cristae on the lateral cusps and also one on the median cusp. $X$. laevissimus morphotype 3 , which is characterised by shorter lateral edges $(\rightarrow$ upper half of the cusps), displays in addition a short vertical crista on the lingual side. X. humbergensis has normally developed edges along the entire length of the cusps. $X$. humbergensis teeth (3-4 mm) are even smaller than those of $X$. meisenheimensis. It also has, in contrast to $X$. laevissimus, a large number (10 to more than 20) of nutrient foramina on both the upper and lower sides. A thin shaft on the upper side is possible in X. humbergensis, and not, as demonstrated, in the larger British species.

Histologically, $X$. laevissimus is unique with its proximal trabecular dentine socket in the crown. X. meisenheimensis is the only known Xenacanthus which occasionally has a serration in the proximal part of the cusps in larger teeth from lateral jaw positions (see also 'Discussion of Orthacanthus').

$X$. tenuis teeth, $4 \cdot 5-8 \mathrm{~mm}$ high, are smaller than those of $X$. laevissimus. The absence of lateral edges and the inward curvature of the cusp apices are distinctive characters which are not present in the German species.

The more or less parallel arrangement of cusps in $X$. tenuis is somewhat similar to X. remigiusbergensis (Hampe 1994, figs 8, 9), the third known species from the Saar-Nahe basin. $X$. remigiusbergensis is characterised by minute teeth measuring only $0 \cdot 4-0.9 \mathrm{~mm}$ high. First impressions suggest that they belong to juveniles, leading Schneider (1996) to consider them as being without taxonomic value. However, they occur at a locality from which no other Xenacanthus teeth are documented. The oldest known Xenacanthus, the Scottish $X$. elegans, displays some affinities with $X$. remigiusbergensis. They have the parallel cusp arrangement, smooth edges, the presence of a median foramen, and the large lateral angle between base and 
crown $\left(90^{\circ}\right.$ up to $140^{\circ}$ in $X$. remigiusbergensis) in common. Differences are present in terms of tooth height (X. elegans with $1 \cdot 8-2 \cdot 5 \mathrm{~mm})$, the irregular development of the coronal button and the less depressed basal tubercle as well as the whole bottom side in $X$. remigiusbergensis.

The N American X. slaughteri (Johnson 1999, genus with questionmark, figs 21, 22A-I) from the Lower Permian of Texas has teeth most similar to $X$. remigiusbergensis. Like $X$. elegans, X. slaughteri has nearly parallel cusps. In some of the $X$. slaughteri teeth, the mesial cusp is shorter than the median cusp, which separates this species from all other Xenacanthus species (Johnson 1999, fig. 22C, D). The coronal button in $X$. slaughteri is, like that in $X$. remigiusbergensis, usually small relative to the size of the base. Both share this character as well as the flat, 'pancake'-base with Orthacanthus platypternus. X. elegans has a distinctive tongue-shaped, labio-lingually elongated coronal button with lateral constriction. The number of nutrient foramina seems, after the figures of Johnson (1999) to be higher than in X. elegans. X. ossiani (Johnson 1999, genus with questionmark, figs 22J-R, 23, 24), from the Late Carboniferous of Nebraska, is not very different from $X$. slaughteri or $X$. remigiusbergensis. The lateral angle between base and crown and the 'undersized' coronal button combined with the small 'double'-foramen at the lingual edge is exactly the same as in X. remigiusbergensis (see Hampe 1994, fig. 9a, b and Johnson 1999, fig. 24D-F). The shape of the base and the low height of the teeth are further points of similarity, suggesting that $X$. ossiani could be conspecific with $X$. remigiusbergensis. Johnson (1999, p. 261) discussed the possibility that $X$. ossiani might be a variant of Orthacanthus compressus, reflecting dignathic, gynandric or ontogenetic heterodonty, but this is doubtful and probably not provable.

The cranial spines of the SW German species require further investigation; no spines of $X$. remigiusbergensis have been recovered to date. $X$. meisenheimensis shows a typical dorsoventrally compressed spine becoming convex distally on the dorsal side, which is distinct from the rectanguar cross-section in $X$. laevissimus. The denticles are very narrowly separated as in $X$. decheni and $X$. gaudryi. X. meisenheimensis has a relatively strong spine, which may be almost one-quarter of the total body length and is not as slender as in X. elegans.

Xenacanthus tocantinsensis (Silva Santos \& Salgado 1970, figs $1-3)$ represents a minute spine only $3 \mathrm{~cm}$ long from the Lower Carboniferous of Estado do Maranhão, N Brazil. The overall shape of $X$. tocantinsensis is like that of $X$. elegans. However, $X$. elegans spines are three times longer and the cross-section of the proximal part, in contrast to $X$. tocantinsensis, is rounded. The Brazilian spine is strongly compressed dorso-ventrally. The morphology of the denticles is quite similar, both species having denticles with posteriorly directed tips.

In conclusion:

(1) X. laevissimus represents a conservative species which has a trabecular dentine socket in the proximal part of the cusps. This feature is considered to be primitive. It is the only species outside the genera Diplodoselache and Dicentrodus with this characteristic.

(2) X. laevissimus teeth show a mosaic of characteristic which allows the establishment of tooth morphotypes defined on the basis of crown morphology. X. humbergensis from the Saar-Nahe basin, with its additional cristae on the cusps, might be a relic or successor species of the morphotype 3 in the Permian.

(3) $X$. parallelus and $X$. ovalis can be considered as conspecific and $X$. remigiusbergensis can be synonymised with $X$. ossiani. It remains uncertain as to how and why $X$. remigiusbergensis travelled 'through' the Appalachian-
Hercynian mountain range which acted as a barrier for Orthacanthus (see above).

(4) Species determination based upon spines is relatively uncertain. Davis (1892) noted variation in the outline of the diameter of different spines of probably identical species.

\section{Genus Triodus Jordan, 1849}

Type species. Triodus sessilis Jordan, 1849, MB.f.1419.1, represented by a dorso-ventrally preserved head with complete jaws in a nodule plus counterpart from the 'Lebacher Toneisenstein-Lager', upper Lauterecken-Odernheim member, Lower Permian of Lebach, Saar-Nahe basin, SW-Germany (Fig. 18).

Diagnosis (limited to teeth and spines). Tricuspid teeth with cusps of rounded to polygonal cross-section; long median cusp in some species reaching almost the same length as the laterals; surface of the cusps equipped with variable number of always straight vertical cristae; cristae can split dichotomously below the apex of a cusp or in a more proximal position; both crown and base constructed of orthodentine (except the coronal button which is made of trabecular dentine); length of spine less than one-sixth of total body length.

Remarks. Bohemiacanthus is a junior synonym for Triodus, being based on a single articulated specimen from the Lower Permian of the Podkrkonoe basin in Bohemia (originally described by Fritsch 1890 as Pleuracanthus carinatus). It displays no skeletal differences from the German Triodus species from the Saar-Nahe basin. However, Schneider \& Zajíc (1994, p. 125) want to limit the genus Triodus to the sharks with teeth having the specific ' $\mathrm{Y}$ '-shaped bifurcation below the apex of the cusps. Soler-Gijon \& Hampe (1998) were able to demonstrate both Y-shaped bifurcation and irregular splitting of the cristae in $T$. ?frossardi from the Lower Permian of the Autun basin. The name Expleuracanthus (see discussion above) has also been used erroneously for Triodus species: 'E.' carinatus (Zidek 1993a), 'E.' sessilis (Poplin \& Heyler 1989).

\section{Triodus serratus (Davis, 1892)}

(Figs 19d-h, 20a-r, 21)

1892 Pleuracanthus serratus Davis, p. 744, pl. LXXIII, figs 19, 20 Pleuracanthus (?species) Davis, pl. LXVII, fig. 1

1996 Xenacanthus serratus Newman et al., p. 3 Xenacanthus sp. Newman et al., p. 8

Syntypes. HM-G 34.11 and G 34.12, two spines.

Type locality. Newsham, Northumberland.

Type horizon. Shale above Low Main Seam (Lower Westphalian B).

Stratigraphical range. Langsettian to Bolsovian (Westphalian A to C).

Occurrence. Teeth from Fenton, Goldenhill, Hanley, Longton (all WC); Newsham, Newcastle upon Tyne, Brockley Whins, Collyhurst (all WB); Carluke, West Wylam, Burnley (all WA); spines from Airdrie, Newsham (both WB); Carluke (WA); shoulder girdle fragments from Newsham (WB).

Diagnosis (emend. after Davis 1892). Largest teeth reaching up to $5 \mathrm{~mm}$ in height; intercalated shorter vertical cristae can occur in addition to the normal pattern for the genus; broad basal tubercle sometimes of rhombic outline; short cranial spine with trapezoid-shaped denticles.

Description. For the first time, determinate teeth of this species can be associated with spines which Davis (1892) 


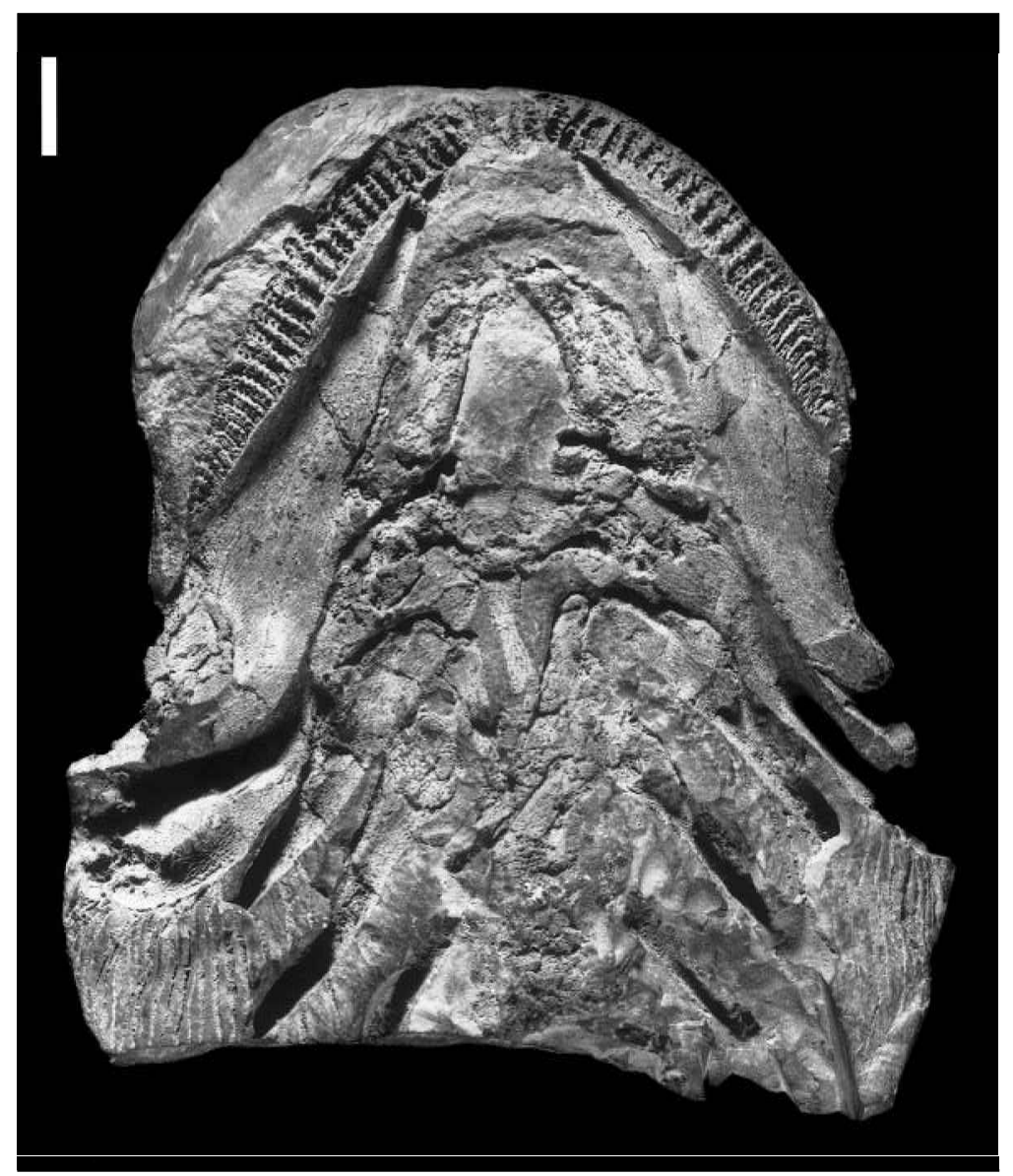

Figure 18 Type specimen of Triodus, T. sessilis, MB.f. 1419.1 from the Lower Permian (Odernheim Formation) of the Saar-Nahe basin, originally described but not figured in Jordan (1849). Kner (1867, pl. VI, fig. 1) published an illustration before the specimen was deposited in the Berlin Museum. Hampe (1989) erroneously cited the whereabouts of the type specimen as unknown. The nodule contains a dorso-ventrally compressed skull showing the cranial and branchial skeleton and practically the complete upper jaw dentition. Scale bar, $1 \mathrm{~cm}$.

described as Pleuracanthus serratus. The association leaves no doubt that the spines belong to a species of Triodus. The teeth (Figs 19d-h, 20a-p) have a height ranging from $1.5 \mathrm{~mm}$ to $5 \mathrm{~mm}$ with an average of about $2-3 \mathrm{~mm}$. The height of the median cusp is consistently half to two-thirds that of lateral cusps. They are occasionally longer than three-quarters of the lateral cusp height (e.g. Fig. 20c). The cross-section of the slightly inwardly curved cusps (Fig. 20b-e) is rounded to polygonal in the upper parts. Six to eight vertical cristae are regularly situated in the upper third to upper half of the lateral cusps as well as on the median cusp. The cristae sometimes exhibit intercalation (Fig. 201) or splitting (Fig. 20g, k).

The oval base has a robust appearance and has a concave depression basally (Figs 19g, h, 20m-p). The coronal button is remarkably prominent (Figs 19d, 20a-e), rounded, often contoured like a drop with a short lingual shaft. Two to five nutrient foramina can be counted on the upper side of the base. A median foramen could not be detected between the coronal button and the median cusp. The base has between three and six nutrient foramina on the bottom. The mostly broad, generally oval to rounded basal tubercle is sometimes also of rhombic outline (Figs 19g, h, 20m, n, p). It is occasionally equipped with a lingually directed shaft, situated as usual at the labial margin of the base. The basal tubercle has a typical basal depression. The lateral angle between base and crown ranges from $100^{\circ}$ to $115^{\circ}$. Although a different range of tooth size (height) is documented, the dentition type seems to be relatively homodontous.
The tooth histology of $T$. serratus is identical to that of all other species of Triodus investigated from SW Germany and the Czech Republic, comprising orthodentine which makes up both crown and base. The orthodentine shows growth lines, called Owen's lines, indicative of circumpulpar development around a medium-sized pulp cavity in the lateral cusps (Fig. 21a). The dentine tubules run perpendicular to the growth lines and are clearly visible (Fig. 21c). The growth lines can also be followed in the base (Fig. 21b). A few canals of narrow spaced lumina are situated in the centre of the base. Enameloid is absent.

The cranial spine of $T$. serratus is relatively short. The syntypes show lengths of only $3.4 \mathrm{~cm}$ and $4.0 \mathrm{~cm}$. A $5.5 \mathrm{~cm}$-long broken spine lacking its proximal end and possessing a short distal end is estimated to have been about $8 \mathrm{~cm}$ when complete. The spines may be curved. The cross-section is rounded but characterised by a modest dorso-ventral compression with a delicate raised median line on the dorsal side. The maximum width/length ratio is around $1: 13$ to $1: 14$. A single row of denticles, each distinctly trapezoid in lateral view and pointing bodywards with an even outer edge, is situated on both lateral sides (Fig. 20q). The denticles stand very close to each other on what are probably juvenile spines (Fig. 20r). A simple system of striations is present on the denticle-covered distal part of the spine. The proximal part of the spine has a more or less smooth surface developing extremely delicate grooves resembling hairline cracks.

A slab of coal shale from the Westphalian B of Newsham, previously figured in Davis (1892, pl. LXVII, fig. 1), contains 

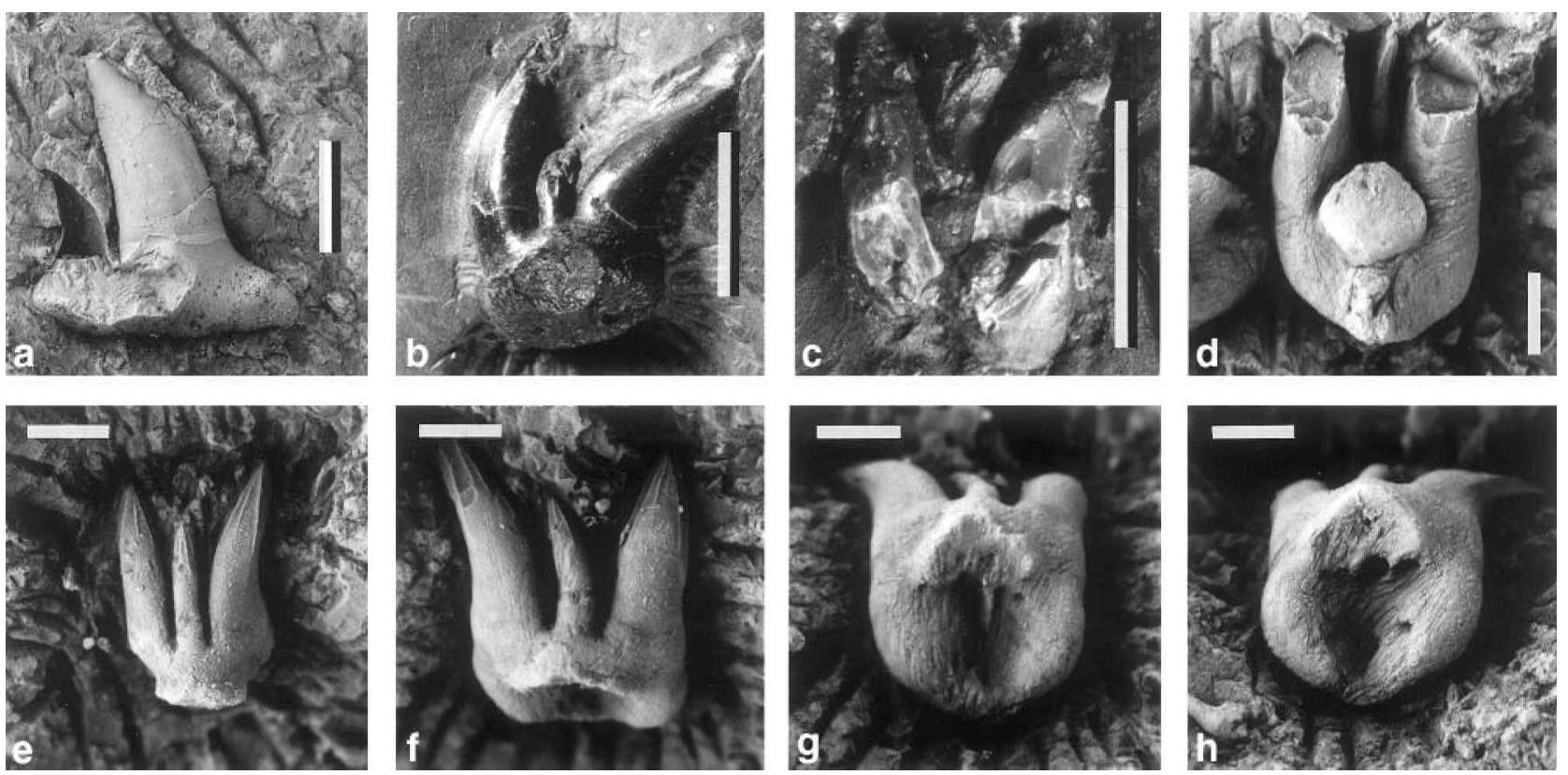

Figure 19 Teeth of British xenacanthids: (a) Dicentrodus bicuspidatus, BMNH P 2295, neotype; tooth with broken distal cusp from Edge Coal Group, Carboniferous Limestone, Pendleian (Lower Namurian A) of Burghlee, Midlothian; labial aspect. The serration on the inner edge of the mesial cusp is clearly visible. (b) Orthacanthus gibbosus, BMNH P 497, lectotype; single tooth from the Coal Measures (Westphalian C) of Silverdale, Staffordshire; labial aspect. (c) Xenacanthus tenuis, BMNH $20695 \mathrm{Nr}$. 3, one of the syntypes; broken tooth showing the circular growing lines of the orthodentine, Westphalian A of Carluke; labial aspect. (d-h) Triodus serratus from slab BMNH P 6684: (d) tooth D with broken cusps from lingual; (e) tooth A from labial with excellent preserved vertical cristae, (f) tooth B from labial; (g) tooth B from basal showing the triangular-shaped basal tubercle; (h) tooth $\mathrm{C}$ with three big foramina from basal. Scale bars, $5 \mathrm{~mm}(\mathrm{a}-\mathrm{c}), 1 \mathrm{~mm}(\mathrm{~d}-\mathrm{h})$.

cartilage fragments in association with teeth of $T$. serratus (HM-G34.35). Determination is hampered by the overlapping of fragments. A probable scapulocoracoid lacking the connective parts (suprascapular and procoracoid) and with eroded articular processes is present, together with several elements of the hyobranchial apparatus. The material, therefore, cannot be characterised.

A piece of shale from the Westphalian $\mathrm{C}$ of Longton (BMNH-P 8126) has teeth of T. serratus in association with a spine of $X$. laevissimus. This is probably an example of a predator-prey relationship (Xenacanthus feeding on Triodus; see Hampe 1988b, p. 755, Boy \& Schindler 2000, fig. 1).

?Triodus pulchellus (Davis, 1880)

(Fig. 20s)

1880b Pleuracanthus pulchellus Davis, pp. 327ff, fig. 4, pl. XII, fig. 2

Holotype. BMNH-P 7687, spine fragment.

Type locality. Tingley, W Yorkshire.

Type horizon. Cannel Coal, Middle Coal Measures (Westphalian B).

Stratigraphical range. Langsettian and Duckmantian (Westphalian A and B).

Occurrence. Only spines from Tingley (WB) and Carluke, W Wylam (both WA).

Diagnosis (emend. after Davis 1880b). Small, always straight spines; proximal part extremely broad, dorso-ventrally flattened with median groove on both sides disappearing distally.

Description. The spines belonging to ?T. pulchellus are comparatively small. They can only be designated to Triodus because of their total length (the preserved specimens are definitely fully grown). The denticles show a decrease in size proximally, which means that they have already passed their maximum growth speed (see Soler-Gijón 1999 for further details on the growth of occipital xenacanthid spines). Triodus is the smallest known xenacanthid genus to date. Therefore, it is the most parsimonious decision to incorporate the British specimens into that genus.

The length of the consistently straight spines varies between $3.5 \mathrm{~cm}$ and $3.7 \mathrm{~cm}$. They are characterised by being broad proximally with a distinct dorso-ventralflattening and the formation of a median groove on both sides (Fig. 20s). The ventral groove reaches the zone of denticulation. The relatively rough ornamentation consists of longitudinal striation. The cross-section of the spine becomes rounded distally. The spine tapers very rapidly to the distal end. The maximum width/length ratio ranges from about 1:12 to over 1:15. The denticles are situated typically on each of the lateral sides, but are not as closely set as in $T$. serratus. The denticles are pointed towards the base in their distal portion, but their tips turn outwards at the proximal denticulation area (Fig. 20s). The denticles have a more slender, sharp outline than those of $T$. serratus.

Discussion of Triodus. Most species of Triodus are known from the Rotliegend (Lower Permian) of the SW German Saar-Nahe basin. Undoubtedly, $T$. serratus shows most affinities with T. palatinus (Boy 1976, fig. 11e-g; Hampe 1989, fig. 4) and with T. obscurus (Hampe 1989, fig. 5), both from the lower Rotliegend (for detailed stratigraphical range, see Hampe 1994; Schneider et al. 2000). The range of the median cusp length in $T$. serratus is similar to that in both German species, as is the bifurcation type of the vertical cristae, the presence of a lingual shaft to the coronal button, and the number of nutrient foramina on the bottom side. Differences exist in the shape of the basal tubercle, which in T. serratus is rhombic, but in T. palatinus and T. obscurus is rounded. The lateral angle between base and crown is between $90^{\circ}$ and $120^{\circ}$ in the German species, which is more variable than in the English species $\left(100^{\circ}\right.$ to $\left.115^{\circ}\right)$. T. serratus teeth, reaching $5 \mathrm{~cm}$ 


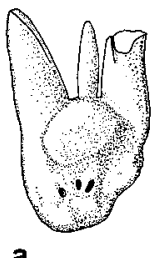

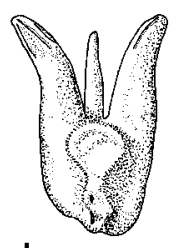

b
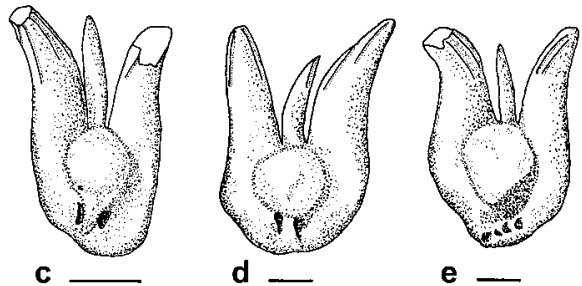

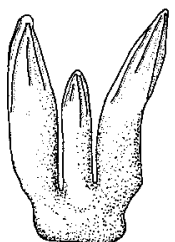

f

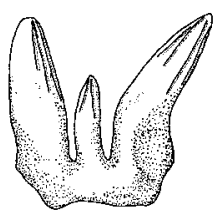

$\mathbf{g}$

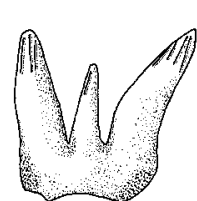

h

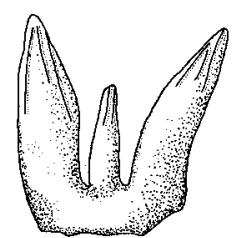

i
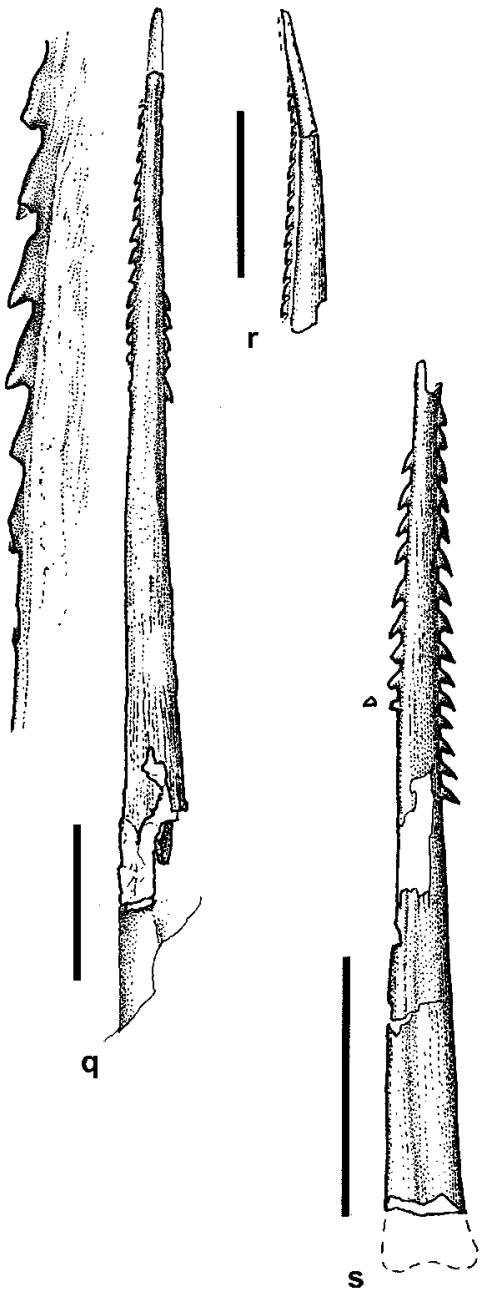

m

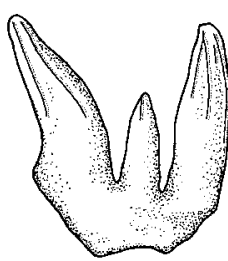

j

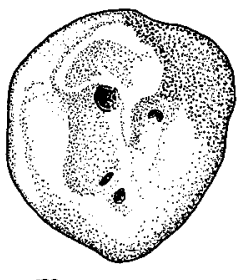

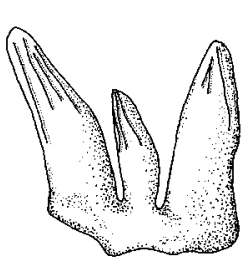

k

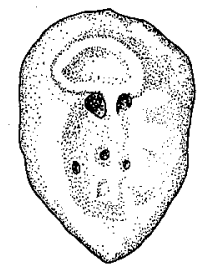

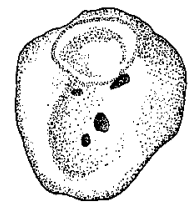

o
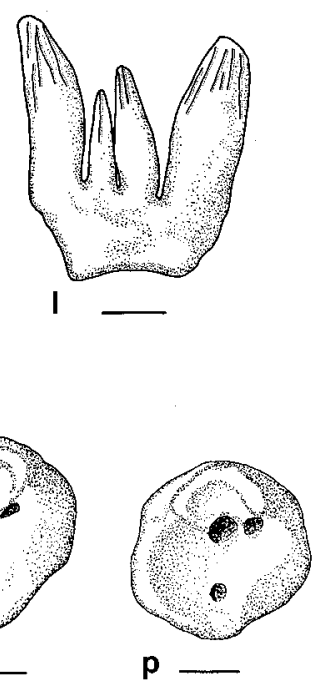

Figure 20 Teeth of Triodus serratus in lingual (a-e), labial ( $\mathrm{f}-1)$, and basal ( $\mathrm{m}-\mathrm{p}$ ) aspects and spines of T. serratus (q, r) and of ?T. pulchellus (s): (a) HM G 183.35 Nr. 4; (b) HM G 183.35 Nr. 3; (c) HM G 183.35 Nr. 5, all Lower Westphalian B of Newsham. (d) BMNH P 8151 c; (e) BMNH P 8151 b, (f) BMNH P 6684 a; (g) BMNH P 6684 c all Lower Westphalian C of Fenton. (h) HM G 183.35 Nr. 1, Lower Westphalian B of Newsham. (i) BMNH P 8161 [D3], Westphalian C of Longton. (j) HMUG V2976, Westphalian A of Carluke. (k) BMNH P 6684 b, Lower Westphalian C of Fenton. (1) MM LL.11601a, a quadricuspidate from the Westphalian B of Collyhurst. (m) BMNH P 6684 b, Lower Westphalian C of Fenton. (n) MM LL.11601a, Westphalian B of Collyhurst. (o) HM G 183.35 Nr. 1, Lower Westphalian B of Newsham. (p) BMNH P 6684 c, Lower Westphalian C of Fenton. (q) HMUG V 2976, dorsal aspect with a detail of denticle morphology, Westphalian A of Carluke. (r) HM G 34.11, dorso-lateral aspect of the syntype, Lower Westphalian B of Newsham. (s) BMNH P 7687, holotype of ?T. pulchellus, Westphalian B of Tingley. Scale bars, $1 \mathrm{~mm}(\mathrm{a}-\mathrm{p}), 1 \mathrm{~cm}(\mathrm{q}-\mathrm{s})$.

in height, are generally bigger than the German ones. The absence of cristae on the lingual surface of the cusps, characteristic of T. obscurus, is unknown in T. serratus. The number of cristae in $T$. serratus is similar to that of $T$. palatinus, but the number of nutrient foramina on the upper side of the base is lower on average in $T$. serratus. Similarities between $T$. serratus and the teeth of Triodus sp. ZÖ from the basal Rotliegend of Lower Austria (Schindler \& Hampe 1996, fig. 2) include the length of the median cusp, bifurcation type and the relative number of nutrient foramina on both the upper and bottom sides of the base. Differences between the two include the large angle between base and crown $\left(130^{\circ}\right.$ to $\left.135^{\circ}\right)$ in $T$. sp. $\mathrm{ZO}$ and the rounded basal tubercle. A lingual shaft has not been observed in $T$. sp. ZÖ.

$T$. serratus has a few similarities with $T$. lauterensis from the Stephanian C and lowermost Rotliegend of the Saar-Nahe basin (Hampe 1989, fig. 3), such as the arrangement of the vertical cristae, the lingual shaft on the upper side of the base as well as the angle between base and crown $\left(100^{\circ}-110^{\circ}\right)$. How- ever, $T$. lauterensis has smaller teeth $(1 \cdot 0-1 \cdot 5 \mathrm{~cm})$, a longer median cusp (half to four-fifths that of lateral cusps), a variable number of vertical cristae (three to eight), more nutrient foramina on the base and a rounded basal tubercle as in all other known species.

Teeth from the Lower Permian of Muse in the Autun basin in France (Heyler \& Debriette 1986, pl. I, figs 3, 4, 7) definitely belong to Triodus. Broken specimens have circumpulpar dentine (orthodentine) in crown and base, a characteristic which is shared only by Triodus species. The teeth are allocated to T. ?frossardi by Soler-Gijón \& Hampe (1998, figs 1-4). The French species has only the number of vertical cristae at the cusps, a lingual shaft on the upper side of the base and the number of nutrient foramina (about four) on the bottom side within the range of $T$. serratus. Significant differences are the long median cusp of $T$. ?frossardi, the occurrence of an inverted ' $Y$ '-shaped bifurcation in addition to 'normal' branching, fewer nutrient foramina on the upper side, the rounded basal tubercle and the smaller angle between base and crown $\left(90^{\circ}-95^{\circ}\right)$. 

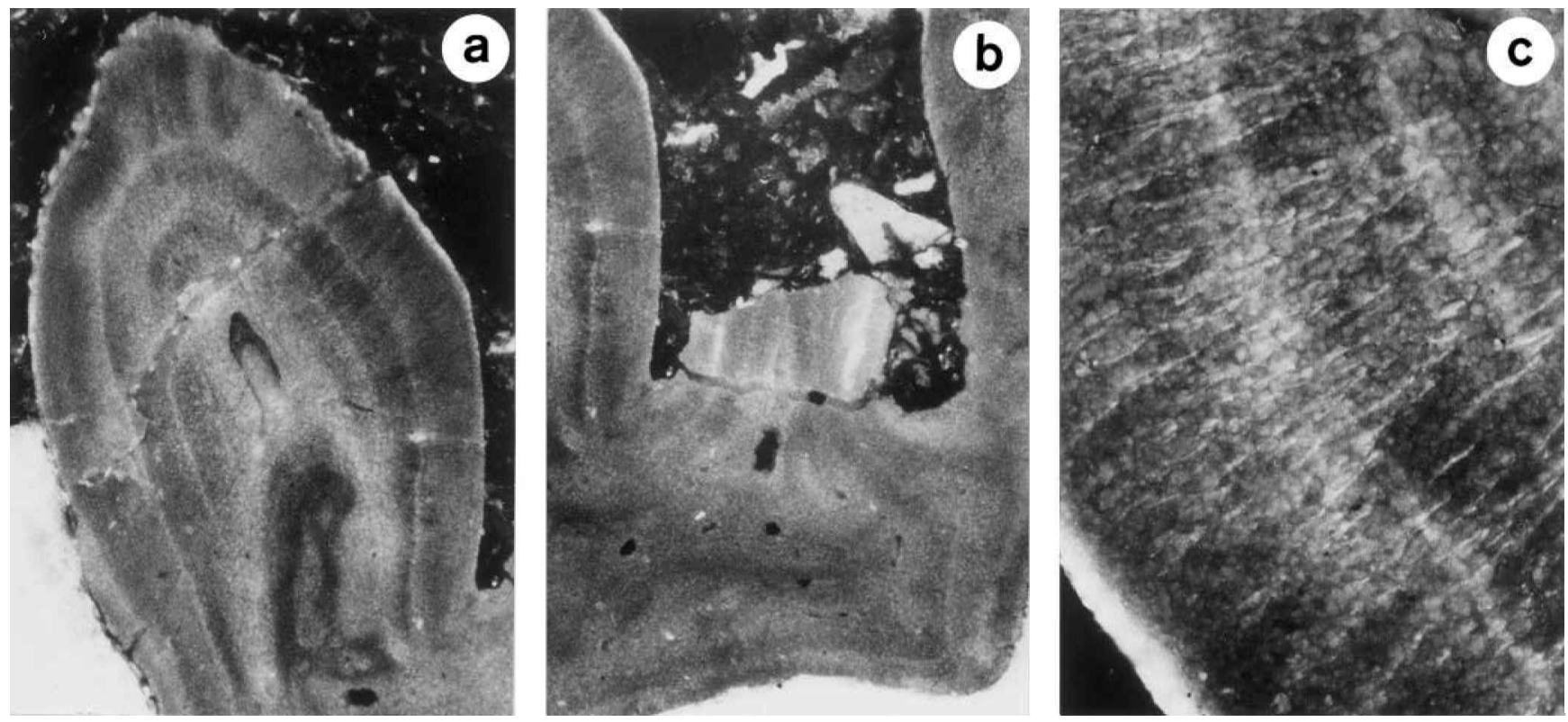

Figure 21 Tooth histology of Triodus serratus, all MM LL.11601e: (a) vertical section through a lateral cusp with normal developed orthodentine; B q, t $\supset 22.10 \mathrm{sec}, \times 43$; (b) vertical section through the base, also constructed of orthodentine with minor nutrient canals and clearly visible growth lines; B q, t $\supset 20.84 \mathrm{sec}, \times 43$; (c) enlarged part of the cusp showing the perpendicular dentine tubules; $\mathrm{B}$ q, t $\supset 3.27 \mathrm{sec}, \times 175$.

$T$. serratus has only the bifurcation pattern and the length of the median cusp (half to two-thirds that of lateral cusps) in common with $T$. carinatus from the basal Permian of the Podkrkonoše basin, Boskovice furrow and Silesia (Fritsch 1890, pl. 97; Schneider \& Zajíc 1994, fig. 21; pl. 2 as 'Bohemiacanthus'). All other characters differ in the two species. $T$. sessilis from the lower Rotliegend of the Saar-Nahe basin (e.g. Kner 1867, pl. VI; Schneider 1985, pl. IV, figs 9-17; Hampe 1989, figs 1-2) and T. kraetschmeri from the lowermost upper Rotliegend of the Saar-Nahe basin (Hampe 1989, fig. 6; Hampe 1993, figs 3c, 4e) also show clear differences to T. serratus. The median cusp is longer in the SW German species (greater than two-thirds of the length of the lateral cusps in T. sessilis; greater than three-quarters in T. kraetsch$m e r i$ ), the number of vertical cristae is lower (six in T. sessilis; five to six in $T$. kraetschmeri), they have a typically rounded as opposed to rhombic basal tubercle, a different number of nutrient foramina on the bottom side (four to nine in T. sessilis; two to four in T. kraetschmeri), and a different angle between base and crown (constantly $90^{\circ}$ in T. sessilis; constantly $100^{\circ}$ in T. kraetschmeri). Both German species share a specific bifurcation pattern: an exclusively inverted $\mathrm{Y}$-shape near the tip of the cusps. They have the lingual shaft of the upper side of the base in common with $T$. serratus. In addition, T. kraetschmeri has a nearly similar number of nutrient foramina (two to four) on the upper side.

Johnson (1999, text-fig. 20) described a few teeth from the Asselian of Pennsylvania as Orthacanthus aff. compressus with straight vertical cristae on labio-lingually compressed cusps. These teeth combine characters known from Triodus and Plicatodus (Hampe 1995, see below). Further investigation is needed to determine the true affinities of the American specimens. Johnson \& Thayer (1999) reported Triodus teeth (as ?Xenacanthus) from the Early Pennsylvanian (Westphalian A?) of Arizona, the only known representatives of this genus from America. Detailed comparisons are not yet possible.

Species of Plicatodus (e.g. Hampe 1995, figs 1-6), known from the Lower Permian of the Saar-Nahe basin (P. jordani), Stephanian B of Bohemia (P. plicatus) and probably from the Upper Permian of Brazil (?P. santosi), share several character- istics with Triodus and Xenacanthus. The wide lumina of the pulp cavities and cusps bearing vertical cristae are characteristic of Triodus. However, the hybodont-like undulating pattern of the cristae in Plicatodus is different from that of Triodus. A flattened base, the large number of nutrient foramina and the often relatively small and flat coronal button are generally common between Xenacanthus and Plicatodus. The cusps of most Xenacanthus species have a lanceolate cross-section as shown above, which is only slightly expressed in Plicatodus. Plicatodus has a dorsal spine, equipped with a single row of denticles laterally, a condition practically indistinguishable from Triodus and Xenacanthus. Teeth of the Namurian B specimen of Hagenoselachesippeli (Hampe \& Heidtke 1997, figs 4-6) from Germany (Sauerland area) show greatest affinities with the genus Triodus in the presence of vertical cristae and the deeply depressed basal tubercle. The dentine structure is exactly the same as in Triodus; an enameloid layer is, as in all other xenacanthids, unproven. The cristae, however, are restricted to the very distal part of the cusps and the vascularisation system displays narrower lumina than in Triodus. No spine of this primitive xenacanthid is known to date, although one specimen is still in preparation (Westfälisches Museum für Naturkunde, Münster).

Xenacanthid teeth related to ?Triodus, belonging to the socalled 'moorei'-group, are known from Upper Triassic deposits with ?T. moorei (Woodward 1889b, pl. XIV, figs 4, 5; Seilacher 1943, figs 47-50; Johnson 1979, pls 18-20; Johnson 1980, textfigs 1, 3-5) from Britain, S Germany and Texas, ?T. indicus (Jain 1980, fig. 2) from India and ?T. parvidens (Woodward 1908, pl. I, figs 3-5) from Australia. They are the last survivors of this successful group of sharks. Typical for all Upper Triassic species (Hampe \& Schneider, in prep.) is the fragile appearance of the tricuspid teeth with a drop-shaped lingually pointed base and an extremely flat diamond-shaped coronal button. The dentition is rather homodont and cusps of the moorei group share the ornament of vertical cristae with Triodus.

There is some doubt as to whether 'Xenacanthus' luedersensis (Berman 1970, pl. 7e-g; Johnson 1996, fig. 3H-J) from the Lower Permian of Texas and Oklahoma is a xenacanthid at all. Its general morphology could be interpreted as an example 
of parallelism. The teeth of ' $X$.' luedersensis are always bicuspid and are ornamented with a large number of vertical cristae (about eight to sixteen) per cusp. The lingually positioned cristae are more strongly developed, and sometimes arranged spirally in a wavy pattern. The base has one or two labial foramina, a condition which never occurs in xenacanthids. The basal tubercle is somewhat rhombic as well as the coronal button which occupies nearly the whole upper side of the base. Histologically, ' $X$.' luedersensis has a base of mostly trabecular dentine luminated like Swiss cheese and covered by an orthodentine layer which differs from Triodus. The dentine tubules are widely spaced, whereas in Triodus there is a ramifying network of reticular branches (Hampe 1991). Sections reveal that ' $X$.' luedersensis possesses an enameloid. The rhombic outline of ' $X$.' luedersensis is similar to $T$. serratus. No other species of Triodus has a similar high number of vertical cristae. The nutrient foramina of ' $X$.' luedersensis are very often arranged in a distinct diagonal row (upper side as well as lower side). The base, in contrast with all other species of Triodus is of almost rectangular outline (Johnson 1979, text-figs 18-21). A notch often occurs on the lingual side. Johnson (1999) recognised this as a new but unnamed genus. Zidek (pers. comm.) reported a large skull (estimated body length $4.5 \mathrm{~m}$ to $5 \mathrm{~m}$ ) with hundreds of luedersensis teeth and believes this shark to be a filter feeder.

Bransonella is a genus erected by Harlton (1933), for B. tridentata from the Lower Pennsylvanian of Oklahoma, and erroneously identified as a conodont. The crushing-type teeth (see Schneider 1996) have a tricuspid crown of relatively strong cusps displaying a distinctive chevron-shaped ornamentation. In addition to $B$. tridentata, $B$. nebraskensis is known from the Late Pennsylvanian of Nebraska (Johnson 1984, figs 1, 214, 16) and Kansas (Tway \& Zidek 1983, fig. 52 as 'Subtype 173') as well as from the Lower Permian of Kansas (Schultze 1985, fig. 4.1 as Xenacanthus luedersensis), and B. lingulata from the Lower Namurian of the Moscow syncline (Ivanov \& Ginter 1996, figs 3, 4, 5B-D). The latter authors also found B. nebraskensis in Viséan deposits from the Polar and South Urals of Russia and from the Holy Cross Mountains of Poland (Ivanov \& Ginter 1996, fig. 1). They allocated Bransonella to the xenacanthids. However, there are significant characters in Bransonella which never occur in xenacanthid sharks: the characteristic chevron-shaped or inverted-Vnested ornamentation reaching the base, a small kidneyshaped basal tubercle and the presence of labial foramina on the base. It is therefore doubtful whether Bransonella is allied to the xenacanthids. There are some similarities with Jalodus australiensis (originally described as Phoebodus) from the Late Devonian (middle Fammenian) to the Tournaisian which is known from many places in the world (see Ginter 2000, tab. 1). Jalodus australiensis also has very robust teeth and strong cusps (e.g. Long 1990, figs 2, 3F-O, 4; Ginter \& Ivanov 1996, fig. 3A-C; Ginter 1999, pl. 1) showing consistently bifurcating vertical cristae as inverted V's nested within one another. This ornament is identical to that in Bransonella and is never seen in Triodus. A similar design is present in the teeth of Adamantina from the Tournaisian of Russia (A. foliacea, Ivanov 1999, fig. 4, pl. 6, fig. 11) and the Upper Permian of E Greenland (A. benedictae, Bendix-Almgreen 1993, figs 3A-E, 9A-C) which are considered here as phoebodontids. Teeth described under ?Triodus sp. from the Late Carboniferous of the Amazon basin in Brazil (Duffin et al. 1996, fig. 7d-g) also belong to Bransonella.

Although most species of Triodus are known from articulated material as well as cranial spines, the spines need further investigation. Skeletons are documented from T. kraetschmeri, T. sessilis, T. obscurus (partially), T. palatinus, T. carinatus and
T. frossardi. The spines are generally less than one-sixth of the total body length. It is difficult to identify isolated spines to species level. For example, the spine of $T$. sessilis has closely spaced denticles, possesses a narrow longitudinal groove on the ventral side, and shows a smooth distal surface with fine striations proximally, a suite of characters present in the spines of many species. By contrast, $T$. serratus sometimes has a distinctive curved spine bearing closely spaced trapezoid-shaped denticles in dorsal or ventral view.

?T. pulchellus has small spines which are always straight. They are dorso-ventrally flattened with a median groove on both dorsal and ventral side which disappears distally. T. sessilis has in contrast a groove only on the ventral side. Formerly, Davis (1892) integrated the pulchellus spines into X. laevissimus, but the development of the denticles (see above) leads to the conclusion that these small occipital spines are from adult specimens. $X$. laevissimus developed much bigger spines.

The spine of $T$. frossardi as figured in Gaudry (1883, fig. 221) shows similarities with ?T. pulchellus in having a broad proximity. It remains an open question as to whether $T$. frossardi developed a longitudinal groove on both dorsal and ventral sides of the spine.

The spine described as T. carinatus (Fritsch 1890, fig. 210, pl. 97) has a ventral groove and a dorsal ridge and therefore differs from the other species. The outline of the cross-section is somewhat triangular. The denticles are slender and point backwards, quite similar to the condition documented in the distal portion of the ?T. pulchellus spine.

A spine probably belonging to Triodus is presented by Bendix-Almgreen (1976, fig. 452E, F) from the Lower Permian of the Mesters Vig area, Greenland. It is a small specimen with distinctive denticles in the shape of a parallelogram. There could be some relation with the trapezoid-shaped denticles of T. serratus.

Schneider et al. (1988) were the first to attempt to establish a biozonation scheme based upon xenacanthid teeth for correlating of non-marine and continental deposits. They employed Triodus for stratigraphical purposes utilising the general reduction of the cristae. Later, Schneider (1996) modified this idea, pointing out that teeth can vary relative to their position in the jaws. Hampe (1994) emphasised that stratigraphic correlations are only valuable within one depositional basin. Correlations based upon xenacanthid teeth are not possible between different basins or across facies boundaries in the small, dissected, younger Palaeozoic sedimentary basins of central Europe. Research suggests that populations within separate basins of deposition display different evolutionary trends. A detailed zonation based on elasmobranch teeth with xenacanthids predominating has recently been defined for the Stephanian, Autunian and early Saxonian in the Saar-Nahe basin (Schneider et al. 2000, fig. 4).

The above discussion leads to the following conclusions:

(1) The highest number of Triodus species is known from the Lower Permian of the German Saar-Nahe basin. The reason why they are so uncommon in other regions is that the smaller teeth may simply have been overlooked in some localities. Without intensive bulk sampling they would often remain undiscovered.

(2) The first records of Triodus from N America are based upon teeth described by Johnson \& Thayer (1999) from the Early Pennsylvanian of Arizona.

(3) Teeth of the British T. serratus are the largest so far recorded within the genus.

(4) Material from France formerly described as 'Expleuracanthus' can be assigned to Xenacanthus and Triodus (see Soler-Gijón \& Hampe 1998). There are no significant char- 
acter on which to define and maintain 'Expleuracanthus' as a separate genus.

(5) The small elasmobranch Triodus (on average about $50 \mathrm{~cm}$ long based upon a complete skeleton from the Saar-Nahe basin; see Schwind 1991, pl. 1-46) is interpreted as an inefficient swimmer, perhaps lying in wait for prey in nearshore areas like an ambush predator (Hampe 1997b).

\section{Ontogenetic note}

Tooth morphology of probable juveniles can show considerable intergeneric similarity: juvenile teeth of Orthacanthus bohemicus, for example, do not have serrated edges and look Xenacanthus-like (Fritsch 1889: 105; pl. 82, figs 1, 2, 14). O. platypternus teeth have a comparatively longer median cusp and show considerable variation in the development of the lateral edges (Zidek 1993b, fig. 1). The shape of juvenile Lebachacanthus senckenbergianus teeth (Hampe 1988a, fig. 2, separated square) resembles that of typical Xenacanthus teeth. However, serration is very well developed in L. senckenbergianus juveniles in contrast to $O$. bohemicus. On the other hand, O. gibbosus juveniles (Fig. 17e) may have both serrated and non-serrated cusps in the dentition.

Schneider (1996) considered X. remigiusbergensis to be a juvenile because of its small teeth. He neglected to consider, however, that $X$. remigiusbergensis was the only xenacanthid elasmobranch so far discovered at that locality (Hampe 1994). There is no indication as to why that particular fauna should contain juveniles only. There is currently no suite of characters by which to identify the teeth of xenacanthid juveniles.

The ontogeny of xenacanthid spines became much clearer through the work of Soler-Gijón (1999) on Orthacanthus species. The histology of all xenacanthid spines is generally identical, irrespective of its site of insertion (Hampe 1997b). The inner architecture is constructed of trabecular dentine closed by lamellar dentine in the outer zone as observed, for example, in remains of Diplodoselache woodi (see Dick 1981, fig. 13), Dicentrodus bicuspidatus (recently collected RSM material from Cowdenbeath), Anodontacanthus alatus (BMNH-P 8401), Orthacanthus gibbosus (BMNH-P 6689) and Xenacanthus elegans (BMNH-P 1136).

Denticles are dermal derivatives like teeth and scales, and were fused secondarily onto the spine by means of dentine while the spine was erupting through the skin. Growth rate and denticulation are both subject to seasonal cyclicity, but the ratio of length of the denticulated region to the total length of the spine can change throughout ontogeny. Consequently, those features cannot be used for systematic purposes without careful analysis of their variation. However, the largest denticle indicates the age of maturity of an individual. Succeeding smaller denticles show a decline in growth rate according to Soler-Gijón (1999). The number of denticles on an individual spine as used in descriptions by former authors (e.g. Davis 1892) is no longer taxonomically relevant.

\section{Problematic remains}

The majority of teeth in older collections in Britain are indeterminable because of their poor or fragmentary preservation. Many specimens described by nineteenth century authors received little in the way of preparation. Although most published records can be determined, there are occasional exceptions (e.g. a tooth in Garner 1844, pl. 6, fig. 11).
Several doubtful traces of fossil chondrichthyans, especially spines, are held in the British collections besides clearly determinable remains of xenacanthids. One of these is a spine from the Coalbrookdale coalfield in Shropshire which Prestwich (1840, pl. 41, fig. 15) originally described as Pleuracanthus. This straight spine (Fig. 22a) is preserved in a concretion and its ventral side is characterised by a relatively strong ornamentation of longitudinal striations proximally, and with small additional tubercles distally. The spine surface is somewhat similar to a stem of Sigillaria. An irregular arrangement of sharply pointed, very short denticles mixed with much larger ones is present on the lateral sides. The spine fragment shows remarkable similarity to the spine of the Irish Gnathacanthus triangularis from the Lower Carboniferous Mountain limestone of Armagh (see Davis 1883, pl. XLVIII, fig. 11), a specimen which is classified as a presumed elasmobranch ichthyodorulite (after Zangerl 1981).

Imperfect spines published under the name Pleuracanthus horridulus (type specimen erected but not figured by Traquair 1882 and now believed to be lost) from the Pendleian of Burghlee and from the Westphalian A of Clifton, W Yorkshire (Davis 1892, pl. LXXII, figs 22, 23) show a strange morphology. They are very short (fragments ranging between $2.8 \mathrm{~cm}$ and $4.8 \mathrm{~cm}$ ), extremely slender and fragile looking, and taper to a point. Davis $(1892$, p. 739$)$ described them as having a double row of large recurved denticles. However, only one row of denticles (Fig. 22c, see also 22b) could be detected in the original material (an artifact of preservation?). The proximal part of the spine is striated, while the distal part is smooth. It is not certain whether these elements belong to elasmobranchsat all. Newberry (1874, pl. XL) described Compsacanthus laevis spines of uncertain origin represented by numerous examples from the Middle Pennsylvanian of

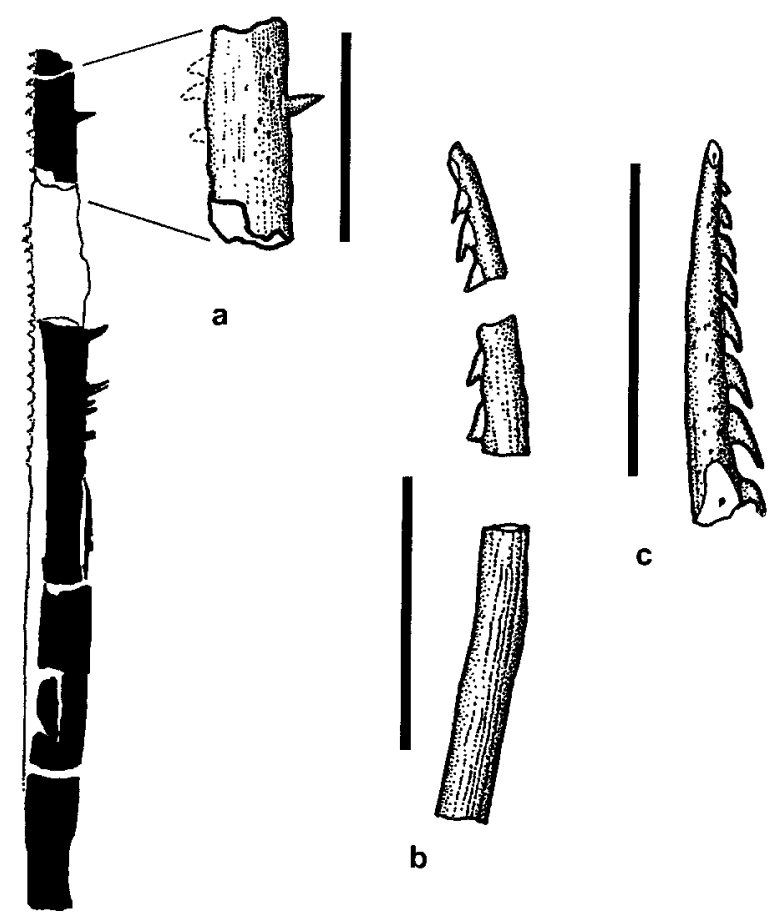

Figure 22 Problematic spines: (a) BMNH P 34248, close-up of the distal part of an indeterminate spine presumably belonging to an elasmobranch preserved in a nodule from the Westphalian B of Coalbrookdale, Shropshire; (b) BMNH P 11363, Pendleian of Loanhead; (c) BMNH P 8441, Pendleian of Burghlee. Both remains of uncertain origin perhaps belonging to acanthodian or holocephalan. Scale bars, $1 \mathrm{~cm}$. 
Linton, Ohio. There is a possibility that these spines belong to an acanthodian, or perhaps a holocephalan. Duffin (1981, fig. 1, pl. 1) figured a myriacanthid chimaeriform spine of similar morphology from the Lower Jurassic of Lyme Regis, Dorset which he named Recurvacanthus uniserialis. Davis (1883, pl. XLVIII, figs 7-9) also described quite similar spines from the Mountain Limestone of Armagh as Homacanthus microdus.

As demonstrated above, Xenacanthus tenuis is defined on its teeth (after Woodward 1889a). The literature reveals a spine sharing the same species name: Pleuracanthus tenuis (Davis 1880b, fig. 3; pl. XII, fig. 1). The spine is poorly preserved. It is a heavily abraded specimen with no determinable characteristics visible (Fig. 23a). The spine is rounded and very slender, $11.6 \mathrm{~cm}$ in length, ornamented with fine lines over the entire surface. Undulating thickenings are present instead of denticles on the presumed ventral side. This so-far-undetermined spine may belong to a xenacanthid, but the preservation is too poor to define a taxon or to distinguish it as one of the known species.

Phricacanthus biserialis is another curious spine taxon, erected by Davis (1879, pl. X, fig. 16) from the Westphalian A of Clifton, W Yorkshire. It is a $10.7 \mathrm{~cm}-$ long, regularly and gently curved element with extremely wide standing prominences on the ventral side (Fig. 23b). The surface is obscured by a thin layer of coal. The wide spaces between the knobs are unknown in any other xenacanthid described so far. Davis discussed the similarity of Phricacanthus to Orthacanthus. Later Woodward (1889a) referred this specimen to Orthacanthus cylindricus ( $\supset$ O. gibbosus). The morphology of O. gibbosus spines is completely different to Phricacanthus, being large, straight and erect, and bearing two rows of numerous, small denticles. In confusion, Davis (1892) designated a new species name for it because biserialis was preoccupied, and placed Phricacanthus into Pleuracanthus, now as P. obtusus. Zidek (1993a) also considers Phricacanthus to be a synonym for Orthacanthus with indeterminate species. Minor similarities can be seen with the spines of $O$. denticulatus. However, $O$. denticulatus has more slender spines and its proximal end does not increase in diameter as in Phricacanthus. In the current state of knowledge, and with the lack of suitable articulated material, it is not certain if Phricacanthus is a xenacanthid. An association with ctenacanthoid elasmobranchs cannot be excluded. Similar spines are known from the Westphalian A in Ireland (Fig. 23c, d).

Only a few skeletal remains are known from British xenacanthids. This is because most of the material was collected as chance discoveries while exploring for productive coal. Fragmentary skeletons of xenacanthid elasmobranchs do exist in
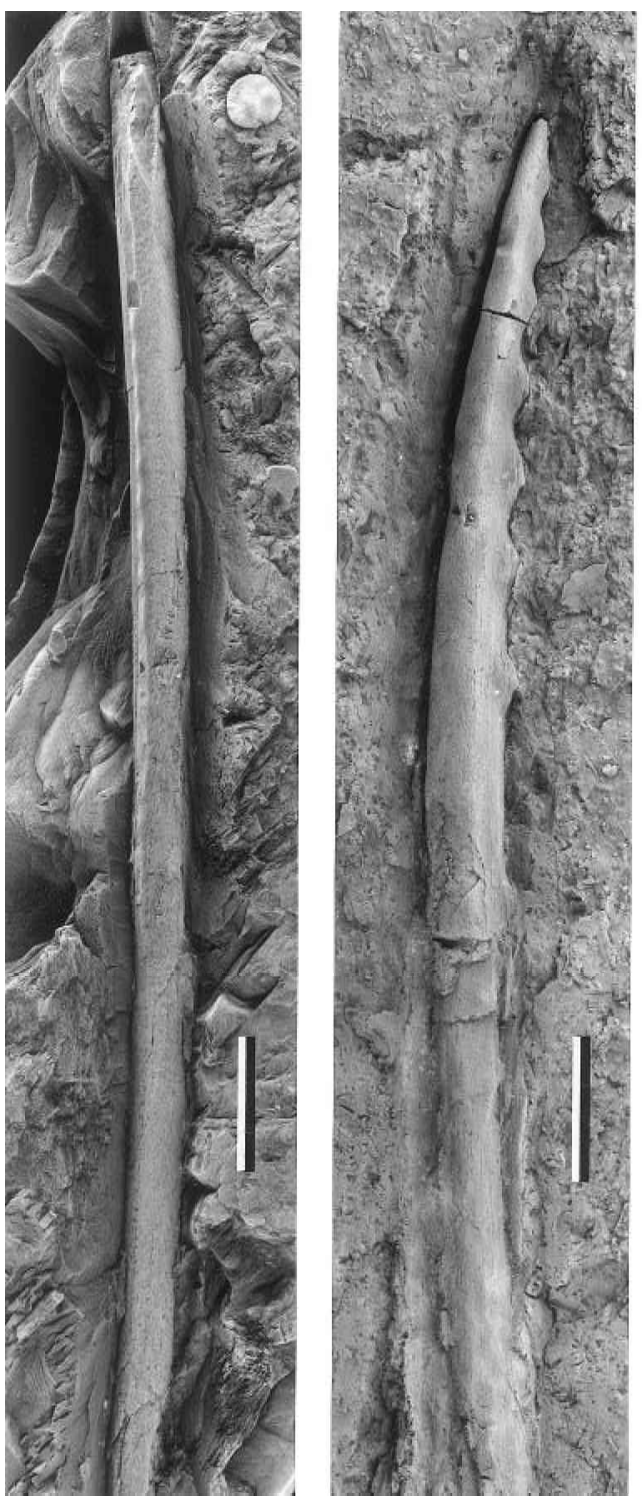
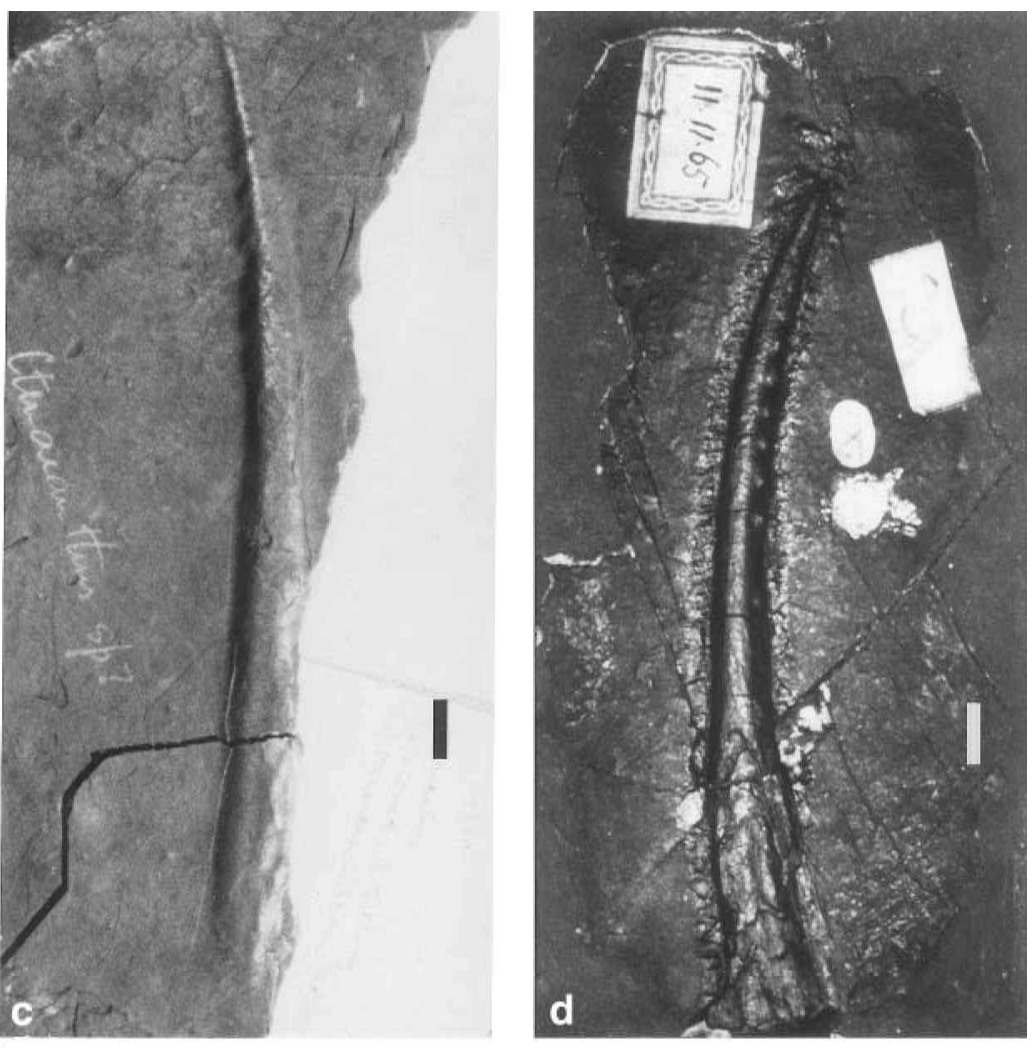

Figure 23 Problematic spines of ?Phricacanthus: (a) BMNH P 7689,?tenuis type spine; (b) BMNH P 7679, biserialis, obtusus, both Westphalian A of Clifton. (c) NMI F 16859, Westphalian A of Castlecomer, Kilkenny. (d) BMNH P 43501, Upper Westphalian A of Clogh. Scale bars, $1 \mathrm{~cm}$. 
addition to the more-or-less complete skeleton of Diplodoselache woodi which was found in 1972, with additional material collected in 1974. The nineteenth-century collections contain scattered head fragments and many radial elements of different fins of Xenacanthus laevissimus (see plates in Davis 1892). Jaw fragments are known from Dicentrodus bicuspidatus (e.g. ceratohyal, fig. 8o). Skeletal remains of the genera Orthacanthus and Triodus have not been recognised with certainty, although cartilages are known from localities yielding teeth of these genera (e.g. Knowles Ironstone of Longton and Fenton, Staffordshire).

In the collections of the Hancock Museum is a slab which preserves conjoined patches of cartilage. This is a xenacanthid neurocranium exposed in ventral view (Fig. 16). Most of the neurocranium is overlain by thin layers of coal shale. The length of the braincase is about $13.6 \mathrm{~cm}$ in the midline and the width is about $10.3 \mathrm{~cm}$ across the postorbital processes. Associated with this braincase are small, $5 \mathrm{~mm}$-high teeth bearing cusps with a lanceolate cross-section and smooth lateral edges. The major part of the slab is unprepared, and the provenance is unknown. The otic plus occipital regions are clearly longer than the ethmoid plus orbital regions, a significant characteristic indicating probably xenacanthid identity, and possibly Xenacanthus itself (only Tamiobatis has these proportions in common with xenacanthids; see Fig. 17). The neurocranium was probably found in a coal-mining area of Northumberland.

Table 2 List, with classification, of valid xenacanthid species referred to in this paper. For synonyms of the British species, see 4 . The generic position of the species antiqua Lebedev 1996 is uncertain. The genus Bransonella Harlton 1933 and the elasmobranch 'Xenacanthus' luedersensis Berman 1970 need further information and/or investigation. 'Anodontacanthus' ruthenorum Chabakov 1928 Antarctilamna prisca Young 1982, and Leonodus carlsi Mader 1986 are not xenacanthids.

\begin{tabular}{|c|c|}
\hline Class: & Chondrichthyes Huxley 1880 \\
\hline Subclass: & Elasmobranchii Bonaparte 1838 \\
\hline Order: & Xenacanthida Glikman 1964 \\
\hline Family: & Diplodoselachidae Dick 1981 \\
\hline Genus: & $\begin{array}{l}\text { Diplodoselache Dick } 1981 \\
\text { Diplodoselache parvulus (Traquair 1881) } \\
\text { Diplodoselache woodi Dick } 1981\end{array}$ \\
\hline Genus: & $\begin{array}{l}\text { Dicentrodus } \text { Traquair 1888a } \\
\text { Dicentrodus bicuspidatus (Traquair 1881) } \\
\text { ?Dicentrodus belemnoides (Zidek 1978) }\end{array}$ \\
\hline Genus: & $\begin{array}{l}\text { Hagenoselache Hampe \& Heidtke } 1997 \\
\text { Hagenoselache sippeli Hampe \& Heidtke } 1997\end{array}$ \\
\hline Genus: & $\begin{array}{l}\text { Lebachacanthus Soler-Gijón } 1997 \\
\text { Lebachacanthus senckenbergianus (Fritsch 1889) } \\
\text { ?Lebachacanthus ventricosus (Fritsch 1889) } \\
\text { ?Lebachacanthus americanus (Hussakof 1911) }\end{array}$ \\
\hline Genus: & $\begin{array}{l}\text { Orthacanthus Agassiz } 1843 \\
\text { Orthacanthus gibbosus (Binney 1840) } \\
\text { Orthacanthus gracilis (Giebel 1848) } \\
\text { Orthacanthus compressus (Newberry 1856) } \\
\text { [= 'Diplodus' gracilis et latus (Newberry 1856)] } \\
\text { Orthacanthus bohemicus Fritsch } 1879 \\
\text { Orthacanthus denticulatus Davis 1880b } \\
\text { Orthacanthus texensis (Cope 1884) } \\
\text { Orthacanthus platypternus (Cope 1884) } \\
\text { Orthacanthus kounoviensis Fritsch 1889 } \\
\text { [=Orthacanthus pinguis Fritsch 1889 } \\
\text { and Orthacanthus buxieri Heyler \& Poplin 1989] } \\
\text { Orthacanthus huberi Zidek 1992 } \\
\text { Orthacanthus meridionalis Soler-Gijón } 1997\end{array}$ \\
\hline
\end{tabular}

Because of the overlying coal shale, only a few details can be discerned. The ethmoidal region is characterised by two parallel elliptical depressions on the internasal plate. The preorbital processes are quite short and directed anteriorly. The following postorbital processes have a small groove on the posterior side distally: the articular fovea for the palatoquadrate(Fig. 16 left). The lateral otic processes are directed posteriorly and the occipital segment shows slight lateral extremities. On the ventral surface the foramina carrying the two dorsal aortic canals can clearly be detected.

Comparisons with neurocrania of other known xenacanthids, as well as with further Palaeozoic elasmobranchs, confirm resemblance with the Xenacanthida. Other Palaeozoic neurocrania show variable outlines, stronger projecting processes (in Bibractopiscis niger, fig. 17), or generally more compact morphology (the symmoriid Akmonistion zangerli, the possible phoebodontid Antarctilamna prisca). The braincase of the ctenacanthoid Tamiobatis vetustus shows a different morphology. Schaeffer (1981) pointed out the similarities with an Orthacanthus texensis ('Xenacanthus sp.') neurocranium. Williams (1998) showed the correspondence of Tamiobatis with ctenacanthoid sharks on the basis of a second specimen associated with typically ctenacanthoid teeth, scales and spines from the Late Devonian Cleveland Shale in Ohio.

The Hancock Museum specimen shares most affinities in outline with Triodus (Fig. 17, middle row). This is displayed in the general proportions and projections of the postorbital

\begin{tabular}{|c|c|}
\hline Family: & incertae sedis \\
\hline Genus: & $\begin{array}{l}\text { Anodontacanthus Davis } 1881 \\
\text { Anodontacanthusalatus (Davis 1880b) } \\
\text { Anodontacanthus triangularis (Davis 1880a) }\end{array}$ \\
\hline Family: & Xenacanthidae Fritsch 1889 \\
\hline Genus: & $\begin{array}{l}\text { Xenacanthus Beyrich } 1848 \\
\text { Xenacanthus laevissimus (Agassiz 1837) } \\
\text { Xenacanthus decheni (Goldfuss 1847) } \\
\text { Xenacanthus elegans (Traquair 1881) } \\
\text { Xenacanthus gaudryi (Brongniart \& Sauvage 1888) } \\
\text { Xenacanthus tenuis Woodward 1889a } \\
\text { Xenacanthus parallelus (Fritsch 1890) } \\
\text { [='Pleuracanthus' ovalis Fritsch 1890] } \\
\text { Xenacanthus oelbergensis Fritsch 1890 }\end{array}$ \\
\hline
\end{tabular}

Xenacanthus meisenheimensis Hampe 1994 Xenacanthus humbergensis Hampe 1994 Xenacanthus remigiusbergensis Hampe 1994 [= Xenacanthus ossiani Johnson 1999] Xenacanthus slaughteri Johnson 1999

Genus:

Triodus Jordan 1849

Triodus sessilis Jordan 1849

Triodus frossardi (Gaudry 1883)

Triodus carinatus (Fritsch 1890)

Triodus serratus (Davis 1892)

Triodus lauterensis Hampe 1989

Triodus palatinus Hampe 1989

Triodus obscurus Hampe 1989

Triodus kraetschmeri Hampe 1989

?Triodus pulchellus (Davis 1880b)

?Triodus moorei (Woodward 1889b)

?Triodus parvidens (Woodward 1908)

?Triodus albuquerquei (Silva Santos 1946)

?Triodus indicus (Jain 1980)

Genus:

Plicatodus Hampe 1995

Plicatodus plicatus (Fritsch 1879)

Plicatodus jordani Hampe 1995

?Plicatodus santosi (Würdig-Maciel 1975) 
and otic processes (angle and extent). The foramina for the paired aorta on the ventral side of the occipital region each possess a rostrally directed elongated groove which is crescentshaped in the British neurocranium but longer and less curved in female T. sessilis (Schwind 1991, pl. 1, fig. 4). A distinct difference to Tamiobatis vetustus is the lack of a tapered rostrum

\section{Phylogenetic implications}

This study of British xenacanthid sharks permits a reassessment of their phylogenetic relationships, although the fundamental question regarding their origins remains unresolved. Earlier analyses (e.g. Hampe \& Long 1999) suggest that phoebodontid elasmobranchs are the most likely ancestors. The Phoebodontidae are currently known only from teeth (Ginter 1998), rather limiting our understanding of this group.

Additional taxa (main character sources in brackets) are included here to support an extended discussion between the different genera for the current phylogenetic analysis. A hypothethical form was chosen for outgroup comparison. The genera Antarctilamna (Middle-Upper Devonian of Antarctica: Young 1982; Long \& Young 1995; Hampe \& Long 1999), Phoebodus (Upper Devonian, nearly worldwide distribution, e.g. Ginter 1990, 1995, 2000; Ginter \& Ivanov 1992, 1995), Adamantina (Tournaisian of Russia: Ivanov 1999 and Upper Permian of E Greenland: Bendix-Almgreen 1993) as well as Cobelodus (Upper Carboniferous of $\mathrm{N}$ America: Zangerl \& Case 1976) are included in the discussion.

In addition to the results presented here, data for Lebachacanthus (Lower Permian, Saar-Nahe basin) are taken from Fritsch (1889), Heidtke (1982, 1998, 1999a), Hampe (1988a) and Soler-Gijón (1997b), for Hagenoselache (Namurian B, Sauerland) from Hampe \& Heidtke (1997), and for Plicatodus (Lower Permian, Saar-Nahebasin, Lower Austria and Bohemia) from Schneider \& Zajíc (1994), Hampe (1995) and Schindler \& Hampe (1996).

The analysis was performed using the heuristic search setting and delayed transformation (DELTRAN) character-state optimisation. A hypothetical outgroup was chosen here because of the taxonomic unconformity of ctencanthoid elasmobranchs which have often been used for outgroup comparison (SolerGijón 1997b; Hampe \& Heidtke 1997; Heidtke 1999a; Hampe \& Long 1999). Twelve distinct features characterise the genera of the Xenacanthida (Fig. 24), of which the lack of a labially positioned nutrient foramina on the tooth base [6] and an undivided, elongated dorsal fin [26] are autapomorphic characters for the Order (node IV). Only the cusp histology, consisting exclusively of orthodentine [10], is a homoplasy with Cobelodus and the reliability of character [29] cannot be established with certainty because of the lack of information in the fossil record.

The closest known relative of the Xenacanthida is Phoebodus. Both share the autapomorphic character of a welldefined coronal button [8]. By contrast, Antarctilamna (sister group of Adamantina) is removed from the xenacanthid sharks. Young (1982) suggested Antarctilamna as a xenacanthid, a position discussed by Maisey (1984, p. 365) and finally accepted by Janvier (1996). This theory was refuted by Hampe \& Long (1999), who pointed out that the Antarctic genus is more similar to phoebodontid or phalacanthoid elasmobranchs (see morphology of the braincase and spine, Young 1982, text-fig. 5-7, pl. 87, 88).

The family Xenacanthidae is supported by at least seven characters, of which two are autapomorphic: a dorso-ventrally compressed spine with clearly laterally positioned rows of

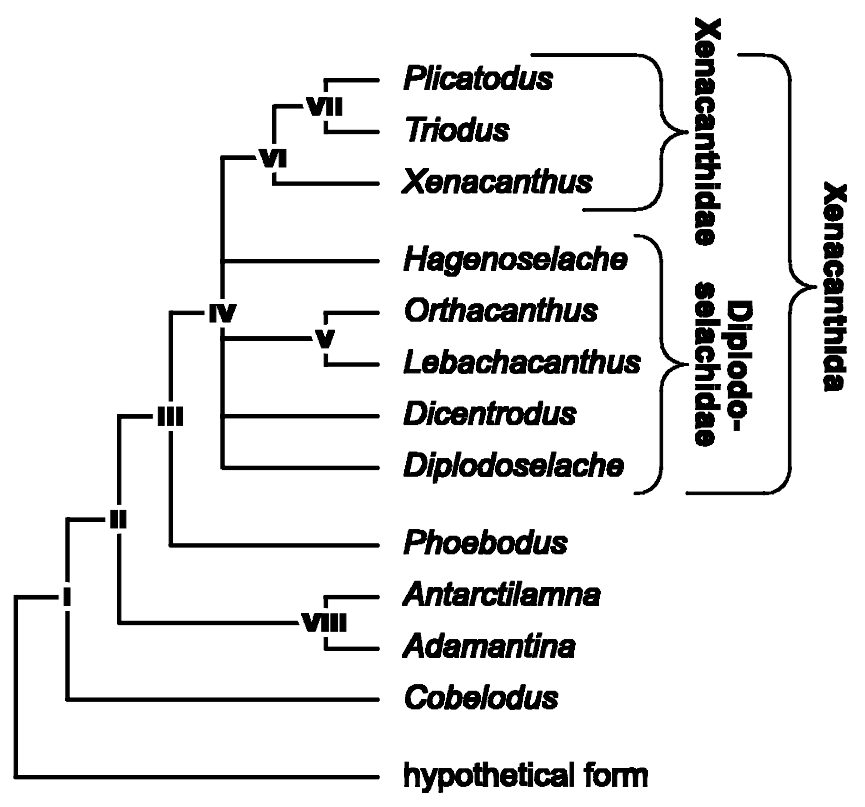

Figure 24 Phylogenetic relationships of xenacanthid sharks [consensus of eight trees; heuristic search setting; optimisation DELTRAN with hypothetical outgroup; tree length $\supset 68$; consistency index (CI) $\supset 0 \cdot 809$; consistency index excluding uninformative characters $\supset$ 0.701 ; retention index $\supset 0.768$; rescaled consistency index $\supset 0.621]$. Explanations, nodal character states, see text.

denticles [14], and the bibasal articulation of the pectoral fins [23].

Concerning the often-discussed distinction between Lebachacanthus and Orthacanthus, Fritsch (1889), later followed by Zidek (1993a), referred to differences in the spine position and morphology of various species of Orthacanthus (cranial spine in $O$. bohemicus from the Westfalian $\mathrm{D}$, Plzen basin), while Soler-Gijón (1997b, 2000) argued for the erection of a new family, Lebachacanthidae, for Lebachacanthus. Heidtke (1998, 1999a) maintained the same distinction, but at the subgenus level. However, Heyler \& Poplin (1989) had previously erected for Orthacanthus the new family Orthacanthidae. Both families were erected on the morphology of the wellknown, completely preserved species 'O.' senckenbergianus (Heyler \& Poplin 1989 as Orthacanthus, Soler-Gijón 1997 as Lebachacanthus n. gen.). Many characters used as diagnostic features by the authors cited above are also known in other xenacanthids, or are plesiomorphic characters, e.g. serrated crown (Soler-Gijón 1997; Heidtke 1998, also in Dicentrodus: this paper), tiny central cusp (Heyler \& Poplin 1989, also in Diplodoselache: Dick 1981, this paper), median foramen on the upper side in front of the median cusp (Heidtke 1998, also in Hagenoselache and some Triodus species: Hampe 1989, 1994; Hampe \& Heidtke 1997), circular cross-section of the spine bearing two parallel ventral rows of denticles (Heyler \& Poplin 1989, also in Diplodoselache, Dicentrodus: this paper), short, stout, circular dorsal spine ('dorsal spine type B', Soler-Gijón 1997, also in Diplodoselache, Dicentrodus), and dermal denticles of 'Cladodus' pattersoni type (Soler-Gijón 1997, also in Triodus: Hampe 1997b).

The more primitive xenacanthids are grouped in the family Diplodoselachidae based on the dorsal spine which always has a rounded cross-section and a ventrally arranged double row of denticles: autapomorphic character [14]. Anodontacanthus was left out of the analysis because it has too many unknown character states in the matrix (only spine morphology is known). 


\subsection{Characters scored for cladistic analysis}

[1] Teeth multicuspid (0), tricuspid (1), bicuspid (2), monocuspid (3).

[2] No median cusp developed (0), median cusp seldom of equal length to the laterals, but mostly distinctly longercladodont bauplan (1), median cusp always shorter than laterals (2).

[3] Cusps without lateral cutting edges (0), cusps lanceolate with lateral edges always smooth (1), edges muricated (2), edges serrated (3).

[4] No crescent-shaped incline of the cusps (0), crescentshaped distal incline developed (1).

[5] Vertical cristae always straight (0), cristae of wavy design (1), lack of vertical cristae (2).

[6] Labially positioned nutrient foramina on the tooth base present (0), lack of labial foramina (1).

[7] Outline of the base exclusively mesio-distally widened (0), outline usually rounded or labio-lingually stretched (1).

[8] No distinctly developed coronal button on the upper side of the base (0), well-defined coronal button present (1).

[9] No basal tubercle developed on the bottom side of the base (0), bottom side of base with a prominently developed, halfmoon-shaped basal tubercle (1), closed and rounded with concave depression (2), rounded without depression (3).

[10] Crown of teeth (cusps) consisted of trabecular dentine (0), cusp with only basal cone-like trabecular dentine coreremaining tissue orthodentine (1), exclusively orthodentine (2).

[11] Base of teeth consists of trabecular dentine (0), base consists of orthodentine (1).

[12] Enameloid-like cover present (0), enameloid absent (1).

[13] Dorsal spine not cranial (0), dorsal spine cranial (1).

[14] Dorsal spine triangular or laterally compressed (0), dorsal spine of rounded cross-section with ventrally arranged double row of denticles (1), spine dorso-ventrally compressed with clearly laterally positioned rows of denticles (2).

[15] Adult dorsal spine robust with an overall length/maximum width ratio $(\leqslant 1: 12(0)$, dorsal spine slender with a ratio $>1: 12(1)$.

[16] Dorsal spine curved (0), spine regularly straight (1).

[17] Dorsal spine with strong longitudinal ridges and grooves (0), irregular, bark-like surface structure (1), relatively smooth surface including delicate striations (2).

[18] Regio oticalis + occipitalis of the neurocranium in relation to regio ethmoidalis + orbitalis of more or less equal length $(0)$, regio oticalis + regio occipitalis distinctly longer than regio ethmoidalis + regio orbitalis (1).

[19] Postorbital process projected backwards (0), postorbital process not projected sideways or anteriorly (1).

[20] Neurocranium without tapered rostrum (0), tapered rostrum present (1).

[21] Foramina for paired dorsal aorta absent (0), foramina for paired dorsal aorta + efferent hyoidean artery present (1), only foramina for paired dorsal aorta present (no perforation for efferent hyoidean artery) (2).

[22] Pectoral fins not of archipterygium type (0), biserial archipterygium (1).

[23] Articulation of pectoral fins multibasal with additional anterior basal elements (0), articulation tribasal (1), bibasal-propterygium lost (2), monobasal-propterygium and mesopterygium lost (3).

[24] No basipterygoidal axis developed (0), division of the basipterygoidal axis of the pelvic fin with increased number $(>5)$ of segments (1), basipterygoidal axis in five or fewer segments (2).
[25] Pterygopodials without medial hook developed (0), distal hypertrophied medial hook present (1).

[26] Development of short sail-shaped dorsal fins (0), undivided, elongated dorsal fin (1).

[27] Caudal fin heterocercal (0), caudal fin diphycercal (1).

[28] No major axis present in the hypochordal lobe (0), hypochordal lobe developed an axial structure (1).

[29] Anal fin absent (0), division of the skeleton of the anal fin into five or fewer segments (1), division into eight radials (2).

[30] Dermal denticles multicuspid or shovel-shaped with strong ornamentation (0), integument of monocuspid dermal denticles of 'non-growing' type (1).

\subsection{Nodal character states (bold $\supset$ autapomorphies)}

Node I [1] 0-1, [25] 0-1

Node II [2] 0-2, [7] 0-1, [12]0-1, [16]0-1, [19] 0-1, [21] $0-1$

Node III $\quad[\mathbf{8}] \mathbf{0}-\mathbf{1}$

Node IV [6] 0-1, [9] 0-2, [10] 0-2, [14] 0-1, [17] 0-2, [18] $0-1,[22] 0-1,[23] 0-1,[24] 0-1$, [26] 0-1, [29] 0$2,[30] 0-1$

Node V [3] 0-3, [5] 0-2, [9] 2-3, [20] 0-1, [24] 1-2

Node VI [13] 0-1, [14] 1-2, [15] 0-1, [23] 1-2, [24] 2-1, [27] $0-1,[28] 0-1$

Node VII [11] $0-1$

Node VIII [5] 0-1

Plicatodus [5] 0-1

Triodus [21] 1-2

Xenacanthus [3] 0-1

Hagenoselache [11] 0-1, [23] 1-3, [29] 2-1, [24] 1-2

Orthacanthus [13] 0-1, [15] 0-1

Lebachacanthus [28] 0-1

Dicentrodus [1] 1-2, [2] 2-0, [3] 0-3, [4] 0-1, [5] 0-2, [7] 1-0, [10] 2-1, [17] 2-1

Diplodoselache [3] 0-2, [10]2-1, [17] 2-1, [22] 1-0, [30] 1-0

Phoebodus [1] 1-0, [2] 2-1, [9] 0-1

Antarctilamna ./.

Adamantina ./.

Cobelodus [10] 0-2, [20] 0-1, [21] 0-2

\section{Conclusions}

(1) Six genera and fourteen species of British Xenacanthida can be distinguished after systematic revision. They first appear in the Viséan and are found throughout the Carboniferous except in the Namurian Millstone Grit deposits.

(2) The unique characters of the Early Carboniferous Diplodoselache suggest that this early taxon represents a dead end in xenacanthid evolution. The Early Carboniferous Brazilian Xenacanthus tocantinsensis, is, if correctly dated, the oldest Xenacanthus known so far. That implies either parallel development with Diplodoselache, or that a common ancestor of Diplodoselache and Xenacanthus must be found somewhat earlier in Earth's history.

(3) Dicentrodus, formerly described as Cladodus (Traquair 1881), belongs to the xenacanthids.

(4) Orthacanthus kounoviensis is known from the Pennines, the Saar-Nahe basin, the Saale depression and in Bohemia, indicating that faunal exchange took place between these intramontainous basins during the Carboniferous. Connections must have persisted through Westphalian and Stephanian times, allowing interbasinal migrations as well as migration between the Palaeo-Tethys sea and single basins (Schneider et al. 2000). Thus, Schindler \& 
Hampe (1996) note a southern connection between the Zöbing area in Austria and the Boskovice furrow in Bohemia with marine deposits of the Alps. The similarities between $O$. kounoviensis and the Autunian O. buxieri of France suggest that the French species is only a geographic variant of $O$. kounoviensis.

(5) No further material than spines could be assigned to Anodontacanthus.

(6) Some faunal elements probably immigrated from other palaeogeographic regions. The German $X$. remigiusbergensis and the $\mathrm{N}$ American $X$. ossiani can be considered as conspecific. However, it remains uncertain as to how and why $X$. remigiusbergensis travelled 'through' the Appalachian-Hercynian mountain range which formed a barrier for Orthacanthus. N American species of Orthacanthus developed separately behind the barrier and are quite different from the European representatives of the genus (Johnson 1999). Boy \& Schindler (2000, p. 103) discuss an immigration of $\mathrm{N}$ American fishes like the hybodont Lissodus zideki (Johnson 1981; Schneider et al. 2000) and the lungfish Gnathoriza (Berman 1976) from $\mathrm{W}$ to $\mathrm{E}$ into the German basins (Early Permian 'Remigiusberg' Invasion).

(7) Xenacanthus laevissimus teeth show a mosaic of characters which permit the establishment of morphotypes. The Lower Permian $X$. humbergensis from the SW German Saar-Nahe basin seems to be a Permian successor of one of the morphotypes.

(8) Mosaic characters can often be observed in xenacanthid teeth represented by a large number of specimens. It is then necessary to filter the principal characterisation in order to work with relationships based on phylogenetic analyses. The variation shown by xenacanthid taxa can be established with some confidence for the European material, where all genera are represented by large numbers of specimens, including articulated material. Arguments based upon single and specific features to the neglect of accessory characters are inadequate in the identification of xenacanthid remains. In articulated specimens, Woodward (1891) suggested that different types of xenacanthid teeth can occur in a single species (see also Davis 1892).

(9) The small xenacanthid Triodus, mostly known from the Lower Permian of the Saar-Nahe basin, is identified from British deposits for the first time.

(10) Fossil xenacanthid remains from France formerly described as 'Expleuracanthus' are assigned to Xenacanthus or Triodus (this paper and Soler-Gijón \& Hampe 1998). There remains no significant character with which to define and maintain 'Expleuracanthus' which was introduced by Heyler (1969).

(11) The cladistic analysis indicates that Phoebodus has a close relationship with the Xenacanthida. Phoebodontid elasmobranchs were probably ancestral to the xenacanthids, and this is consistent with their stratigraphic distribution (Givetian to Famennian; e.g. Ginter \& Ivanov 2000). However, phoebodonts are so far only known on the basis of isolated teeth, limiting their usefulness. The Middle Devonian Antarctilamna is not a xenacanthid shark.

(12) The more primitive xenacanthids, except Anodontacanthus, are united in the family Diplodoselachidae.
(13) The stratigraphicalcorrelation of the xenacanthid-bearing localities in the British Isles was studied in parallel with the systematic revision. This indicates that Diplodoselache appears in the Dinantian only and that Dicentrodus is currently restricted to the Pendleian. Orthacanthus gibbosus and Xenacanthus laevissimus occur throughout the entire Westphalian.

\section{Acknowledgements}

I am greatly indebted to the following persons, colleagues, and cooperative partners for all their kind assistance. Without their help, this revision would not have been possible.

For access to the collections I would particularly like to thank (in alphabetical order): Alison Armstrong, Cliffe Castle Museum, Keighley; Gaynor Boon, Sheffield City Museum; Jenny Clack, University Museum of Zoology, Cambridge; Neil Clark, Hunterian Museum, Glasgow; Thomas Engel, Naturhistorisches Museum, Mainz; Paul Ensom, Yorkshire Museum, now The Natural History Museum, London; Peter L. Forey, The Natural History Museum, London; Helen Fothergill, Sunderland Museum \& Art Gallery; Alastair Gunning, Kelvingrove Art Gallery and Museum, Glasgow; Ivor P. Harkin, National Museum of Ireland, Dublin; Rod Long, Sedgwick Museum, Cambridge; Alison Longbottom, The Natural History Museum, London; John Martin, Leicestershire Museums \& Art Gallery; Steve McLean, The Hancock Museum, Newcastle upon Tyne; Dave Norman, Sedgwick Museum, Cambridge; John R. Nudds, The Manchester Museum; Roberta L. Paton, Royal Museum of Scotland, Edinburgh; Jon D. Radley, Bristol City Museum \& Art Gallery; Don Stewart, City Museum Stoke-on-Trent; Michael A. Taylor, Royal Museum of Scotland, Edinburgh; Steve Tunnicliff, British Geological Survey, Nottingham; Patrick N. Wyse Jackson, Trinity College - Geological Museum, Dublin; Sally V.T. Young, The Natural History Museum, London.

For preparation of specimens, photography, illustrations, and other information I would especially like to thank: Lutz Berner, Waltraud Harre and Carola Radke, all Museum für Naturkunde Berlin; Phil Hurst, The Natural History Museum London; Jörg-Peter Mendau, Museum für Naturkunde, Berlin; Armin Otto, Freie Universität Berlin; Karl Schuchmann, Institut für Geowissenschaften-Universität Mainz; Stephan Schultka and Elke Siebert, both Museum für Naturkunde, Berlin; Don T.J. Smith, University of Derby; David M. Unwin, Museum für Naturkunde, Berlin.

For a series of most helpful and fruitful discussions, I convey my cordial thanks to: Jürgen A. Boy, Institut für Geowissenschaften-Universität Mainz; Chris J. Cleal, National Museum of Wales, Cardiff; Chris Duffin, Sutton, Surrey; Ulrich H.J. Heidtke, Pfalzmuseum für Naturkunde, Bad Dürkheim; Hans-Peter Schultze and Rodrigo Soler-Gijón, both Museum für Naturkunde, Berlin; Susan Turner, Queensland Museum, Brisbane.

I am also extremely grateful to the Deutsche Forschungsgemeinschaft for their financial support during the years 1996-8.

Finally, I would like to thank John G. Maisey, American Museum of Natural History, New York; Michael Ginter, Warsaw University; and Michael I. Coates, University of Chicago, for their careful review of the manuscript. 


\section{Character matrix}

\begin{tabular}{|c|c|c|c|c|c|}
\hline & 1 & & & & \\
\hline Hypothetical form & 0 & 0 & 0 & 0 & 0 \\
\hline Phoebodus & 0 & 1 & 0 & 0 & $0 \& 1$ \\
\hline Antarctilamna & $0 \& 1$ & 2 & 0 & 0 & 1 \\
\hline Adamantina & 1 & 2 & 0 & 0 & 1 \\
\hline Cobelodus & $1 \& 3$ & $0 \& 1$ & 0 & 0 & 0 \\
\hline Diplodoselache & 1 & 2 & 2 & 0 & 0 \\
\hline Dicentrodus & 2 & 0 & 3 & 1 & 2 \\
\hline Lebachacanthus & 1 & 2 & 3 & 0 & 2 \\
\hline Hagenoselache & 1 & 2 & 0 & 0 & 0 \\
\hline Orthacanthus & 1 & 2 & 3 & $0 \& 1$ & 2 \\
\hline Xenacanthus & 1 & 2 & 1 & 0 & $0 \& 2$ \\
\hline Triodus & 1 & 2 & 0 & 0 & 0 \\
\hline Plicatodus & 1 & 2 & 0 & 0 & 1 \\
\hline
\end{tabular}

$\begin{array}{lllll}11 & & & & \\ / & & & & \\ 0 & 0 & 0 & 0 & 0 \\ 0 & 0 \& 1 & ? & ? & ? \\ 0 & 1 & 0 & 0 & 0 \\ ? & ? & ? & ? & ? \\ ? & ? & 0 & ? & ? \\ 0 & 1 & 0 & 1 & 0 \\ 0 & 1 & 0 & 1 & 0 \\ 0 & 1 & 0 & 1 & 0 \\ 1 & 1 & ? & ? & ? \\ 0 & 1 & 1 & 1 & 1 \\ 0 & 1 & 1 & 2 & 1 \\ 1 & 1 & 1 & 2 & 1 \\ 1 & 1 & 1 & 2 & 1\end{array}$

$\begin{array}{llllll} & 16 & & & & \\ \text { Hypothetical form } & \text { / } & & & & \\ \text { Phoebodus } & ? & ? & ? & ? & ? \\ \text { Antarctilamna } & 1 & 0 & 0 & 1 & 0 \\ \text { Adamantina } & ? & ? & ? & ? & ? \\ \text { Cobelodus } & ? & ? & 0 & 0 & 1 \\ \text { Diplodoselache } & 1 & 1 & ? & ? & ? \\ \text { Dicentrodus } & 1 & 1 & ? & ? & ? \\ \text { Lebachacanthus } & 1 & 2 & 1 & 1 & 1 \\ \text { Hagenoselache } & ? & ? & 1 & 1 & ? \\ \text { Orthacanthus } & 0 \& 1 & 2 & 1 & 1 & 1 \\ \text { Xenacanthus } & 1 & 2 & 1 & 1 & 0 \\ \text { Triodus } & 1 & 2 & 1 & 1 & 0 \& 1 \\ \text { Plicatodus } & 1 & 2 & ? & ? & ?\end{array}$

\section{References}

Agassiz, L. 1837. Recherches sur les Poissons fossiles. Vol. 3, Contenant l'Histoire de l'Ordre des Placö̈des, 1-72. Neuchâtel: Petitpierre.

Agassiz, L. 1843. Recherches sur les Poissons fossiles. Vol. 3, Contenant l'Histoire de l'Ordre des Placö̈des, 157-390. Neuchâtel: Petitpierre.

Andrews, S. M. 1982. The discovery of fossil fishes in Scotland up to 1845 with checklists of Agassiz's figured specimens. Edinburgh: Royal Scottish Museum.

Barkas, T. P. 1873. Illustrated guide to the fish, amphibian, reptilian, and supposed mammalian remains of the Northumberland Carboniferous strata. London: Hutchings.

Barkas, J. W. 1874. On the microscopical structure of fossil fishes from the Northumberland True Coal Measures. Chapter II. The Monthly Review of Dental Surgery 2, 344-9.

Bendix-Almgreen, S. E. 1976. Palaeovertebrate faunas of Greenland. In Escher, A. \& Watt, W.S. (eds) Geology of Greenland, 537-73. Copenhagen: Grønlands Geologiske Undersøgelse.

Bendix-Almgreen, S. E. 1993. Adamantina benedictae n.g et sp.-an nyhed fra Østgrønlands marine Øvre Perm. In Johnsen, O. (ed.) Geologisk Museum 100 År på Østervold, 48-58. Copenhagen: Rhodos.

Berman, D. S. 1970. Vertebrate fossils from the Lueders Formation, Lower Permian of north-central Texas. University of California Publications, Geological Sciences 86, 1-39.

Berman, D. S. 1976. Cranial morphology of the Lower Permian lungfish Gnathoriza (Osteichthyes: Dipnoi). Journal of Paleontology 50(6), 1020-33.

Beyrich, E. 1848. Über Xenacanthus decheni und Holacanthus gracilis, zwei Fische aus der Formation des Rothliegenden in Norddeutschland. Berichte der Königlich-Preussischen Akademie der Wissenschaften 1848, 24-33.

Binney, E. W. 1840. On the fossil fishes of the Pendleton Coal Field. Transactions of the Geological Society of Manchester 1840, 153-78.

Bonaparte, C. L. P. 1838. Introduzione alla Classie IV. Pesci. Iconografia della Fauna Italica per le quattro Classi degli Animali Vertebrati, Vol. 3. Rome: Salviucci.

Boy, J. A. 1976. Überblick über die Fauna des saarpfälzischen Rotliegenden (Unter-Perm). Mainzer geowissenschaftliche Mitteilungen $5,13-85$.

Boy, J. A. \& Schindler, T. 2000. Ökostratigraphische Bioevents im Grenzbereich Stephanium/Autunium (höchstes Karbon) des Saar-Nahe-Beckens (SW-Deutschland) und benachbarter Gebiete.

$\begin{array}{lllll}21 & & & & \\ / & & & & \\ 0 & 0 & 0 & 0 & 0 \\ ? & ? & ? & ? & ? \\ 1 & ? & ? & ? & ? \\ ? & ? & ? & ? & ? \\ 2 & 0 & 0 & 0 & 1 \\ ? & 0 & 1 & 1 & ? \\ ? & ? & ? & ? & ? \\ ? & 1 & 1 & 2 & 1 \\ ? & 1 & 3 & 2 & 1 \\ 1 & 1 & 1 & ? & ? \\ 1 & 1 & 2 & 1 & 1 \\ 2 & 1 & 2 & 1 & 1 \\ ? & ? & ? & ? & ?\end{array}$

$\begin{array}{lllll}26 & & & & \\ / & & & & \\ 0 & 0 & 0 & 0 & 0 \\ ? & ? & ? & ? & ? \\ ? & ? & ? & ? & 0 \\ ? & ? & ? & ? & 0 \\ 0 & 0 & 0 & 0 & ? \\ 1 & 0 & 0 & 2 & 0 \\ ? & ? & ? & ? & ? \\ 1 & 0 & 1 & 2 & 1 \\ 1 & 0 & 0 & 1 & 1 \\ 1 & ? & ? & ? & ? \\ 1 & 1 & 1 & 2 & ? \\ 1 & 1 & 1 & 2 & 1 \\ ? & ? & ? & ? & ?\end{array}$

Neues Jahrbuch für Geologie und Paläontologie Abhandlungen 216(1), 89-152.

Brongniart, M. C. \& Sauvage, M. E. 1888. Faunes ichthyologique et entomologique. Bulletin de la Société de l'Industrie minérale, 3. série 2, 1-120.

Cadell, H. M. \& Wilson, J. S. G. 1906. The Oil-Shales of the Lothians. Part 1. The Geology of the Oil-Shale Fields. Glasgow: Memoirs of the Geological Survey of Scotland.

Cameron, I. B. \& Stephenson, D. 1985. British regional geology. The Midland Valley of Scotland. London: British Geological Survey.

Carruthers, R. G., Caldwell, W., Bailey, E. M. \& Conacher, H. R. J. 1927. The Oil-Shales of the Lothians. Edinburgh: Memoirs of the Geological Survey of Scotland.

Chabakov, A.W. 1928. Anodontacanthus ruthenorum sp. n., novyi ikhtiodorulit iz permskikh otlozhenii Evropeiskoi chasti SSSR. Annuaire de la Société Paléontologique de Russie 7, 127-32.

Cleal, C. J. 1997. The palaeobotany of the upper Westphalian and Stephanian of southern Britain and its geological significance. Review of Palaeobotany and Palynology 95, 227-53.

Cleal, C. J. \& Thomas, B. A. 1994. Plant fossils of the British Coal Measures. Palaeontological Association Field Guide to Fossils 6, $1-222$.

Cleal, C. J. \& Thomas, B. A. 1995. Palaeozoic palaeobotany of Great Britain. London: Chapman \& Hall.

Cleal, C. J. \& Thomas, B. A. 1996. British Upper Carboniferous stratigraphy. London: Chapman \& Hall.

Clough, C. T., Hinxman, L. W., Wilson, J. S. G., Crampton, C. B., Wright, W. B., Bailey, E. B., Anderson, E. M. \& Carruthers, R. G. 1911. The geology of the Glasgow District. Edinburgh: Memoirs of the Geological Survey of Scotland.

Coates, M. I. \& Sequeira, S. E. K. 1998. The braincase of a primitive shark. Transactions of the Royal Society of Edinburgh: Earth Sciences 89, 63-85.

Coates, M. I. \& Sequeira, S. E. K. 2001. A new stethacanthid chondrichthyan from the Lower Carboniferous of Bearsden, Scotland. Journal of Vertebrate Paleontology 21, 438-59.

Cope, E. D. 1884. On the structure of the skull in the elasmobranch genus Didymodus. Proceedings of the American Philosophical Society 21, 572-90.

Cox, L. R. 1926. Anthracopupa britannica sp. nov., a land gastropod from the Red Beds of the Uppermost Coal-Measures of Northern Worcestershire. Quarterly Journal of the Geological Society of London 82, 401-10. 
Davis, J. W. 1879. Notes on Pleurodus affinis, sp. ined., Agassiz, and description of three spines of cestracionts from the Lower CoalMeasures. Quarterly Journal of the Geological Society of London 35, 181-8.

Davis, J. W. 1880a. On the fish-remains found in the Cannel Coal in the Middle Coal-Measures of the West Riding of Yorkshire, with the description of some new species. Quarterly Journal of the Geological Society of London 36, 56-67.

Davis, J. W. 1880b. On the genus Pleuracanthus, Agass., including Orthacanthus, Agass., and Goldf., Diplodus, Agass., and Xenacanthus, Beyr. Quarterly Journal of the Geological Society of London 36, 321-36.

Davis, J. W. 1880c. On the distribution of fossil fishes in the Yorkshire Coal Fields. Proceedings of the Yorkshire Geological Society 7, $228-41$.

Davis, J. W. 1881. On Anodontacanthus, a new genus of fossil fishes from the Coal-Measures; with descriptions of three new species. Quarterly Journal of the Geological Society of London 37, 427-9.

Davis, J. W. 1883. On the fossil fishes of the Carboniferous Limestone Series of Great Britain. The Scientific Transactions of the Royal Dublin Society 1, 327-548.

Davis, J. W. 1892. On the fossil fish-remains of the coal measures of the British Islands. The Scientific Transactions of the Royal Dublin Society 4, 703-48

Dick, J. R. F. 1981. Diplodoselache woodi gen. et sp. nov., an early Carboniferous shark from the Midland Valley of Scotland. Transactions of the Royal Society of Edinburgh: Earth Sciences 72, 99-113.

Dick, J. R. F., Coates, M. I. \& Rolfe, W. D. I. 1986. Fossil sharks. Geology Today 2, 82-4.

Donelan, C. \& Johnson, G. D. 1997. Orthacanthus platypternus (Chondrichthyes: Xenacanthida) occipital spines from the Lower Permian Craddock Bonebed, Baylor County, Texas. Journal of Vertebrate Paleontology Supplement 17(3), 43A.

Duffin, C. J. 1981. The fin spine of a new holocephalan from the Lower Jurassic of Lyme Regis, Dorset, England. Géobios 14, 469-75.

Duffin, C. J. 1993. Late Triassic sharks teeth (Chondrichthyes, Elasmobranchii) from Saint-Nicolas-de-Port (north-east France). Belgian Geological Survey Professional Paper 264: Elasmobranches et Stratigraphie, 7-32.

Duffin, C. J., Richter, M. \& Neis, P. A. 1996. Shark remains from the Late Carboniferous of the Amazon Basin, Brazil. Neues Jahrbuch für Geologie und Paläontologie Monatshefte 1996(4), 232-56.

Edwards, W., Wray, D. A. \& Mitchell, G. H. 1940. Geology of the country around Wakefield. London: British Geological Survey.

Edwards, W., Mitchell, G. H. \& Whitehead, T. H. 1950. Geology of the district north and east of Leeds. London: British Geological Survey.

Edwards, W. \& Trotter, F. M. 1954. British Regional Geology. The Pennines and adjacent areas. London: British Geological Survey.

Evans, W. B., Wilson, A. A., Taylor, B. J \& Price, D. 1968 Geology of the Country around Macclesfield, Congleton, Crewe and Middlewich. London: Memoirs of the Geological Survey Great Britain.

Flint, S., Aitken, J. \& Hampson, G. 1995. Application of sequence stratigraphy to coal-bearing coastal plain successions: implications for the UK Coal Measures. In Whateley, M. K. G. \& Spears, D. A. (eds) European Coal Geology. Geological Society, London, Special Publication 82, 1-16.

Flügel, E., Kiessling, W. \& Golonka, J. 2001. Paleo Reef DatabaseA database of Phanerozoic reefs with graphic presentations. http:// www.geol.uni-erlangen.de/pal/palreef/sl12.gif

Forsyth, I. H., Hall, I. H. S. \& McMillan, A. A. 1996. Geology of the Airdrie district. London: British Geological Survey.

Fowler, A. 1936. The geology of the country around Rothbury, Amble and Ashington. London: Memoirs of the Geological Survey of England and Wales.

Fox-Strangways, C. 1900. The geology of the country between Atherstone and Charnwood Forest. London: Memoirs of the Geological Survey of England and Wales.

Fritsch, A. 1879. Fauna der Gaskohle und der Kalksteine der Permformation Böhmens, Vol. 1(1), 1-92. Prague: Řivnáč.

Fritsch, A. 1889. Fauna der Gaskohle und der Kalksteine der Permformation Böhmens, Vol. 2(4), 93-114. Prague: Řivnáč.

Fritsch, A. 1890. Fauna der Gaskohle und der Kalksteine der Permformation Böhmens, Vol. 3(1), 1-48. Prague: Řvnáč.

Garner, R. 1844. The Natural History of the County of Stafford; comprising its geology, zoology, botany, and meteorology: also its antiquities, topography, manufactures, etc. London: van Voorst.

Gaudry, A. 1883. Les enchainements du monde animal dans les temps géologiques. Fossiles Primaires. Paris: Libraire F. Savy.

Geikie, A. 1902. The geology of Eastern Fife: Being a description of sheet 41 and parts of sheets 40, 48, and 49 of the geologicalmap. Glasgow: Memoirs of the Geological Survey of Scotland.
George, T. N., Johnson, G. A. L., Mitchell, M., Prentice, J. E., Ramsbottom, W. H. C., Sevastopulo, G. D. \& Wilson, R. B. 1976. A correlation of Dinantian rocks in the British Isles. Geological Society Special Report 7, 1-87.

German Stratigraphic Commission (ed.) 2002. Stratigraphic Table of Germany 2002. Potsdam: Stein.

Gibson, W. 1905. The geology of the North Staffordshire coalfields. London: Memoirs of the Geological Survey of England.

Gibson, W. 1925. The geology of the country around Stoke-upon-Trent. London: Memoirs of the Geological Survey of England.

Gibson, W. 1927. Coal in Great Britain. The composition, structure, and resources of the coalfields, visible and concealed, of Great Britain. London: Edward Arnold \& Co.

Giebel, C. G. 1848. Fauna der Vorwelt mit steter Berücksichtigung der lebenden Thiere, Vol 1, Wirbelthiere. Abt. 3: Fische. Leipzig: Brockhaus.

Giebel, C. G. 1849. Fischüberreste. In Germar, E. F. (ed.) Die Versteinerungen des Steinkohlengebirges von Wettin und Löbejün im Saalkreise, Vol. 6, 69-79. Halle: Schwetschke und Sohn.

Ginter, M. 1990. Late Famennian shark teeth from the Holy Cross Mts, Central Poland. Acta Geologica Polonica 40(1-2), 69-81.

Ginter, M. 1995. Ichthyoliths and Late Devonian events in Poland and Germany. Ichthyolith Issues Special Publication 1, 23-30.

Ginter, M. 1998. Taxonomic problems with Carboniferous 'Cladodontlevel' sharks' teeth. Ichthyolith Issues Special Publication 4, 14-16.

Ginter, M. 1999. Famennian-Tournaisian chondrichthyan microremains from the Eastern Thuringian Slate Mountains. Abhandlungen und Berichte für Naturkunde 21, 25-47.

Ginter, M. 2000. Late Famennian pelagic shark assemblages. Acta Geologica Polonica 50(3), 369-86.

Ginter, M. \& Ivanov, A. 1992. Devonian phoebodont shark teeth. Acta Palaeontologica Polonica 37(1), 55-75.

Ginter, M. \& Ivanov, A. 1995. Middle/Late Devonian Phoebodontbased ichthyolith zonation. In Lelièvre, H., Wenz, S., Blieck, A. \& Cloutier, R. (eds) Premiers Vertébrés et Vertébrés inférieurs. Géobios Mémoire spécial 19, 351-5.

Ginter, M. \& Ivanov, A. 1996. Relationships of Phoebodus. Modern Geology 20, 263-74.

Ginter, M. \& Ivanov, A. 2000. Stratigraphic distribution of chondrichthyans in the Devonian on the East European Platform margin. Courier Forschungsinstitut Senckenberg 223, 325-39.

Glikman, L. S. 1964. Klass Chondrichthyes, Podklass Elasmobranchii. In Orlov, Y.A. (ed.) Osnovy Paleontologii, 11. Agnathes, Pisces, 195-236. Moscow: Nauka.

Goldfuss, G. A. 1847. Beiträge zur vorweltlichen Fauna des Steinkohlengebirges. Bonn: Henry \& Cohen.

Goto, M., Kaneko, N., Suzuki, Y. \& Okura, M. 2000. First record of a xenacanth shark tooth from the Palaeozoic of Japan. Journal of the Geological Society of Japan 106(11), 737-42.

Griffith, E., Pidgeon, E. \& Gray, G. 1832. The class Insecta arranged by the Baron Cuvier with supplementary additions to each order. In Griffith, E. (ed.) The animal kingdom arranged in conformity with its organization, by the Baron Cuvier, member of the institute of France, \&c. \&c. \&c. with supplementary additions to each order, Vol. 14, 1-570. London: Whittaker, Treacher, and Co.

Hains, B. A. \& Horton, A. 1969. British Regional Geology. Central England. London: British Geological Survey.

Hamblin, R. J. O. \& Coppack, B. C. 1995. Geology of Telford and the Coalbrookdale Coalfield. London: British Geological Survey.

Hampe, O. 1988a. Über die Bezahnung des Orthacanthus (Chondrichthyes: Xenacanthida; Oberkarbon-Unterperm). Paläontologische Zeitschrift 62(3/4), 285-96.

Hampe, O. 1988b. Über die Bezahnung des Xenacanthus (Chondrichthyes: Xenacanthida; Unterperm, SW-Deutschland). Neues Jahrbuch für Geologie und Paläontologie Monatshefte 1988(12), $743-56$.

Hampe, O. 1989. Revision der Triodus-Arten (Chondrichthyes: Xenacanthida) aus dem saarpfälzischen Rotliegenden (Oberkarbon-Perm, SW-Deutschland) aufgrund ihrer Bezahnung. Paläontologische Zeitschrift 63(1/2), 79-101.

Hampe, O. 1991. Histologische Untersuchungen an fossilen Zähnen der Haifisch-Ordnung Xenacanthida (Chondrichthyes: Elasmobranchii) mit Hilfe der Fluoreszenzmikroskopie. Leica Mitteilungen für Wissenschaft und Technik 10(1), 17-27.

Hampe, O. 1993. Variation of xenacanthid teeth in the PermoCarboniferous deposits of the Saar-Nahe Basin (SW-Germany). In Heidtke, U. (comp.) New Research on Permo-Carboniferous Faunas. POLLICHIA-Buch 29, 37-51.

Hampe, O. 1994. Neue Erkenntnisse zur permokarbonischen Xenacanthiden-Fauna (Chondrichthyes: Elasmobranchii) und deren Verbreitung im südwestdeutschen Saar-Nahe-Becken. Neues Jahr- 
buch für Geologie und Paläontologie Abhandlungen 192(1), $53-87$.

Hampe, O. 1995. Plicatodusjordanin.g., n.sp., a new xenacanthid shark from the Lower Permian of Europe (Saar-Nahe Basin, Germany). In Arsenault, M., Lelièvre, H. \& Janvier, P. (eds) VIIth International Symposium, Studies on Early Vertebrates, 9-22 June 1991, Miguasha Parc, Quebec. Bulletin du Muséum National d'Histoire Naturelle, $4^{e}$ série C17(1-4), 209-26.

Hampe, O. 1997a. Dental growth anomalies and morphological changes in teeth of the Xenacanthida (Lower Permian; SaarNahe basin, SW-Germany). Modern Geology 21(1/2), 121-35.

Hampe, O. 1997b. Zur funktionellen Deutung des Dorsalstachels und der Placoidschuppen der Xenacanthida (Chondrichthyes: Elasmobranchii; Unterperm). Neues Jahrbuch für Geologie und Paläontologie Abhandlungen 206(1), 29-51.

Hampe, O. \& Heidtke, U. H. J. 1997. Hagenoselache sippeli $\mathrm{n}$. gen. n. sp., ein früher xenacanthider Elasmobranchier aus dem Oberkarbon (Namurium B) von Hagen-Vorhalle (NW-Sauerland/ Deutschland). Geologie und Paläontologie in Westfalen 47, 5-42.

Hampe, O. \& Long, J. A. 1999. The histology of Middle Devonian chondrichthyan teeth from southern Victoria Land, Antarctica. Records of the Western Australian Museum Supplements 57, 23-36.

Harlton, B. H. 1933. Micropaleontology of the Pennsylvanian Johns Valley shale of the Ouachita Mountains, Oklahoma, and its relationship to the Mississippian Caney shale. Journal of Paleontology 7, 3-29.

Heidtke, U. 1982. Der Xenacanthide Orthacanthus senckenbergianus aus dem pfälzischen Rotliegenden (Unter-Perm). Mitteilungen POLLICHIA 70, 65-86.

Heidtke, U. H. J. 1998. Revision der Gattung Orthacanthus Agassiz 1843 (Chondrichthyes: Xenacanthida). Paläontologische Zeitschrift 72, 135-47.

Heidtke, U. H. J. 1999a. Orthacanthus (Lebachacanthus) senckenbergianus Fritsch 1889 (Xenacanthida: Chondrichthyes): Revision, Organisation und Phylogenie. Freiberger Forschungsheft C481, 63-106.

Heidtke, U. H. J. 1999b. Notizen aus dem geowissenschaftlichen Arbeitskreis. POLLICHIA-Kurier 15(3), 16.

Heintz, A. 1934. Fischreste aus dem Unterperm Norwegens. Norsk geologisk tidsskrift 14, 176-94.

Heyler, D. 1969. Vertébres de l'Autunien de France. In Lehman, J.P. (ed.) Cahiers de Paléontologie, 1-259. Paris: CNRS

Heyler, D. \& Debriette, P. 1986. Sur les Xénacanthiformes (Poissons, élasmobranches), à la lumière de découvertes récentes dans le Permo-Carbonifère de France. Actes du $111^{e}$ Congrès National des Sociétés Savantes, Section des Sciences 1, 89-109.

Heyler, D. \& Poplin, C. 1982. Sur quelques neurocrânes d'elasmobranches du Permien du Bassin d'Autun (Saône-et-Loire, France). Annales de Paléontologie (Vertébrés-Invertébrés) 68(1), 15-32.

Heyler, D. \& Poplin, C. 1989. Systematics and relationships among the Xenacanthiformes (Pisces, Chondrichthyes) in the light of Carboniferous and Permian French material. Acta Musei Reginaehradecensis A22, 69-78.

Heyler, D. \& Poplin, C. 1990. Les Vertébrés autuniens de Buxières-lesMines (Allier, France). Bulletin du Muséum National d'Histoire Naturelle, $4^{e}$ série, Section C12(2), 225-39.

Hotton, N. 1952. Jaws and teeth of American Xenacanth sharks. Journal of Paleontology 26, 489-500.

Hussakof, L. 1911. The Permian fishes of North America. Publications of the Carnegie Institution of Washington 146, 155-78.

Huxley, T. H. 1880. On the application of the laws of evolution to the arrangement of the Vertebrata, and more particularly of the Mammalia. Proceedings of the Scientific Meetings of the Zoological Society of London 1880, 649-62.

Huxley, T. H. \& Wright, E. P. 1867. On a collection of fossil vertebrata, from the Jarrow Colliery, County of Kilkenny, Ireland. Transactions of the Royal Irish Academy of Science 24(8), 351-69.

International Commission on Zoological Nomenclature 1999. INTERNATIONAL CODE OF ZOOLOGICAL NOMENCLATURE, $4^{\text {th }}$ edn. London: International Trust of Zoological Nomenclature.

Ivanov, A. 1999. Late Devonian-Early Permian chondrichthyans of the Russian Arctic. Acta Geologica Polonica 49(3), 267-85.

Ivanov, A. \& Ginter, M. 1996. Early Carboniferous xenacanthids (chondrichthyes) from eastern Europe. Bulletin de la Société géologique de France 167(5), 651-6.

Jaekel, O. 1895. Über die Organisation der Pleuracanthiden. Sitzungsberichte der Gesellschaft der Naturforschenden Freunde 1895, 6986.

Jaekel, O. 1906. Neue Rekonstruktionen von Pleuracanthus sessilis und von Polyacrodus (Hybodus) Hauffianus. Sitzungsberichte der Gesellschaft der Naturforschenden Freunde 1906, 155-9.
Jain, S. L. 1980. Freshwater xenacanthid (= pleuracanth) shark fossils from the Upper Triassic Maleri Formation, India. Journal of the Geological Society of India 21, 39-47.

Janvier, P. 1996. Early vertebrates. Oxford Monographs on Geology and Geophysics 33, 1-393.

Johnson, G. D. 1979. Early Permian vertebrates from Texas: Actinopterygii (Schaefferichthys), Chondrichthyes (including Pennsylvanian and Triassic Xenacanthodii), and Acanthodii. Dallas. (Unpublished Ph.D. dissertation, Southern Methodist University.)

Johnson, G. D. 1980. Xenacanthodii (Chondrichthyes) from the Tecovas Formation (Late Triassic) of West Texas. Journal of Paleontology 54(5), 923-32.

Johnson, G. D. 1981. Hybodontoidei (Chondrichthyes) from the Wichita-Albany Group (Early Permian) of Texas. Journal of Vertebrate Paleontology 1(1), 1-41.

Johnson, G. D. 1984. A new species of Xenacanthodii (Chondrichthyes, Elasmobranchii) from the late Pennsylvanian of Nebraska. In Mengel, R.M. (ed.) Papers in Vertebrate Paleontology honoring Robert Warren Wilson. Carnegie Museum of Natural History, Special Publication 9, 178-86.

Johnson, G. D. 1995. Does Xenacanthus(Chondrichthyes: Xenacanthiformes) occur in the Upper Paleozoic of North America? Journal of Vertebrate Paleontology Supplement 15(3), 38A.

Johnson, G. D. 1996. Vertebrate microfossils from the Lueders Formation, Albany Group, and the faunal transition from the Wichita Group into the Clear Fork Group, Lower Permian of Texas. Modern Geology 20, 371-82.

Johnson, G. D. 1999. Dentitions of Late Palaeozoic Orthacanthus species and new species of ?Xenacanthus (Chondrichthyes: Xenacanthiformes) from North America. Acta Geologica Polonica 49(3), 215-66.

Johnson, G. D. \& Thayer, D.W. 1999. Early Pennsylvanian xenacanth sharks from the Swisshelm Mountains, Arizona. In Hills, L. \& Bamber, W. (eds) XIV International Congress on the Carboniferous and Permian Programme with Abstracts, 68.

Jones, J. M., Magraw, D. \& O'Mara, P. T. 1995. Carboniferous Westphalian Coal Measures. In Johnson, G. A. L. (ed.) Robson's geology of North East England. Transactions of the Natural History Society of Northumbria 56(5), 267-82.

Jordan, H. 1849. Triodus sessilis, ein neuer Fisch der Kohlenformation von Lebach. Neues Jahrbuch für Mineralogie, Geologie und Paläontologie 1849, 843

Kidston, R. 1923. Fossil plants of the Carboniferous rocks of Great Britain. Memoirs of the Geological Survey of Great Britain, Paleontology 2(4), 275-376.

Klausewitz, W. 1986. Redescription of Orthacanthus senckenbergianus Fritsch. In Uyeno, T, Arai, R., Taniuchi, T. \& Matsuura, K. (eds) Proceedings of the Second International Conference on Indo-Pacific Fishes, 125-32. Tokyo: Ichthyological Society of Japan.

Klausewitz, W. 1987. Der 'senckenbergische Urdornhai' Orthacanthus senckenbergianus. Natur und Museum 117(5), 135-42.

Kner, R. 1867. Über Orthacanthus dechenii Goldf. oder Xenacanthus dechenii Beyr. Sitzungsberichte der Mathematisch-Naturwissenschaftlichen Classe der Kaiserlichen Akademie der Wissenschaften $\mathbf{5 5}, 540-84$

Koken, E. 1889. Über Pleuracanthus Ag. oder Xenacanthus Beyr. Sitzungsberichte der Gesellschaft der Naturforschenden Freunde 1889, 77-94.

Land, D. H. 1974. Geology of the Tynemouth district. London: Memoirs of the Geological Survey Great Britain.

Lebedev, O. A. 1996. Fish assemblages in the Tournaisian-Viséan environments of the East European platform. In Strogen, P., Somerville, I. D. \& Jones, G. L. (eds) Recent advances in Lower Carboniferous geology. Geological Society, London, Special Publication 107, 387-415.

Long, J. A. 1990. Late Devonian chondrichthyans and other microvertebrate remains from Northern Thailand. Journal of Vertebrate Paleontology 10(1), 59-71.

Long, J. A. \& Young, G. C. 1995. Sharks from the Middle-Late Devonian Aztec Siltstone, southern Victoria Land, Antarctica. Records of the Western Australian Museum 17, 287-308.

Lund, R. 1976. General geology and vertebrate biostratigraphy of the Dunkard basin. In Falke, H. (ed.) The continental Permian in Central West, and South Europe, 225-39. Dordrecht: Reidel.

Mader, H. 1986. Schuppen und Zähne von Acanthodiern und Elasmobranchiern aus dem Unter-Devon Spaniens (Pisces). Göttinger Arbeiten zur Geologie und Paläontologie 28, 1-59.

Maisey, J. G. 1975. The interrelationships of phalacanthous selachians. Neues Jahrbuch für Geologie und Paläontologie Monatshefte 1975(9), 553-67. 
Maisey, J. G. 1982. The anatomy and interrelationships of Mesozoic hybodont sharks. American Museum Novitates 2724, 1-48.

Maisey, J. G. 1984. Chondrichthyan Phylogeny: A look at the evidence. Journal of Vertebrate Paleontology 4(3), 359-71.

Maisey, J. G. 1987. Cranial anatomy of the Lower Jurassic shark Hybodus reticulatus (Chondrichthyes: Elasmobranchii), with comments on hybodontid systematics. American Museum Novitates 2878, $1-39$

Masson, A. G. \& Rust, B. R. 1984. Freshwater shark teeth as paleoenvironmental indicators in the Upper Pennsylvanian Morien Group of Sydney Basin, Nova Scotia. Canadian Journal of Earth Sciences 21, 1151-5.

Milner, A. R. 1980. The temnospondyl amphibian Dendrerpeton from the Upper Carboniferous of Ireland. Palaeontology 23(1), 125-41.

Milner, A. R., Smithson, T. R., Milner, A. C., Coates, M. I. \& Rolfe, W. D. I. 1986. The search for early tetrapods. Modern Geology 10, 1-28.

Moy-Thomas, J. A. 1936. The structure and affinities of the fossil elasmobranch fishes from the Lower Carboniferous rocks of Glencartholm, Eskdale. Proceedings of the Zoological Society of London 3, 761-88.

Newberry, J. S. 1856. Description of several new genera and species of fossil fishes, from the Carboniferous strata of Ohio. Proceedings of the Academy of Natural Sciences of Philadelphia 8, 96-100.

Newberry, J. S. 1874. Klassification und geologische Verbreitung unserer fossilen Fische. Bericht über die Geologische Aufnahme von Ohio, Vol. 1, Geologie und Paläontologie. II. Theil. Paläontologie, 247350. Columbus, Ohio: Heinmiller.

Newberry, J. S. 1875. Descriptions of fossil fishes. Report of the Geological Survey of Ohio 2(2), 1-64.

Newman, A., McLean, S. G. \& Hudson, D. 1996. A catalogue of the type, figured and cited fossil vertebrates in the Hancock Museum, Newcastle upon Tyne. Newcastle upon Tyne: J. \& P. Bealls Ltd.

Olson, E. C. 1946. Fresh- and brackish-water vertebrate-bearing deposits of the Pennsylvanian of Illinois. Journal of Geology 54, 281-305.

Olson, E. C. 1956. Fauna of the Vale and Choza: 13. Diadectes, Xenacanthus, and specimens of unknown affinities. Fieldiana: Geology 10(27), 329-34.

Owen, R. 1867. On the dental characters of genera and species, chiefly of fishes, from the Low Main Seam and shales of coal, Northumberland. Transactions of the Odontological Society of Great Britain 5, 323-92.

Owen, T. R. 1976. The geological evolution of the British Isles. Oxford: Pergamon.

Panchen, A. L. \& Walker, A. D. 1960. British Coal Measure labyrinthodont localities. The Annals and Magazine of Natural History 13(3), 321-32.

Paton, R. L. 1994. Elasmobranch fishes from the Viséan of East Kirkton, West Lothian, Scotland. Transactions of the Royal Society of Edinburgh: Earth Sciences 84, 329-30.

Poplin, C. \& Heyler, D. 1989. Évolution et phylogénie des Xenacanthiformes ( $\supset$ Pleuracanthiformes) (Pisces, Chondrichthyes). Annales de Paléontologie (Vertébrés-Invertébrés) 75(4), 187-222.

Prestwich, J. 1840. On the geology of Coalbrook Dale. Transactions of the Geological Society of London 5(3), 413-95.

Pyrah, B. J. 1979. Catalogue of type and figured fossils in the Yorkshire Museum: Part 4. Proceedings of the Yorkshire Geological Society 42(3), 415-37.

Rafinesque Schmaltz, C. S. 1810. Indice d'Ittiologia Siciliana ossia Catalogo metodico dei Nomi Latini Italiani, e Siciliani dei Pesci, che si rinvengono in Sicilia disposti secondo un Metodo Naturale e seguito da un Appendice che contiene la Descrizione di Alcuni nuovi Pesci siciliani illustrato da due Piance. Messina: Giovanni del Nobold.

Ramsbottom, W. H. C., Calver, M. A., Eagar, R. M. C., Hodson, F., Holliday, D. W., Stubblefield, C. J. \& Wilson, R. B. 1978. A correlation of Silesian rocks in the British Isles. Geological Society, London, Special Report 10, 1-81.

Reif, W.-E. 1978. Types of morphogenesis of the dermal skeleton in fossil sharks. Paläontologische Zeitschrift 52(1/2), 110-28.

Reif, W.-E. 1979. Protective and hydrodynamic function of the dermal skeleton of elasmobranchs. Neues Jahrbuch für Geologie und Paläontologie Abhandlungen 157, 133-41.

Reif, W.-E. 1980. A mechanism for tooth pattern reversal in sharks: The Polarity Switch Model. Wilhelm Roux' Archiv für Entwicklungsmechanik 188, 115-22.

Riley, N. J. 1993. Dinantian (Lower Carboniferous) biostratigraphy and chronostratigraphy in the British Isles. Journal of the Geological Society, London 150, 427-46.

Romer, A. S. 1942. Notes on certain American Paleozoic fishes. American Journal of Science 240(3), 216-28.
Romer, A. S. 1964. The braincase of the Paleozoic elasmobranch Tamiobatis. Bulletin of the Museum of Comparative Zoology 131(4), 87-105.

Schaeffer, B. 1981. The xenacanth shark neurocranium, with comments on elasmobranch monophyly. Bulletin of the American Museum of Natural History 169(1), 1-66.

Schindler, T. \& Hampe, O. 1996. Eine erste Fischfauna (Chondrichthyes, Acanthodii, Osteichthyes) aus dem Permokarbon Niederösterreichs (Zöbing, NE Krems) mit paläoökologischen und biostratigraphischen Anmerkungen. Beiträge zur Paläontologie 21, 93-103.

Schneider, J. 1985. Elasmobranchier-Zahntypen (Pisces, Chondrichthyes) und ihre stratigraphische Verbreitung im Karbon und Perm der Saale-Senke (DDR). Freiberger Forschungshefte C400, 90-100.

Schneider, J. 1988. Grundlagen der Morphogenie, Taxonomie und Biostratigraphie isolierter Xenacanthodier-Zähne (Elasmobranchii). Freiberger Forschungshefte C419, 71-80.

Schneider, J. W. 1996. Xenacanth teeth-A key for taxonomy and biostratigraphy. Modern Geology 20, 321-40.

Schneider, J., Walter, H. \& Werneburg, R. 1988. New biostratigraphical methods for the Upper Carboniferous and Lower Permian in Central Europe. Zeitschrift für geologische Wissenschaften 16(9), 917-27.

Schneider, J. W., Hampe, O. \& Soler-Gijón, R. 2000. The Late Carboniferous and Permian: Aquatic vertebrate zonation in southern Spain and German basins. Courier Forschungsinstitut Senckenberg 223, 543-61.

Schneider, J. \& Zajíc, J. 1990. Revision of Permo-Carboniferous xenacanthodian sharks from Middle Europe. In Schweiss, D. \& Heidtke, U. (comp.) Symposium New research on Permocarboniferous fauna, September 24-28, 1990, Pfalzmuseum für Naturkunde (POLLICHIA-Museum) Bad Dürkheim, FRG, 26-7.

Schneider, J. W. \& Zajíc, J. 1994. Xenacanthiden (Pisces, Chondrichthyes) des mitteleuropäischen Oberkarbon und Perm-Revision der Originale zu Goldfuss 1847, Beyrich 1848, Kner 1867 und Fritsch 1879-1890. Freiberger Forschungsheft C452, 101-51.

Schönlaub, H. P. 1979. Das Paläozoikum in Österreich. Abhandlungen der Geologischen Bundesanstalt in Wien 33, 1-124.

Schroeder, H. E. 1992. Orale Strukturbiologie. Entwicklungsgeschichte, Struktur und Funktion normaler Hart- und Weichgewebe der Mundhöhle und des Kiefergelenks. Stuttgart: Thieme.

Schultze, H.-P. 1985. Marine to onshore vertebrates in the Lower Permian of Kansas and their paleoenvironmental implications. University of Kansas Paleontological Contributions 113, 1-18.

Schultze, H.-P. \& Bolt, J.R. 1996. The lungfish Tranodis and the tetrapod fauna from the Upper Mississippian of North America. Special Papers in Palaeontology 52, 31-54.

Schwind, C. 1991. Zur Organisation und zur Phylogenie der beiden Gattungen Triodus und Xenacanthus. (Mainz: Unpublished Ph.D. dissertation.)

Scotese, C. R. 2001. The Late Carboniferous a time of great coal swamps. http://www.scotese.com/late.htm

Seilacher, A. 1943. Elasmobranchier-Reste aus dem oberen Muschelkalk und dem Keuper Württembergs. Neues Jahrbuch für Mineralogie, Geologie und Paläontologie Monatshefte 1943, 256-92.

Sevastopulo, G. D. 1981. Upper Carboniferous. In Holland, C.H. (ed.) A geology of Ireland, 173-87. Edinburgh: Scottish Academic Press.

Silva Santos, R. da 1946. Duas novas formas de elasmobranquios do Paleozoico do Meio do Norte, Brasil. Anais da Academia Brasileira de Ciências 18(4), 281-5.

Silva Santos, R. da \& Salgado, M. S. 1970. Um Espinho de Xenacanthus do Carbonífero do Estado do Maranhão. Anais da Academia Brasileira de Ciências 42(2), 223-7.

Smith, B. \& George, T. N. 1961. British Regional Geology. North Wales. London: British Geological Survey.

Smith, D. B. 1994. Geology of the country around Sunderland. London: Memoirs of the British Geological Survey, England \& Wales.

Smith, R. A., Stephenson, D. \& Monro, S. K. 1994. The geological setting of the southern Bathgate Hills, West Lothian, Scotland. Transactions of the Royal Society of Edinburgh: Earth Sciences 84, 189-96.

Soler-Gijón, R. 1997a. Orthacanthus meridionalis, a new xenacanth shark (Elasmobranchii) from the Upper Carboniferous of the Puertollano basin, Spain. Neues Jahrbuch für Geologie und Paläontologie Abhandlungen 204(2), 141-69.

Soler-Gijón, R. 1997b. New discoveries of xenacanth sharks from the Late Carboniferous of Spain (Puertollano Basin) and Early Permian of Germany (Saar-Nahe Basin): Implications for the phylogeny of xenacanthiform and anacanthous sharks. Neues Jahrbuch für Geologie und Paläontologie Abhandlungen 205(1), 1-31. 
Soler-Gijón, R. 1999. Occipital spine of Orthacanthus (Xenacanthidae, Elasmobranchii): structure and growth. Journal of Morphology 242(1), 1-45.

Soler-Gijón, R. 2000. Phylogenetic relationships of Lebachacanthidae Soler-Gijón 1997 (Xenacanthiformes; Elasmobranchii). Paläontologische Zeitschrift 74(3), 363-77.

Soler-Gijón, R. \& Hampe, O. 1998. Evidence of Triodus Jordan 1849 (Elasmobranchii: Xenacanthidae) in the Lower Permian of the Autun basin (Muse, France). Neues Jahrbuch für Geologie und Paläontologie Monatshefte 1998(6), 335-48.

St. John, O. \& Worthen, A. H. 1875. Descriptions of fossil fishes. Geological Survey of Illinois, Palaeontology 6, 245-488.

Steward, D. 1994. Fossil fishes of Fenton and Longton. The John Ward Collection. Stoke-on-Trent: City Museum \& Art Gallery.

Stock, T. 1880. On a spine (Lophacanthus Taylori, mihi, nov. gen. et spec.) from the Coal-Measures of Northumberland. The Annals and Magazine of Natural History 5(5), 217-20.

Tonks, L. H., Jones, R. C. B., Lloyd, W. \& Sherlock, R. L. 1931. The geology of Manchester and the South-East Lancashire Coalfield. London: Memoirs of the Geological Survey of England \& Wales.

Traquair, R. H. 1881. Notice of new fish remains from the Blackband Ironstone of Borough Lee near Edinburgh. Geological Magazine Decade II 8(1), 34-7.

Traquair, R. H. 1882. Notice of new fish remains from the Blackband Ironstone of Borough Lee, near Edinburgh. No. III. Geological Magazine Decade II 9(12), 540-6.

Traquair, R. H. 1888a. Notes on Carboniferous Selachii. Proceedings of the Royal Physical Society of Edinburgh 9(3), 412-21.

Traquair, R. H. 1888b. Further notes on Carboniferous Selachii. Proceedings of the Royal Physical Society of Edinburgh 9(3), 421-6.

Traquair, R.H. 1901. The Carboniferous fishes of the West of Scotland. In Elliot, G.F., Laurie, M. \& Murdoch, J.B. (eds) Fauna, flora \& geology of the Clyde area, 512-16. Glasgow: British Association.

Traquair, R. H. 1903. On the distribution of fossil fish-remains in the Carboniferous rocks of the Edinburgh district. Transactions of the Royal Society of Edinburgh 40, 687-707.

Traquair, R. H. 1905. Notes on the Lower Carboniferous fishes of Eastern Fifeshire. Proceedings of the Royal Physical Society of Edinburgh 16(1), 80-6.

Turner, S. 1993. Early Carboniferous microvertebrates from the Narrien Range, central Queensland. Memoir of the Association of Australasian Palaeontologists 15, 289-304.

Tway, L. E. \& Zidek, J. 1983. Catalog of late Pennsylvanian ichthyoliths, Part II. Journal of Vertebrate Paleontology 2(4), 414-38.

Wagner, R. H. 1974. The chronostratigraphic units of the Upper Carboniferous in Europe. Bulletin de la Société Belge de Géologie 83(4), 235-53.

Ward, J. 1890. The geological features of the North Staffordshire CoalFields, their organic remains, their range and distribution; with a catalogue of the fossils of the Carboniferous system of North Staffordshire. Transactions of the North Staffordshire Institute of Mining and Mechanical Engineers 10(5), 1-189.

Waters, C. N., Aitkenhead, N., Jones, N. S. \& Chisholm, J. I. 1996. Late Carboniferous stratigraphy and sedimentology of the Bradford area, and its implications for the regional geology of northern England. Proceedings of the Yorkshire Geological Society 51(2), 87-101.

Waterston, C. D. 1954. Catalogue of type and figured specimens of fossil fishes and amphibians in the Royal Scottish Museum, Edinburgh. Transactions of the Edinburgh Geological Society 16, 1-91.

Wedd, C. B., Smith, B., Simmons, W. C. \& Wray, D. A. 1923. The geol- ogy of Liverpool, with Wirral and part of the Flintshire coalfield. London: Memoirs of the Geological Survey Great Britain.

Whitehead, T. H. \& Pocock, R. W. 1947. Dudley and Bridgnorth. London: Memoirs of the Geological Survey Great Britain.

Williams, M. E. 1985. The 'Cladodont level' sharks of the Pennsylvannian Black Shales of Central North America. Palaeontographica Abteilung A 190(3-6), 83-158.

Williams, M. E. 1998. A new specimen of Tamiobatis vetustus (Chondrichthyes, Ctenacanthoidea) from the Late Devonian Claveland Shale of Ohio. Journal of Vertebrate Paleontology 18(2), 251-60.

Wilson, A. A., Rees, J. G., Crofts, R. G., Howard, A. S., Buchanan, J. G. \& Waine, P. J. 1992. Stoke-on-Trent: A geological background for planning and development. Nottingham: British Geological Survey Technical Report.

Woodward, A. S. 1889a. Catalogue of the fossil fishes in the British Museum (Natural History). Part I. containing the Elasmobranchii. London: Taylor \& Francis.

Woodward, A. S. 1889b. Palæichthyological notes. 2. On Diplodus Moorei, sp. nov., from the Keuper of Somersetshire. The Annals and Magazine of Natural History 3(6), 297-302.

Woodward, A. S. 1891. Dr. Anton Fritsch on Palæozoic elasmobranch fishes. Geological Magazine 8(3), 375-78.

Woodward, A. S. 1908. The fossil fishes of the Hawkesbury series at St. Peters. Memoirs of the Geological Survey of New South Wales: Palaeontology 10, 1-352.

Woodward, A. S. \& Sherborn, C. D. 1890. A catalogue of British fossil vertebrata. London: Dulau \& Co.

Wright, E. P. \& Huxley, T. H. 1866. On a collection of fossils from the Jarrow Colliery, Kilkenny, Ireland. Geological Magazine 3, 16571.

Würdig-Maciel, N. L. 1975. Ichtiodontes e ichtiodorulitos (Pisces) da Formação Estrada Nova e sua aplicação na estratigrafia do Grupo Passa Dois. Pesquisas 5, 7-83.

Young, G. C. 1982. Devonian sharks from south-eastern Australia and Antarctica. Paleontology 25(4), 817-43.

Zajíc, J. 1989. Remains of Permo-Carboniferous vertebrates from the HK-1 borehole (Horní Kalná, Krkonoše Piedmont Basin, East Bohemia). Věstnik Ústředniho Ústavu Geologického 64(5), 287-96.Zangerl, R. 1981. Chondrichthyes I-Paleozoic Elasmobranchii. In Schultze, H.-P. (ed.) Handbook of Paleoichthyology, Vol. 3A. Stuttgart: Gustav Fischer.

Zangerl, R. \& Case, G. R. 1976. Cobelodus aculeatus (Cope), an anacanthous shark from the Pennyslvanian Black Shales of North America. Palaeontographica Abteilung A 154(4-6), 107-57.

Zidek, J. 1978. New chondrichthyan spines from the Late Paleozoic of Oklahoma. Journal of Paleontology 52(5), 1070-8.

Zidek, J. 1988. Hamilton quarry (Kansas, Late Pennsylvanian) Chondrichthyes. Regional Geology and Paleontology of the Upper Paleozoic Hamilton area, KGS Guidebook Series, Vol. 6, 167-72.

Zidek, J. 1992. Late Pennsylvanian Chondrichthyes, Acanthodii, and deep-bodied Actinopterygii from the Kinney Quarry, Manzanita Mountains, New Mexico. New Mexico Bureau Mines \& Mineral Resources Bulletin 138, 145-82.

Zidek, J. 1993a. Xenacanthid genera: How many and how to tell them apart? In Heidtke, U. (comp.) New Research on PermoCarboniferous Faunas. POLLICHIA-Buch 29, 23-35.

Zidek, J. 1993b. Juvenile Orthacanthus platypternus (Cope 1883) (Elasmobranchii: Xenacanthiformes) from the Upper Carboniferous near Hamilton, Kansas, U.S.A. In Heidtke, U. (comp.) New Research on Permo-Carboniferous Faunas. POLLICHIA-Buch 29, $53-65$.

OLIVER HAMPE, Humboldt-Universität zu Berlin, Naturhistorisches Forschungsinstitut,

Museum für Naturkunde, Institut für Paläontologie, Invalidenstraße 43, D-10115 Berlin, Germany

email: oliver.hampe@museum.hurberlin.de

MS received 2 August 2001. Accepted for publication 6 September 2002. 